Article

\title{
Synthesis of Cucurbitacin B Derivatives as Potential Anti-Hepatocellular Carcinoma Agents
}

\author{
Weizhi Ge ${ }^{1}$, Xinyi Chen ${ }^{1}$, Fangzhi Han ${ }^{1}$, Zhongquan Liu ${ }^{1}$, Tianpeng Wang ${ }^{1}$, \\ Mengmeng Wang ${ }^{2}$, Yue Chen ${ }^{1, *}$, Yahui Ding ${ }^{1, *}$ and Quan Zhang ${ }^{1, *}$ \\ 1 State Key Laboratory of Medicinal Chemical Biology, College of Pharmacy and Tianjin Key Laboratory of \\ Molecular Drug Research, Nankai University, Tianjin 300353, China; geweizhi@aliyun.com (W.G.); \\ chenxinyinku@126.com (X.C.); hfz904529505@163.com (F.H.); lzq9734@163.com (Z.L.); \\ wangtianpeng888@126.com (T.W.) \\ 2 Accendatech Company, Ltd., Tianjin 300384, China; mengmeng.wang@accendatech.com \\ * Correspondence: yuechen@nankai.edu.cn (Y.C.); 017095@nankai.edu.cn (Y.D.); \\ zhangquan@nankai.edu.cn (Q.Z.); Tel.: +86-22-8535-8387 (Q.Z.)
}

Received: 12 November 2018; Accepted: 14 December 2018; Published: 18 December 2018

\begin{abstract}
Cucurbitacin B shows potent activity against tumor cells, but its high toxicity limits its application in the clinic. A series of cucurbitacin B derivatives was synthesized and evaluated for their anti-hepatocellular carcinoma (HCC) activities against the HepG-2 cell line. These compounds were also tested for their toxicity against the $\mathrm{L}-\mathrm{O} 2$ normal cell line. The compound with the most potential, 10b, exhibited potent activity against the HepG-2 cell line with an $\mathrm{IC}_{50}$ value of $0.63 \mu \mathrm{M}$. Moreover, compound $\mathbf{1 0 b}$ showed the highest TI value (4.71), which is a 14.7-fold improvement compared to its parent compound cucurbitacin B. A preliminary molecular mechanism study of $10 \mathrm{~b}$ indicated that $10 \mathrm{~b}$ could inhibit P-STAT3 to induce the activation of mitochondrial apoptotic pathways. An in vivo acute toxicity study indicated that the compound $10 \mathrm{~b}$ has preferable safety and tolerability compared with cucurbitacin B. These findings indicate that compound $10 \mathrm{~b}$ might be considered as a lead compound for exploring effective anti-HCC drugs.
\end{abstract}

Keywords: Cucurbitacin B; Anti-hepatocellular carcinoma; Derivative; Toxicity; Synthesis

\section{Introduction}

Cancer is a disease with high morbidity and mortality. It is the second leading cause of death, after cardiovascular disease, worldwide [1,2]. The World Health Organization has reported that there were approximately 17.5 million new cancer cases and more than 8.7 million cancer-related deaths worldwide in 2015, and cancer-related deaths are expected to increase to 13.1 million by 2030 [3-5]. Cancer is a type of abnormal and excessive growth of tissue, in which abnormal body cells begin to divide uncontrollably by ignoring the principles of normal cell division. Cancer cells invade or spread to other healthy parts of the body, resulting in the formation of new tumor; this process is called metastasis. Approximately $90 \%$ of cancer-linked deaths are caused by it [5-7]. So far, cancer treatments mostly rely on traditional chemotherapy, especially for late-stage or complex cancers. Unfortunately, side effects and acquired drug resistance limit the effectiveness of traditional chemotherapy. Side effects, such as extreme fatigue and leukopenia, are caused by traditional chemotherapy's low selectivity towards cancer cells and normal cells. These unpleasant side effects seriously reduce the life quality of cancer patients [8-10]. Therefore, the development of new chemotherapeutic drugs with high efficiency and low-toxicity side effects is a great challenge for medicinal chemists. Natural compounds can induce apoptosis by targeting multiple cellular signaling pathways; so, the development of new pharmacologically effective chemotherapeutic agents from natural compounds may be feasible [11-13]. 
Cucurbitacins are highly oxygenated tetracyclic and bitter triterpenes that are widely present in plants of the Cucurbitaceae family $[14,15]$. Cucurbitacins have for centuries been exploited for their anti-inflammatory and hepatoprotective activities as traditional herbal medicines in Asia [16]. Cucurbitacins have more than 200 derivatives and are divided into 12 classes, from cucurbitacin A to $\mathrm{T}$, which have been classified according to structural features in ring $\mathrm{A}$, side chain modifications, stereochemistry considerations, and glycosylated forms $[14,17,18]$. Cucurbitacins have been the subject of extensive scientific research due to their broad range of pharmacological effects, including anti-inflammatory, antitumor, antidiabetic, antifertility, antiviral, and anticancer activities [19-23]. Cucurbitacin B, D, E, and I (Figure 1) are the most active anticancer cucurbitacin derivatives [14,24]. Recent studies have revealed that cucurbitacins can cause cell-cycle arrest, apoptosis, and the suppression of cancer cell growth through inhibition of the JAK-STAT3, Wnt, PI3K/Akt, and MAPK signaling pathways, which play important roles in the apoptosis and survival of cancer cells $[14,25]$.

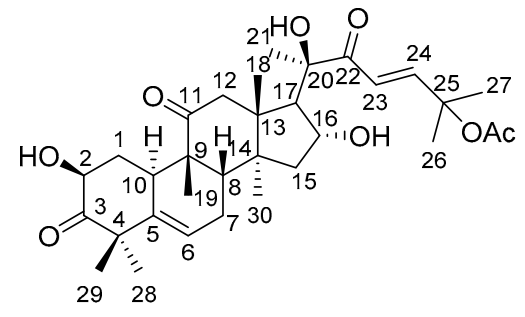

Cucurbitacin B (1)

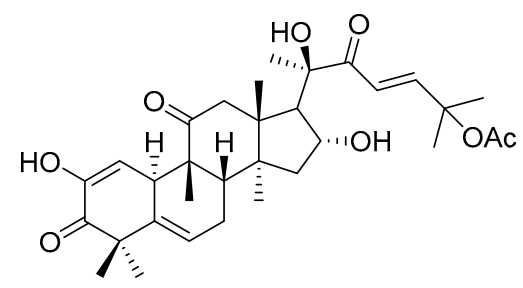

Cucurbitacin E

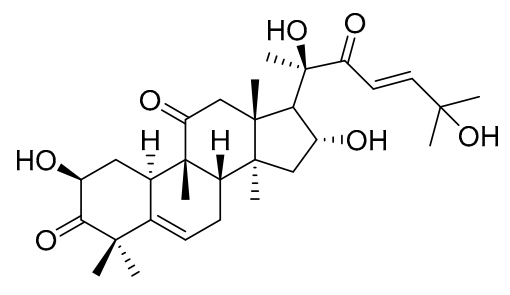

Cucurbitacin D

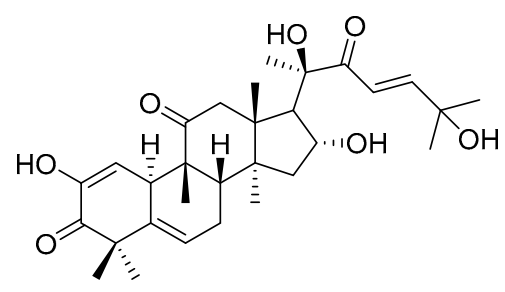

Cucurbitacin I

Figure 1. The chemical structures of cucurbitacin B (1), cucurbitacin D, cucurbitacin E, and cucurbitacin I.

Cucurbitacin B (1) is one of the most abundant forms of cucurbitacins, and one of the best-studied compounds of the cucurbitacins family [26-30]. Cucurbitacin B possesses a variety of bioactivities, such as anti-inflammatory, hepatoprotective, and anticancer activities. It has demonstrated potent anticancer activities in solid tumors in vitro and in vivo [31,32]. Cucurbitacin B is capable of inhibiting the growth of a wide spectrum of malignant human cells, such as laryngeal squamous cell carcinoma, breast cancer, pancreatic cancer, hepatocellular carcinoma (HCC), lung cancer, and melanoma cells [28,33-36]. The mechanism underlying the anticancer effect of cucurbitacin B is not clear; however, several studies have shown that cucurbitacin B inhibits the proliferation of, and induces apoptosis in, human cancer cells via STAT3 pathway inhibition and increased intracellular reactive oxygen species (ROS) [29,36-40].

At present, the main problem with cucurbitacin B is its high toxicity, which renders it unlikely to be a drug-able agent. Its low selectivity and narrow treatment window severely limit its clinical application. With cucurbitacin B as the starting substrate, we designed and synthesized a series of cucurbitacin B derivatives for the exploration of structure-activity relationships and the discovery of potential anti-HCC agents with potent anti-HCC activity and low toxicity. 


\section{Results and Discussion}

\subsection{Chemistry}

The starting material cucurbitacin B was isolated from Cucumis melo L. The presence of free hydroxyl groups allowed us to prepare ester derivatives of cucurbitacin B for an evaluation of the influence of the ester side chain on their anti-HCC activities. It was reported that the introduction of an acyl group to a 2-hydroxyl moiety greatly reduced the anticancer activity [41]. We planned to explore the effect of selective acylation on a 16-hydroxyl group on the anti-HCC activity. However, a 2-hydroxyl group is more reactive than a 16-hydroxyl group for acylation [41]. Therefore, we first designed protection for the 2-hydroxyl group. As shown in Scheme 1, the treatment of compound 1 with $t$-butyldimethylsilyl chloride (TBSCl) in the presence of imidazole selectively provided the 2-TBS-protected derivative 2 without the influence of the hydroxyl group linked to C20 of the cucurbicin B. The hydroxyl group linked to C20 is a tertiary hydroxyl group that shows a higher steric hindrance effect than the C16 hydroxyl group. Therefore, the C16 hydroxyl group was selectively esterified without affecting the hydroxyl group linked to C20 of the cucurbicin B. Compound 2 was coupled with different patterns of carboxylic acids in the presence of 1-ethyl-3-(3-dimethyllaminopropyl)carbodiimide hydrochloride (EDCI) and 4-dimethylaminopyridine (DMAP), followed by removal of the TBS protection to afford the esters $3 a-3 q$ in yields of $48-86 \%$. Direct conjuation of compound 1 with cinnamic acid provided the derivative 4 in a high yield (90\%).

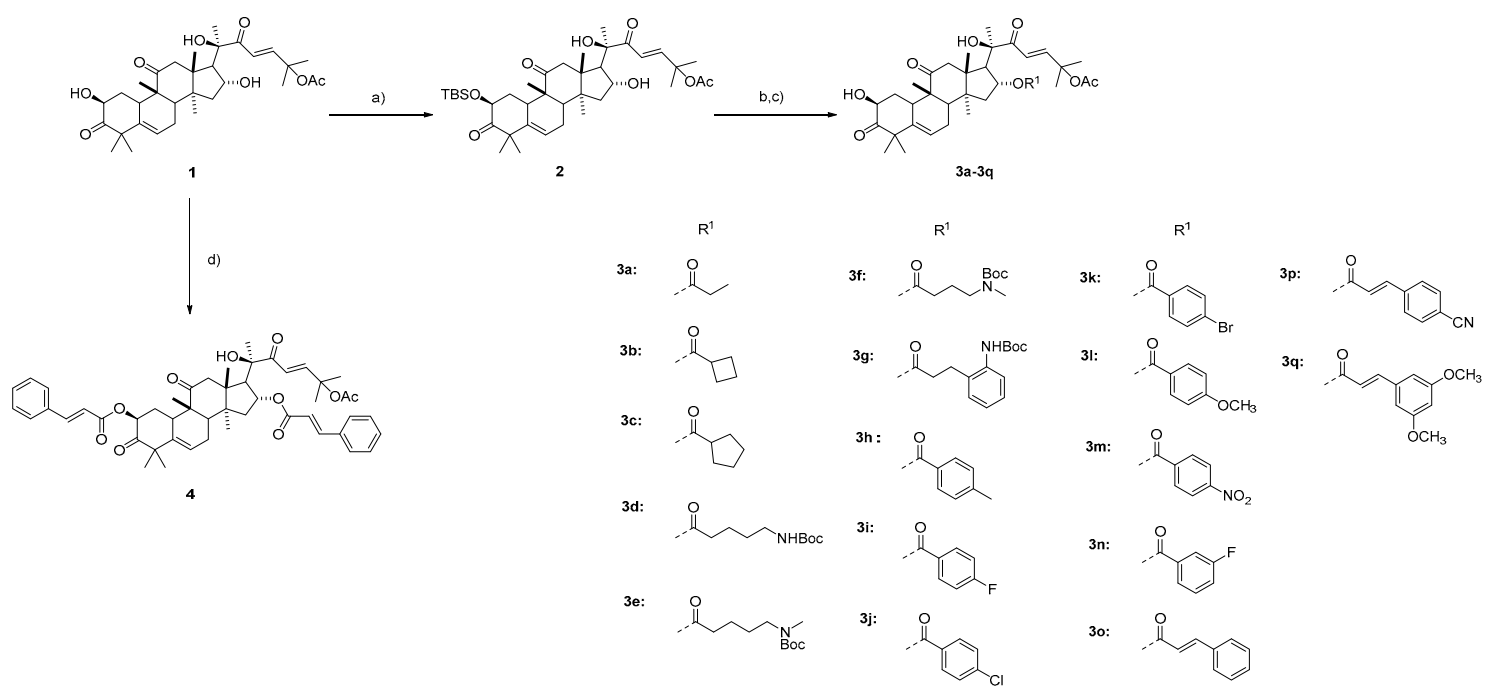

Scheme 1. The synthesis of compounds 3a-3q and 4. Reagents and conditions: a) TBSCl, imidazole, DCM, 43\%; b) R $\mathrm{R}^{1} \mathrm{COOH}$, EDCI, TEA, DMAP, DCM; c) TBAF/AcOH, THF, 47-86\% yield in two steps; d) Cinnamic acid, EDCI, TEA, DMAP, DCM, 90\%.

It was reported that the introduction of a phenylsulfonyl-substituted furoxan NO-releasing moiety could reduce the toxicity of brusatol [42-46]. Accordingly, 18 cucurbitacin B derivatives, 9a-9c and 10a-10o, with the introduction of a phenylsulfonyl-substituted furoxan NO-releasing moiety were designed (Scheme 2). Compound 5 was prepared according to a reported procedure [42]. Reaction of 5 with different diols or alchoholamines gave $\mathbf{6 a - 6 o}$ or $\mathbf{7 a - 7} \mathbf{c}$, respectively [42-44,46]. Compounds $\mathbf{6 a - 6 o}$ were treated with succinic anhydride in the presence of DMAP to produce the corresponding acids, followed by conjuation with compound 2 and removal of the TBS group to yield 10a-10o in yields of $61-82 \%$ in two steps. The acid 8 was obtained by the reaction of 2 and succinic anhydride. The removal of Boc groups of $\mathbf{7 a - 7 c}$ gave the corresponding amines, followed by coupling with the acid 8 in the presence of 2-(7-azabenzotriazol-1-yl)- $N, N, N^{\prime}, N^{\prime}$-tetramethyluronium hexafluorophosphate (HATU) and $N, N$-diisopropylethylamine (DIPEA) and deprotection of the TBS group to afford 9a-9c in yields 
of $44-73 \%$ in three steps. The removal of the TBS group of the acid 8 yielded compound 11 in a yield of $79 \%$.

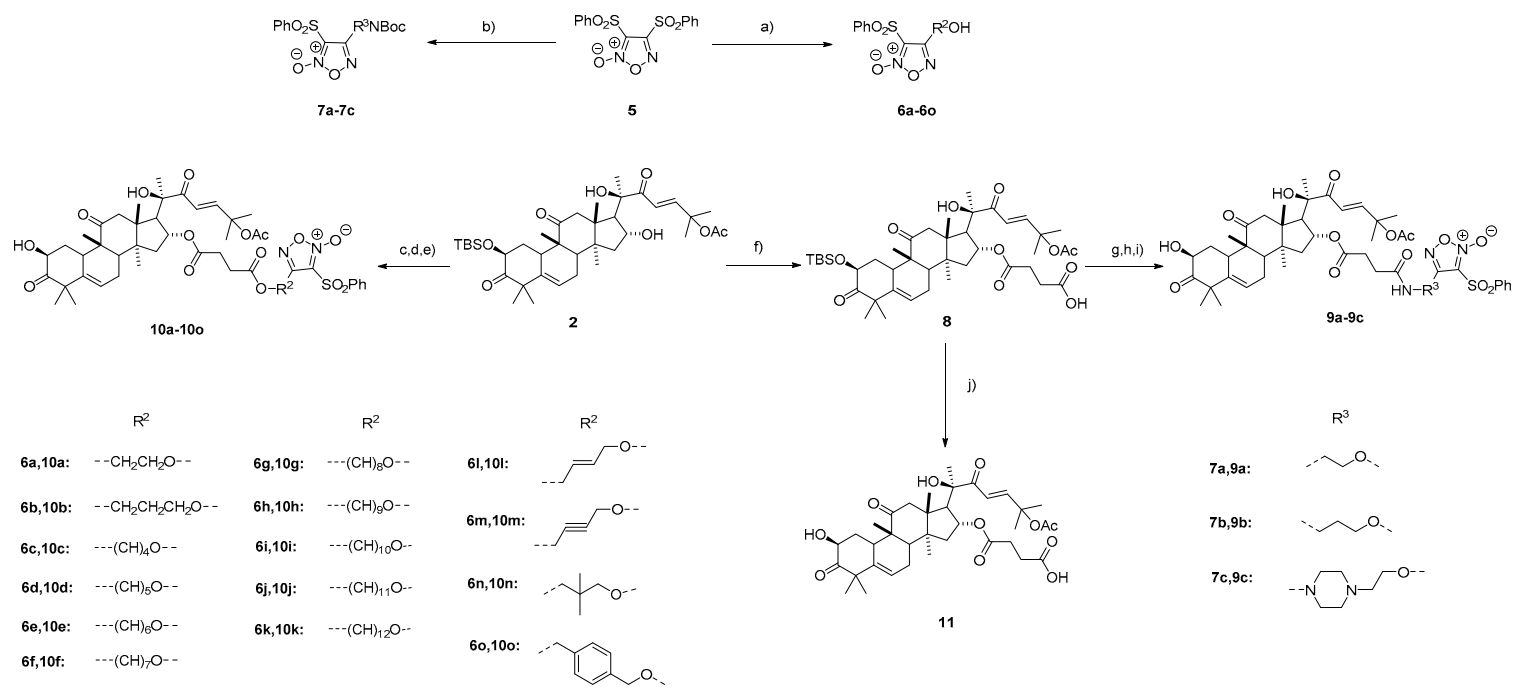

Scheme 2. The synthesis of compounds 9a-9c, 10a-10o, and 11. Reagents and conditions: a) Corresponding diol, 2N NaOH, THF; b) Corresponding alcohol amine, 2N NaOH, THF; c) 6a-6o, succinic anhydride, DMAP, DCM; d) EDCI, TEA, DMAP, DCM; e) TBAF, AcOH, THF, 61-82\% yield in two steps; f) succinic anhydride, DMAP, DCM; g) 7a-7c, TFA, DCM; h) HATU, DIPEA, DMF; i) TBAF, $\mathrm{AcOH}, \mathrm{THF}, 44-73 \%$ yield in three steps; j) TBAF, $\mathrm{AcOH}, \mathrm{THF}, 79 \%$.

\subsection{In Vitro Biological Activities against the HepG-2 Cell Line and the L-O2 Cell Line}

The synthesized cucurbitacin B derivatives 3a-3q, 4, 9a-9c, 10a-10o, and 11 were evaluated for their activity against proliferation of the human hepatocellular carcinoma cell line HepG-2 and the normal hepatocellular cell line L-O2. Cucurbitacin B was also included for comparison. The therapeutic index (TI), a major pharmaceutical parameter that estimates possible future clinical development, was determined as the ratio of $\mathrm{IC}_{50}$ for $\mathrm{L}-\mathrm{O} 2$ to $\mathrm{IC}_{50}$ for HepG-2. The bioactivity of each compound was evaluated by the combination of its $\mathrm{IC}_{50}$ and TI. These results are shown in Tables 1 and 2.

The parent compound 1 exhibited potent activity against HepG-2 $\left(\mathrm{IC}_{50}=0.06 \mu \mathrm{M}\right)$, but appeared to have high toxicity $\left(\mathrm{IC}_{50}=0.019 \mu \mathrm{M}\right)$, which led to a very low therapeutic index $(0.32)$. It was reported that the selective introduction of an acyl group to a 2-hydroxyl moiety greatly reduced the anticancer activity [41]. To further explore the influence of introducing different acyl moieties to a 16-hydroxyl group on anti-HCC activity, we synthesized the 16-mono-acylated derivatives 3a-3q. For subseries of 3a-3q, all compounds showed decreased cytotoxicity against the normal hepatocellular cell line L-O2 $\left(\mathrm{IC}_{50}=0.0422-9.59 \mu \mathrm{M}\right)$ compared to the parent compound $1\left(\mathrm{IC}_{50}=0.019 \mu \mathrm{M}\right)$, which indicated that the introduction of an acyl moiety to a 16-hydroxyl group could reduce the toxicity to normal cells. However, their anti-HCC activities against HepG-2 cells were also greatly decreased, with $\mathrm{IC}_{50}$ values ranging from $0.22 \mu \mathrm{M}$ to $9.62 \mu \mathrm{M}$. Among subseries 3a-3q, compound 3o with a 16-mono-cinnamyl substitution showed the highest TI value $(\mathrm{TI}=2.9)$. Therefore, we further synthesized compound 4 with a 2,16-di-cinnamyl substitution for testing its anti-HCC activity. Unfortunately, compound 4 lost inhibitory activity against HepG-2 ( $\left.\mathrm{IC}_{50}>20 \mu \mathrm{M}\right)$. 
Table 1. The inhibitory activity and clog P of $\mathbf{3 a}-\mathbf{3 q}$ and 4 against the HepG-2 and L-O2 cell lines.

\begin{tabular}{|c|c|c|c|c|}
\hline \multirow{2}{*}{ Compound } & \multicolumn{2}{|c|}{$\mathrm{IC}_{50}{ }^{\mathrm{a}}(\mu \mathrm{M})$} & \multirow{2}{*}{$\mathrm{TI}^{\mathrm{b}}$} & \multirow{2}{*}{$C \log P^{d}$} \\
\hline & HepG-2 & L-O2 & & \\
\hline 1 & $0.060 \pm 0.02$ & $0.019 \pm 0.003$ & 0.32 & 2.96 \\
\hline $3 a$ & $1.01 \pm 0.04$ & $1.02 \pm 0.58$ & 1 & 4.19 \\
\hline $3 b$ & $0.54 \pm 0.04$ & $0.52 \pm 0.08$ & 0.96 & 4.57 \\
\hline $3 c$ & $2.45 \pm 1.75$ & $2.37 \pm 0.09$ & 0.97 & 5.13 \\
\hline $3 d$ & $4.89 \pm 0.92$ & $8.01 \pm 0.47$ & 1.64 & 5.10 \\
\hline $3 e$ & $9.28 \pm 0.37$ & $5.50 \pm 2.48$ & 0.59 & 5.70 \\
\hline $3 f$ & $0.93 \pm 0.06$ & $0.41 \pm 0.11$ & 0.44 & 5.85 \\
\hline $3 g$ & $0.22 \pm 0.11$ & $0.042 \pm 0.001$ & 0.19 & 5.90 \\
\hline $3 h$ & $9.62 \pm 1.34$ & $6.90 \pm 1.37$ & 0.72 & 6.09 \\
\hline $3 \mathbf{i}$ & $7.42 \pm 0.40$ & $4.42 \pm 0.97$ & 0.60 & 5.73 \\
\hline $3 \mathbf{j}$ & $4.67 \pm 0.28$ & $3.57 \pm 2.58$ & 0.76 & 6.30 \\
\hline $3 k$ & $2.99 \pm 2.06$ & $1.93 \pm 0.32$ & 0.65 & 6.45 \\
\hline 31 & $3.71 \pm 1.69$ & $2.47 \pm 0.47$ & 0.67 & 5.76 \\
\hline $3 \mathrm{~m}$ & $0.92 \pm 0.44$ & $0.74 \pm 0.15$ & 0.8 & 5.33 \\
\hline $3 n$ & $4.05 \pm 1.39$ & $2.48 \pm 0.52$ & 0.61 & 5.73 \\
\hline 30 & $3.31 \pm 0.24$ & $9.59 \pm 2.38$ & 2.90 & 5.94 \\
\hline $3 p$ & $2.34 \pm 0.91$ & $1.47 \pm 0.36$ & 0.63 & 5.38 \\
\hline $3 q$ & $3.85 \pm 0.63$ & $5.25 \pm 1.63$ & 1.36 & 5.95 \\
\hline 4 & $>20$ & $>20$ & N.D ${ }^{c}$ & 8.78 \\
\hline $\mathrm{ADR}^{\mathrm{e}}$ & $0.30 \pm 0.05$ & $0.041 \pm 0.013$ & 0.14 & - \\
\hline
\end{tabular}

${ }^{a}$ All values are the mean of three independent experiments. ${ }^{\mathrm{b}}$ TI: Therapeutic Index $=\mathrm{IC}_{50}$ (L-O2) $/ \mathrm{IC}_{50}$ (HepG-2). ${ }^{\mathrm{c}}$ N.D., Not determined. ${ }^{\mathrm{d}} \operatorname{clog} \mathrm{P}$ was calculated by ChemBioDraw Ultra 14.0. ${ }^{\mathrm{e}}$ ADR, adriamycin, was used as a positive control.

Table 2. The inhibitory activity and $\operatorname{cog} \mathrm{P}$ of $\mathbf{9 a}-\mathbf{9 c}, \mathbf{1 0 a}-\mathbf{1 0 o}$, and $\mathbf{1 1}$ against the HepG-2 and L-O2 cell lines.

\begin{tabular}{|c|c|c|c|c|}
\hline \multirow{2}{*}{ Compound } & \multicolumn{2}{|c|}{$\mathrm{IC}_{50}{ }^{\mathrm{a}}(\mu \mathrm{M})$} & \multirow{2}{*}{$\mathbf{T I}^{\mathbf{b}}$} & \multirow{2}{*}{$C \log P^{d}$} \\
\hline & HepG-2 & L-O2 & & \\
\hline 1 & $0.060 \pm 0.02$ & $0.019 \pm 0.003$ & 0.32 & 2.96 \\
\hline $9 a$ & $0.46 \pm 0.14$ & $0.69 \pm 0.43$ & 1.5 & 2.06 \\
\hline $9 b$ & $0.53 \pm 0.01$ & $0.80 \pm 0.40$ & 1.51 & 3.29 \\
\hline $9 c$ & $0.92 \pm 0.16$ & $2.61 \pm 1.77$ & 2.84 & 3.73 \\
\hline $10 a$ & $0.82 \pm 0.33$ & $2.04 \pm 0.67$ & 2.49 & 3.57 \\
\hline $10 \mathrm{~b}$ & $0.63 \pm 0.29$ & $2.97 \pm 0.23$ & 4.71 & 3.97 \\
\hline $10 \mathrm{c}$ & $0.52 \pm 0.09$ & $2.10 \pm 1.41$ & 4.03 & 4.09 \\
\hline $10 d$ & $0.64 \pm 0.26$ & $2.62 \pm 0.52$ & 4.1 & 4.62 \\
\hline $10 \mathrm{e}$ & $1.15 \pm 0.24$ & $3.21 \pm 0.09$ & 2.79 & 5.15 \\
\hline $10 f$ & $0.83 \pm 0.38$ & $3.25 \pm 0.40$ & 3.92 & 5.68 \\
\hline $10 \mathrm{~g}$ & $1.19 \pm 0.55$ & $4.29 \pm 0.66$ & 3.61 & 6.21 \\
\hline $10 \mathrm{~h}$ & $1.15 \pm 0.24$ & $1.17 \pm 0.08$ & 1.02 & 6.74 \\
\hline $10 \mathrm{i}$ & $6.92 \pm 0.75$ & $3.27 \pm 0.43$ & 0.47 & 7.27 \\
\hline $10 \mathrm{j}$ & $10.28 \pm 1.11$ & $6.69 \pm 3.95$ & 0.65 & 7.79 \\
\hline $10 \mathrm{k}$ & $>20$ & $>20$ & N.D ${ }^{c}$ & 8.32 \\
\hline 101 & $1.01 \pm 0.40$ & $2.72 \pm 0.38$ & 2.69 & 4.01 \\
\hline $10 \mathrm{~m}$ & $1.35 \pm 0.10$ & $2.94 \pm 0.09$ & 2.18 & 3.85 \\
\hline $10 n$ & $1.11 \pm 0.22$ & $3.31 \pm 0.18$ & 0.34 & 4.77 \\
\hline $10 o$ & $1.02 \pm 0.28$ & $3.00 \pm 0.26$ & 2.94 & 5.08 \\
\hline 11 & $>20$ & $>20$ & N.D ${ }^{c}$ & 3.43 \\
\hline $\mathrm{ADR}^{\mathrm{e}}$ & $0.30 \pm 0.05$ & $0.041 \pm 0.013$ & 0.14 & - \\
\hline
\end{tabular}

a All values are the mean of three independent experiments. ${ }^{\mathrm{b}}$ TI: Therapeutic Index $=\mathrm{IC}_{50(\mathrm{~L}-\mathrm{O} 2)} / \mathrm{IC}_{50}(\mathrm{HepG}-2)$. ${ }^{\mathrm{c}}$ N.D., Not determined. ${ }^{\mathrm{d}}$ clog P was calculated by ChemBioDraw Ultra 14.0. ${ }^{\mathrm{e}}$ ADR, adriamycin, was used as a positive control. 
Considering that the introduction of a phenylsulfonyl-substituted furoxan NO-releasing moiety could reduce the toxicity of brusatol [42-45], derivatives 9a-9c were synthesized and evaluated for their anti-HCC activity. As shown in Table 2, compounds $9 \mathbf{a}-9 \mathbf{c}$ were less toxic than the parent compound $\mathbf{1}$ and showed improved TI values (ranging from 1.5 to 2.84 ) compared to compound $\mathbf{1}$ (TI $=0.32$ ). These results prompted us to further synthesize more derivatives with a phenylsulfonyl-substituted furoxan NO-releasing moiety, i.e., compounds 10a-10o. They featured with a different linker between cucurbitacin B and the phenylsulfonyl-substituted furoxan NO-releasing moiety. Compounds 10a-10o exhibited potent or moderate activity against HepG-2 cells. Importantly, their cytotoxicity against $\mathrm{L}-\mathrm{O} 2$ was significantly reduced compared to their parent compound cucurbitacin $\mathrm{B}$, with $\mathrm{IC}_{50}$ values ranging from 1.17 to $3.31 \mu \mathrm{M}$. The compound with the most potential, 10b, showed the highest TI value (4.71), which is a 14.7-fold improvement compared to its parent compound cucurbitacin B. Moreover, it still maintained potent activity against HepG-2 cells, with an $\mathrm{IC}_{50}$ value of $0.63 \mu \mathrm{M}$. These results suggested that the introduction of a phenylsulfonyl-substituted furoxan NO-releasing moiety could reduce the toxicity against normal cells and maintain potent anti-HCC activity.

The compound with the most potential, $\mathbf{1 0 b}$, was selected for a preliminary study on its mechanism of action.

\subsection{Preliminary Study of Compound 10b's Mechanism of Action}

To determine whether the cytotoxic effect of compound $\mathbf{1 0 b}$ was associated with apoptosis, a cell apoptosis assay was performed by flow cytometry. As shown in Figure 2A, compound 10b significantly induced cell apoptosis in a dose-dependent manner. To further analyze the mechanism by which compound 10b induces apoptosis, a Western blot assay was performed. STAT3 is associated with the expression of its downstream mitochondrial proteins, such as Bcl-2, Bax, and Bim, which are are critical regulators of cell apoptosis. As a result, we investigated the protein level of STAT3 and P-STAT3 using a Western blot analysis. As shown in Figure 2B, the total expression of STAT3 remained little changed. STAT3 is usually activated by phosphorylation to perform its functions. Inhibition of P-STAT3 plays an important role in cancer therapy. Our data showed that the level of P-STAT3 was clearly inhibited after treatment with compound $\mathbf{1 0 b}$ in a dose-dependent manner. Moreover, the expression of the apoptotic-related members Bax and Bim were strongly increased, while the expression of the anti-apoptotic-related member Bcl-2 was substantially diminished after treatment with compound 10b. As shown in Figure 1B, the level of caspase 3 was decreased. Accordingly, we proposed that compound 10b inhibited P-STAT3 to induce mitochondrial-pathway-mediated apoptosis.
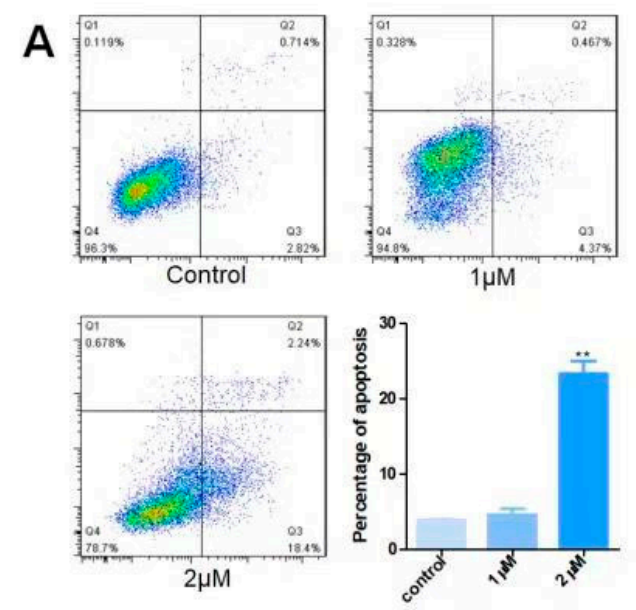

Figure 2. (A) The representative images and the statistical results of flow cytometry after treatment with compound $10 \mathrm{~b}$ at 0,1 , and $2 \mu \mathrm{M}$ in a cell apoptosis assay. ${ }^{* *} p<0.01$. (B) The level of STAT3, P-STAT3, Bax, Bim, Bcl-2, and caspase 3 after treatment with compound $\mathbf{1 0 b}$ at different concentrations by a Western blot assay. 


\subsection{In Vivo Acute Toxicity Study of $\mathbf{1 0 b}$}

To evaluate the toxicity of compound $\mathbf{1 0 b}$, an acute toxicity assay was performed using Balb/C mice. After the administration of cucurbitacin $B$ or compound $10 \mathrm{~b}$ by intravenous injection, the clinical symptoms, deaths, and body weight were observed. As shown in Figure 3A, the percentage of death was $3 / 3,3 / 3,3 / 3,3 / 3$, and $3 / 3$ after the administration of cucurbitacin $B$ at a dose of $2 \mathrm{mg} / \mathrm{kg}$, $5 \mathrm{mg} / \mathrm{kg}, 10 \mathrm{mg} / \mathrm{kg}, 20 \mathrm{mg} / \mathrm{kg}$, and $50 \mathrm{mg} / \mathrm{kg}$, respectively, while the percentage of death was $0 / 3$, $0 / 3,0 / 3,0 / 3$, and $1 / 3$ after the administration of compound $10 \mathrm{~b}$ at a dose of $2 \mathrm{mg} / \mathrm{kg}, 5 \mathrm{mg} / \mathrm{kg}$, $10 \mathrm{mg} / \mathrm{kg}, 20 \mathrm{mg} / \mathrm{kg}$, and $50 \mathrm{mg} / \mathrm{kg}$, respectively. Moreover, as shown in Figure 3B, the body weight did not change after the administration of compound $10 \mathrm{~b}$ at different doses as compared to the vehicle group. These results demonstrate that compound $10 \mathrm{~b}$ shows preferable safety and tolerability as compared with cucurbitacin B.

\begin{tabular}{|c|c|c|}
\hline Dose & 1 & $10 \mathrm{~b}$ \\
\hline $50 \mathrm{mg} / \mathrm{kg}$ & $3 / 3$ & $1 / 3$ \\
\hline $20 \mathrm{mg} / \mathrm{kg}$ & $3 / 3$ & $0 / 3$ \\
\hline $10 \mathrm{mg} / \mathrm{kg}$ & $3 / 3$ & $0 / 3$ \\
\hline $5 \mathrm{mg} / \mathrm{kg}$ & $3 / 3$ & $0 / 3$ \\
\hline $2 \mathrm{mg} / \mathrm{kg}$ & $3 / 3$ & $0 / 3$ \\
\hline
\end{tabular}

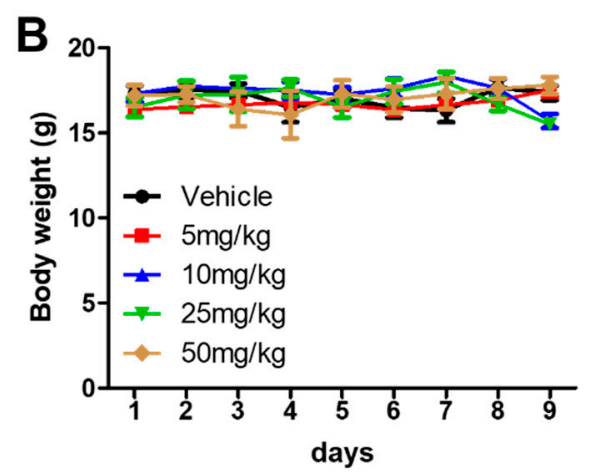

Figure 3. (A) The percentage of death in mice after the administration of cucurbitacin B and compound 10b. (B) The body weight change after the administration of compound $10 \mathrm{~b}$ by intravenous injection.

\section{Experimental}

\subsection{Chemistry}

\subsubsection{General Methods}

Unless otherwise mentioned, all reactions were carried out under a nitrogen atmosphere with dry solvents under anhydrous conditions. Reactions were monitored by thin-layer chromatography carried out on $0.25 \mathrm{~mm}$ Tsingdao silica gel plates (60F-254). Visualization was achieved using UV light, phosphomolybdic acid in ethanol, or potassium permanganate in water, each followed by heating. Tsingdao silica gel (60, particle size $0.040-0.063 \mathrm{~mm}$ ) was used for flash column chromatography. NMR spectra were recorded with a $400 \mathrm{MHz}\left({ }^{1} \mathrm{H}: 400 \mathrm{MHz},{ }^{13} \mathrm{C}\right.$ : $\left.100 \mathrm{MHz}\right)$ spectrometer. Data are reported as follows: chemical shift, multiplicity $(\mathrm{s}=$ singlet, $\mathrm{d}=$ doublet, $\mathrm{t}=$ triplet, $\mathrm{q}=$ quartet, $\mathrm{br}$. $=$ broad, $\mathrm{m}=$ multiplet), coupling constants, and integration. Purity testing was done by means of analytical HPLC on a Shimadzu LD-20A system with an ODS-C18 column $(4.6 \times 150 \mathrm{~mm}, 5 \mu \mathrm{m})$ eluted at $1-1.3 \mathrm{~mL} / \mathrm{min}$ with Milli-Q water and $\mathrm{CH}_{3} \mathrm{CN}$. The purity of all tested compounds was $\geq 95 \%$ by HPLC (Supplementary Materials).

\subsubsection{Preparation of Cucurbitacin B (1)}

The starting material cucurbitacin B (1) was obtained from Pedicellus Melo in a yield of only 0.3\%. (purity: 97\%). ${ }^{1} \mathrm{H}$ NMR $\left(400 \mathrm{MHz}, \mathrm{CDCl}_{3}\right) \delta 7.04(\mathrm{~d}, J=15.6 \mathrm{~Hz}, 1 \mathrm{H}), 6.46(\mathrm{~d}, J=15.6 \mathrm{~Hz}, 1 \mathrm{H})$, $5.77(\mathrm{~d}, J=5.3 \mathrm{~Hz}, 1 \mathrm{H}), 4.47-4.37(\mathrm{~m}, 1 \mathrm{H}), 4.33(\mathrm{dd}, J=14.7,7.4 \mathrm{~Hz}, 1 \mathrm{H}), 4.26(\mathrm{~s}, 1 \mathrm{H}), 3.61(\mathrm{~d}, J=3.8 \mathrm{~Hz}$, $1 \mathrm{H}), 3.23(\mathrm{~d}, J=14.5 \mathrm{~Hz}, 1 \mathrm{H}), 2.72(\mathrm{~d}, J=12.8 \mathrm{~Hz}, 1 \mathrm{H}), 2.66(\mathrm{~d}, J=14.6 \mathrm{~Hz}, 1 \mathrm{H}), 2.48(\mathrm{~d}, J=7.0 \mathrm{~Hz}, 1 \mathrm{H})$, $2.39(\mathrm{dd}, J=19.4,7.9 \mathrm{~Hz}, 1 \mathrm{H}), 2.29(\mathrm{ddd}, J=12.3,5.7,3.3 \mathrm{~Hz}, 1 \mathrm{H}), 2.07-1.92(\mathrm{~m}, 6 \mathrm{H}), 1.85(\mathrm{t}, J=10.2$ $\mathrm{Hz}, 2 \mathrm{H}), 1.55(\mathrm{~s}, 3 \mathrm{H}), 1.53(\mathrm{~s}, 3 \mathrm{H}), 1.45-1.39(\mathrm{~m}, 4 \mathrm{H}), 1.34(\mathrm{~s}, 3 \mathrm{H}), 1.32(\mathrm{~s}, 3 \mathrm{H}), 1.26(\mathrm{~s}, 3 \mathrm{H}), 1.06(\mathrm{~s}, 3 \mathrm{H})$, $0.96(\mathrm{~s}, 3 \mathrm{H}) .{ }^{13} \mathrm{C} \mathrm{NMR}\left(100 \mathrm{MHz}, \mathrm{CDCl}_{3}\right) \delta 213.2,212.3,202.6,170.3,152.1,140.5,120.5,120.4,79.4,78.3$, 
71.7, 71.3, 58.3, 50.8, 50.3, 48.7, 48.5, 48.2, 45.4, 42.5, 36.1, 33.8, 29.5, 26.5, 26.1, 24.0, 23.9, 22.1, 21.4, 20.2, 19.9, 18.9. HRMS (ESI) calcd. for $\mathrm{C}_{32} \mathrm{H}_{46} \mathrm{NaO}_{8}[\mathrm{M}+\mathrm{Na}]^{+} 581.3085$, found 581.3088.

\subsubsection{Procedure for the Synthesis of Compounds 2}

(6R,E)-6-((2S,9R,13R,14S,16R)-2-((tert-butyldimethylsilyl)oxy)-16-Hydroxy-4,4,9,13,14-pentamethyl-3,11dioxo-2,3,4,7,8,9,10,11,12,13,14,15,16,17-tetradecahydro-1H-cyclopenta[a]phenanthren-17-yl)-6-hydroxy-2methyl-5-oxohept-3-en-2-yl acetate (2). To a solution of cucurbitacin B (1) $(200.0 \mathrm{mg}, 0.36 \mathrm{mmol})$ and $\mathrm{TBSCl}(80.9 \mathrm{mg}, 0.54 \mathrm{mmol})$ in dry DCM $(5 \mathrm{~mL})$ was added imidazole $(48.7 \mathrm{mg}, 0.72 \mathrm{mmol})$ at $0{ }^{\circ} \mathrm{C}$. The mixture was stirred for $4 \mathrm{~h}$ at room temperature. The reaction was quenched with saturated aqueous $\mathrm{NH}_{4} \mathrm{Cl}$ and extracted with $\mathrm{CH}_{2} \mathrm{Cl}_{2}(3 \times 15 \mathrm{~mL})$. The combined organic layers were washed with saturated brine, dried over $\mathrm{Na}_{2} \mathrm{SO}_{4}$, and concentrated to give an oily crude product, which was purified on a silica gel column to yield compound $2(104 \mathrm{mg}, 43.2 \%)$ as a white solid. ${ }^{1} \mathrm{H}$ NMR $\left(400 \mathrm{MHz}, \mathrm{CDCl}_{3}\right) \delta 7.04(\mathrm{~d}, J=15.6 \mathrm{~Hz}, 1 \mathrm{H}), 6.45(\mathrm{~d}, J=15.6 \mathrm{~Hz}, 1 \mathrm{H}), 5.73(\mathrm{~d}, J=5.1 \mathrm{~Hz}, 1 \mathrm{H}), 4.45(\mathrm{dd}$, $J=12.7,5.7 \mathrm{~Hz}, 1 \mathrm{H}), 4.34(\mathrm{dd}, J=14.3,7.1 \mathrm{~Hz}, 1 \mathrm{H}), 4.25(\mathrm{~s}, 1 \mathrm{H}), 3.25(\mathrm{~d}, J=14.5 \mathrm{~Hz}, 1 \mathrm{H}), 2.69(\mathrm{t}, J=14.6$ $\mathrm{Hz}, 2 \mathrm{H}), 2.49(\mathrm{~d}, J=7.0 \mathrm{~Hz}, 1 \mathrm{H}), 2.38(\mathrm{dd}, J=19.4,7.8 \mathrm{~Hz}, 1 \mathrm{H}), 2.10-2.02(\mathrm{~m}, 1 \mathrm{H}), 2.01-1.91(\mathrm{~m}, 5 \mathrm{H})$, $1.86(\mathrm{dd}, J=13.0,9.3 \mathrm{~Hz}, 1 \mathrm{H}), 1.77(\mathrm{~d}, J=6.5 \mathrm{~Hz}, 1 \mathrm{H}), 1.54(\mathrm{~d}, J=7.2 \mathrm{~Hz}, 6 \mathrm{H}), 1.42(\mathrm{~s}, 4 \mathrm{H}), 1.34(\mathrm{~s}, 3 \mathrm{H})$, $1.27(\mathrm{~s}, 3 \mathrm{H}), 1.24(\mathrm{~s}, 1 \mathrm{H}), 1.22(\mathrm{~s}, 3 \mathrm{H}), 1.06(\mathrm{~s}, 3 \mathrm{H}), 0.97(\mathrm{~s}, 3 \mathrm{H}), 0.88(\mathrm{~s}, 9 \mathrm{H}), 0.11(\mathrm{~s}, 3 \mathrm{H}),-0.02(\mathrm{~s}, 3 \mathrm{H})$. ${ }^{13} \mathrm{C}$ NMR $\left(100 \mathrm{MHz}, \mathrm{CDCl}_{3}\right) \delta 212.5,210.7,202.6,170.3,151.9,140.5,120.5,119.9,79.4,78.4,73.8,71.4$, 58.3, 51.1, 50.8, 48.9, 48.7, 48.3, 45.5, 42.6, 36.2, 34.5, 29.4, 26.5, 26.1, 25.9, 24.1, 23.9, 22.1, 21.8, 20.2, 19.9, 19.0, 18.6, -4.4, -5.4. HRMS (ESI) calcd. for $\mathrm{C}_{38} \mathrm{H}_{60} \mathrm{NaO}_{8}[\mathrm{M}+\mathrm{Na}]^{+}$695.3950, found 695.3954.

\subsubsection{Procedure for the Synthesis of Compounds 3a-3q}

To a solution of compound 2 (100 mg, $0.15 \mathrm{mmol})$, EDCI $(85 \mathrm{mg}, 0.45 \mathrm{mmol})$, DMAP (1.2 mg, $0.01 \mathrm{mmol})$, and the corresponding acid $(0.45 \mathrm{mmol}, 3 \mathrm{eq})$ in $\mathrm{CH}_{2} \mathrm{Cl}_{2}(2 \mathrm{~mL})$ was added $\mathrm{Et}_{3} \mathrm{~N}(62.5 \mu \mathrm{L}$, $0.45 \mathrm{mmol}$ ) at $0{ }^{\circ} \mathrm{C}$. The mixture was stirred for $8 \mathrm{~h}$ at room temperature. The reaction was quenched with saturated aqueous $\mathrm{NaHCO}_{3}$ and extracted with $\mathrm{CH}_{2} \mathrm{Cl}_{2}(3 \times 15 \mathrm{~mL})$. The combined organic layers were washed with saturated brine, dried over $\mathrm{Na}_{2} \mathrm{SO}_{4}$, and concentrated to give an oily crude product, which was simple purified to yield a white solid. The solid was used for the next step directly. The solid was dissolved in THF $(2 \mathrm{~mL})$. HOAc $(38 \mu \mathrm{L}, 0.65 \mathrm{mmol})$ and TBAF $(169 \mathrm{mg}, 0.65 \mathrm{mmol})$ were added to the mixture. The mixture was stirred at room temperature for $24 \mathrm{~h}$, and then diluted with ethyl acetate $(20 \mathrm{~mL})$. The organic phase was washed with $\mathrm{H}_{2} \mathrm{O}(3 \times 20 \mathrm{~mL})$, dried over $\mathrm{Na}_{2} \mathrm{SO}_{4}$, and concentrated. The residue was purified by column chromatography on silica gel to obtain a white solid 3a-3q.

(2S,9R,13R,14S,16R)-17-((R,E)-6-Acetoxy-2-hydroxy-6-methyl-3-oxohept-4-en-2-yl)-2-hydroxy-4,4,9,13,14pentamethyl-3,11-dioxo-2,3,4,7,8,9,10,11,12,13,14,15,16,17-tetradecahydro-1H-cyclopenta[a]phenanthren-16-yl propionate (3a) (65\% yield in two steps). (purity: $97 \%){ }^{1} \mathrm{H}$ NMR $\left(400 \mathrm{MHz}, \mathrm{CDCl}_{3}\right) \delta 7.12(\mathrm{dd}, J=15.5$, $2.0 \mathrm{~Hz}, 1 \mathrm{H}), 6.40(\mathrm{dd}, J=15.6,1.8 \mathrm{~Hz}, 1 \mathrm{H}), 5.76(\mathrm{~s}, 1 \mathrm{H}), 5.17(\mathrm{t}, J=7.7 \mathrm{~Hz}, 1 \mathrm{H}), 4.49-4.35(\mathrm{~m}, 1 \mathrm{H}), 4.29$ $(\mathrm{s}, 1 \mathrm{H}), 3.60(\mathrm{~s}, 1 \mathrm{H}), 3.24(\mathrm{~d}, J=14.5 \mathrm{~Hz}, 1 \mathrm{H}), 2.71(\mathrm{dd}, J=20.2,10.3 \mathrm{~Hz}, 3 \mathrm{H}), 2.46-2.24(\mathrm{~m}, 2 \mathrm{H}), 2.09(\mathrm{dt}$, $J=7.5,5.6 \mathrm{~Hz}, 2 \mathrm{H}), 2.05-1.97(\mathrm{~m}, 5 \mathrm{H}), 1.71-1.51(\mathrm{~m}, 6 \mathrm{H}), 1.40(\mathrm{~s}, 3 \mathrm{H}), 1.37(\mathrm{~s}, 1 \mathrm{H}), 1.32(\mathrm{~s}, 3 \mathrm{H}), 1.29-1.22$ $(\mathrm{m}, 9 \mathrm{H}), 1.07(\mathrm{~s}, 3 \mathrm{H}), 1.04(\mathrm{dd}, J=7.6,2.0 \mathrm{~Hz}, 2 \mathrm{H}), 1.01(\mathrm{~s}, 3 \mathrm{H}) .{ }^{13} \mathrm{C} \mathrm{NMR}\left(100 \mathrm{MHz}, \mathrm{CDCl}_{3}\right) \delta 213.0$, 211.8, 201.0, 173.9, 169.7, 152.7, 140.5, 120.5, 119.4, 79.3, 77.8, 73.6, 71.7, 54.3, 50.3, 50.1, 48.7, 48.5, 48.1, 43.3, 42.2, 36.1, 33.8, 29.5, 27.3, 26.6, 26.5, 23.9, 23.8, 22.0, 21.4, 20.2, 19.8, 18.9, 9.1. HRMS (ESI) calcd. for $\mathrm{C}_{35} \mathrm{H}_{50} \mathrm{NaO}_{9}[\mathrm{M}+\mathrm{Na}]^{+}$637.3347, found 637.3350.

(9R,13R,14S,16R)-17-((R,E)-6-Acetoxy-2-hydroxy-6-methyl-3-oxohept-4-en-2-yl)-2-hydroxy-4,4,9,13,14pentamethyl-3,11-dioxo-2,3,4,7,8,9,10,11,12,13,14,15,16,17-tetradecahydro-1H-cyclopenta[a]phenanthren-16-yl cyclobutanecarboxylate (3b) (86\% yield in two steps). (purity: 95\%). ${ }^{1} \mathrm{H} \mathrm{NMR}\left(400 \mathrm{MHz}, \mathrm{CDCl}_{3}\right) \delta 7.08$ $(\mathrm{d}, J=15.5 \mathrm{~Hz}, 1 \mathrm{H}), 6.41(\mathrm{~d}, J=15.5 \mathrm{~Hz}, 1 \mathrm{H}), 5.76(\mathrm{~s}, 1 \mathrm{H}), 5.19(\mathrm{t}, J=7.7 \mathrm{~Hz}, 1 \mathrm{H}), 4.40(\mathrm{~d}, J=8.1 \mathrm{~Hz}, 1 \mathrm{H})$, $4.26(\mathrm{~s}, 1 \mathrm{H}), 3.59(\mathrm{~s}, 1 \mathrm{H}), 3.23(\mathrm{~d}, J=14.5 \mathrm{~Hz}, 1 \mathrm{H}), 2.99-2.83(\mathrm{~m}, 1 \mathrm{H}), 2.71(\mathrm{dd}, J=17.2,10.4 \mathrm{~Hz}, 3 \mathrm{H}), 2.34$ 
$(\mathrm{dd}, J=38.6,14.7 \mathrm{~Hz}, 2 \mathrm{H}), 2.22-2.12(\mathrm{~m}, 2 \mathrm{H}), 2.08-1.96(\mathrm{~m}, 7 \mathrm{H}), 1.93-1.83(\mathrm{~m}, 2 \mathrm{H}), 1.58(\mathrm{~s}, 6 \mathrm{H}), 1.40$ $(\mathrm{s}, 3 \mathrm{H}), 1.32(\mathrm{~s}, 3 \mathrm{H}), 1.26(\mathrm{~s}, 9 \mathrm{H}), 1.07(\mathrm{~s}, 3 \mathrm{H}), 1.00(\mathrm{~s}, 3 \mathrm{H}) .{ }^{13} \mathrm{C}$ NMR $\left(100 \mathrm{MHz}, \mathrm{CDCl}_{3}\right) \delta$ 213.0, 211.8, 201.1, 174.9, 169.7, 152.4, 140.6, 120.5, 119.6, 79.3, 77.9, 73.6, 71.7, 54.3, 50.3, 50.2, 48.7, 48.5, 47.9, 43.5, $42.2,37.8,36.1,33.8,29.8,29.5,26.5,25.1,24.9,23.9,23.9,22.0,21.4,20.2,19.8,18.8,18.5$. HRMS (ESI) calcd. for $\mathrm{C}_{37} \mathrm{H}_{52} \mathrm{NaO}_{9}[\mathrm{M}+\mathrm{Na}]^{+} 663.3504$ found 663.3508 .

(2S,9R,13R,14S,16R)-17-((R,E)-6-Acetoxy-2-hydroxy-6-methyl-3-oxohept-4-en-2-yl)-2-hydroxy-4,4,9,13,14pentamethyl-3,11-dioxo-2,3,4,7,8,9,10,11,12,13,14,15,16,17-tetradecahydro-1H-cyclopenta[a]phenanthren-16-yl cyclopentanecarboxylate (3c) (52\% yield in two steps). (purity: $98 \%) .{ }^{1} \mathrm{H}$ NMR $\left(400 \mathrm{MHz}, \mathrm{CDCl}_{3}\right) \delta 7.08$ $(\mathrm{d}, J=15.6 \mathrm{~Hz}, 1 \mathrm{H}), 6.42(\mathrm{~d}, J=15.6 \mathrm{~Hz}, 1 \mathrm{H}), 5.75(\mathrm{dd}, J=3.7,1.9 \mathrm{~Hz}, 1 \mathrm{H}), 5.16(\mathrm{t}, J=7.8 \mathrm{~Hz}, 1 \mathrm{H})$, $4.39(\mathrm{ddd}, J=12.8,5.8,3.9 \mathrm{~Hz}, 1 \mathrm{H}), 4.26(\mathrm{~s}, 1 \mathrm{H}), 3.59(\mathrm{~d}, J=3.9 \mathrm{~Hz}, 1 \mathrm{H}), 3.23(\mathrm{~d}, J=14.6 \mathrm{~Hz}, 1 \mathrm{H}), 2.71$ $(\mathrm{dd}, J=12.8,11.3 \mathrm{~Hz}, 3 \mathrm{H}), 2.53-2.44(\mathrm{~m}, 1 \mathrm{H}), 2.39(\mathrm{dd}, J=19.5,7.9 \mathrm{~Hz}, 1 \mathrm{H}), 2.28(\mathrm{ddd}, J=12.5,5.8,3.4$ $\mathrm{Hz}, 1 \mathrm{H}), 2.04-1.86(\mathrm{~m}, 6 \mathrm{H}), 1.81-1.59(\mathrm{~m}, 6 \mathrm{H}), 1.56(\mathrm{~d}, J=2.2 \mathrm{~Hz}, 6 \mathrm{H}), 1.51-1.48(\mathrm{~m}, 2 \mathrm{H}), 1.39(\mathrm{~s}, 3 \mathrm{H})$, $1.31(\mathrm{~s}, 3 \mathrm{H}), 1.26(\mathrm{~d}, J=3.1 \mathrm{~Hz}, 6 \mathrm{H}), 1.23(\mathrm{~s}, 2 \mathrm{H}), 1.06(\mathrm{~s}, 3 \mathrm{H}), 0.99(\mathrm{~s}, 3 \mathrm{H}) .{ }^{13} \mathrm{C} \mathrm{NMR}\left(100 \mathrm{MHz}, \mathrm{CDCl}_{3}\right) \delta$ 213.0, 211.8, 201.0, 176.1, 169.7, 152.5, 140.5, 120.5, 119.6, 79.3, 77.9, 73.6, 71.7, 54.2, 50.3, 50.1, 48.7, 48.5, $47.9,43.6,43.5,42.2,30.1,29.5,29.5,26.5,26.4,25.8,25.7,23.9,23.8,21.9,21.4,20.1,19.8,18.8$. HRMS (ESI) calcd. for $\mathrm{C}_{38} \mathrm{H}_{54} \mathrm{NaO}_{9}[\mathrm{M}+\mathrm{Na}]^{+}$677.3660, found 677.3665 .

(2S,9R,13R,14S,16R)-17-((R,E)-6-Acetoxy-2-hydroxy-6-methyl-3-oxohept-4-en-2-yl)-2-hydroxy-4,4,9,13,14pentamethyl-3,11-dioxo-2,3,4,7,8,9,10,11,12,13,14,15,16,17-tetradecahydro-1H-cyclopenta[a]phenanthren-16-yl 5-((tert-butoxycarbonyl)amino)pentanoate (3d) (67\% yield in two steps). (purity: 95\%). ${ }^{1} \mathrm{H} \mathrm{NMR}(400 \mathrm{MHz}$, $\left.\mathrm{CDCl}_{3}\right) \delta 7.13(\mathrm{~d}, J=15.6 \mathrm{~Hz}, 1 \mathrm{H}), 6.38(\mathrm{~d}, J=15.6 \mathrm{~Hz}, 1 \mathrm{H}), 5.76(\mathrm{~d}, J=5.3 \mathrm{~Hz}, 1 \mathrm{H}), 5.17(\mathrm{t}, J=8.0 \mathrm{~Hz}$, $1 \mathrm{H}), 4.70(\mathrm{~s}, 1 \mathrm{H}), 4.47-4.32(\mathrm{~m}, 1 \mathrm{H}), 4.26(\mathrm{~s}, 1 \mathrm{H}), 3.59(\mathrm{~d}, J=3.8 \mathrm{~Hz}, 1 \mathrm{H}), 3.23(\mathrm{~d}, J=14.6 \mathrm{~Hz}, 1 \mathrm{H})$, 3.13-3.04 (m, 2H), $2.70(\mathrm{dd}, J=19.5,11.0 \mathrm{~Hz}, 3 \mathrm{H}), 2.39(\mathrm{dd}, J=19.4,7.7 \mathrm{~Hz}, 1 \mathrm{H}), 2.29(\mathrm{ddd}, J=12.4,5.7$, $3.4 \mathrm{~Hz}, 1 \mathrm{H}), 2.10(\mathrm{t}, J=7.2 \mathrm{~Hz}, 2 \mathrm{H}), 2.01(\mathrm{~s}, 3 \mathrm{H}), 2.00-1.92(\mathrm{~m}, 3 \mathrm{H}), 1.57(\mathrm{~s}, 3 \mathrm{H}), 1.54(\mathrm{~s}, 4 \mathrm{H}), 1.47-1.40$ $(\mathrm{m}, 12 \mathrm{H}), 1.39(\mathrm{~s}, 3 \mathrm{H}), 1.35(\mathrm{~s}, 1 \mathrm{H}), 1.32(\mathrm{~s}, 3 \mathrm{H}), 1.27(\mathrm{~d}, J=4.8 \mathrm{~Hz}, 6 \mathrm{H}), 1.23(\mathrm{~s}, 1 \mathrm{H}), 1.07(\mathrm{~s}, 3 \mathrm{H}), 1.00$ (s, 3H). ${ }^{13} \mathrm{C}$ NMR $\left(100 \mathrm{MHz}, \mathrm{CDCl}_{3}\right) \delta 213.0,211.7,201.0,172.9,169.8,156.1,152.9,140.5,120.5,119.4$, 79.3, 77.8, 73.6, 71.7, 54.2, 50.3, 50.0, 48.7, 48.5, 48.1, 43.4, 42.2, 40.1, 36.1, 33.8, 33.3, 29.8, 29.5, 29.3, 28.5, $26.9,26.4,23.9,23.8,21.9,21.8,21.4,20.2,19.8,18.9$. HRMS (ESI) calcd. for $\mathrm{C}_{42} \mathrm{H}_{63} \mathrm{NNaO}_{11}[\mathrm{M}+\mathrm{Na}]^{+}$ 780.4293 , found 780.4296 .

(2S,9R,13R,14S,16R)-17-((R,E)-6-Acetoxy-2-hydroxy-6-methyl-3-oxohept-4-en-2-yl)-2-hydroxy-4,4,9,13,14pentamethyl-3,11-dioxo-2,3,4,7,8,9,10,11,12,13,14,15,16,17-tetradecahydro-1H-cyclopenta[a]phenanthren-16-yl 5-((tert-butoxycarbonyl)(methyl)amino)pentanoate (3e) (66\% yield in two steps). (purity: $96 \%) .{ }^{1} \mathrm{H}$ NMR $\left(400 \mathrm{MHz}, \mathrm{CDCl}_{3}\right) \delta 7.11(\mathrm{~d}, J=15.6 \mathrm{~Hz}, 1 \mathrm{H}), 6.38(\mathrm{~d}, J=15.6 \mathrm{~Hz}, 1 \mathrm{H}), 5.75(\mathrm{~d}, J=5.4 \mathrm{~Hz}, 1 \mathrm{H}), 5.18$ $(\mathrm{t}, J=7.9 \mathrm{~Hz}, 1 \mathrm{H}), 4.44-4.35(\mathrm{~m}, 1 \mathrm{H}), 4.26(\mathrm{~s}, 1 \mathrm{H}), 3.59(\mathrm{~d}, J=3.8 \mathrm{~Hz}, 1 \mathrm{H}), 3.28-3.12(\mathrm{~m}, 3 \mathrm{H}), 2.80(\mathrm{~s}, 3 \mathrm{H})$, $2.69(\mathrm{dd}, J=20.6,11.0 \mathrm{~Hz}, 3 \mathrm{H}), 2.39(\mathrm{dd}, J=19.5,7.8 \mathrm{~Hz}, 1 \mathrm{H}), 2.28(\mathrm{ddd}, J=12.3,5.6,3.4 \mathrm{~Hz}, 1 \mathrm{H}), 2.10$ (s, 2H), 2.03-1.86 (m, 7H), $1.55(\mathrm{~d}, J=5.6 \mathrm{~Hz}, 6 \mathrm{H}), 1.51-1.45(\mathrm{~m}, 4 \mathrm{H}), 1.42(\mathrm{~s}, 9 \mathrm{H}), 1.39(\mathrm{~s}, 3 \mathrm{H}), 1.31$ $(\mathrm{s}, 3 \mathrm{H}), 1.27(\mathrm{~s}, 3 \mathrm{H}), 1.25(\mathrm{~s}, 3 \mathrm{H}), 1.23(\mathrm{~s}, 1 \mathrm{H}), 1.06(\mathrm{~s}, 3 \mathrm{H}), 0.99(\mathrm{~s}, 3 \mathrm{H}) .{ }^{13} \mathrm{C} \mathrm{NMR}\left(100 \mathrm{MHz}, \mathrm{CDCl}_{3}\right) \delta$ 212.9, 211.7, 200.9, 172.9, 169.6, 155.9, 152.7, 140.6, 120.4, 119.4, 79.2, 77.8, 73.5, 71.7, 54.3, 50.3, 50.0, 48.7, 48.5, 48.1, 47.9, 43.4, 42.2, 36.1, 34.2, 33.8, 33.5, 29.8,29.4, 28.6, 26.7, 26.5, 23.9, 23.8, 21.9, 21.9, 21.4, 20.1, 19.8, 18.9. HRMS (ESI) calcd. for $\mathrm{C}_{43} \mathrm{H}_{65} \mathrm{NNaO}_{11}[\mathrm{M}+\mathrm{Na}]^{+} 794.4450$, found 794.4453.

(2S,9R,13R,14S,16R)-17-((R,E)-6-Acetoxy-2-hydroxy-6-methyl-3-oxohept-4-en-2-yl)-2-hydroxy-4,4,9,13,14pentamethyl-3,11-dioxo-2,3,4,7,8,9,10,11,12,13,14,15,16,17-tetradecahydro-1H-cyclopenta[a]phenanthren-16-yl 4-((tert-butoxycarbonyl)(methyl)amino)butanoate (3f) (64\% yield in two steps). (purity: $98 \%$ ). ${ }^{1} \mathrm{H}$ NMR $\left(400 \mathrm{MHz}, \mathrm{CDCl}_{3}\right) \delta 7.11(\mathrm{~d}, J=15.6 \mathrm{~Hz}, 1 \mathrm{H}), 6.39(\mathrm{~d}, J=15.6 \mathrm{~Hz}, 1 \mathrm{H}), 5.76(\mathrm{~d}, J=5.3 \mathrm{~Hz}, 1 \mathrm{H}), 5.20$ $(\mathrm{t}, J=8.0 \mathrm{~Hz}, 1 \mathrm{H}), 4.44-4.35(\mathrm{~m}, 1 \mathrm{H}), 4.25(\mathrm{~s}, 1 \mathrm{H}), 3.59(\mathrm{~d}, J=3.7 \mathrm{~Hz}, 1 \mathrm{H}), 3.28-3.12(\mathrm{~m}, 3 \mathrm{H}), 2.82(\mathrm{~s}, 3 \mathrm{H})$, $2.70(\mathrm{dd}, J=18.3,11.0 \mathrm{~Hz}, 3 \mathrm{H}), 2.40(\mathrm{dd}, J=19.4,7.5 \mathrm{~Hz}, 1 \mathrm{H}), 2.30(\mathrm{ddd}, J=12.3,5.5,3.3 \mathrm{~Hz}, 1 \mathrm{H}), 2.08$ (s, 2H), $2.01(\mathrm{~s}, 3 \mathrm{H}), 1.99(\mathrm{~d}, J=5.7 \mathrm{~Hz}, 2 \mathrm{H}), 1.77-1.69(\mathrm{~m}, 2 \mathrm{H}), 1.56(\mathrm{~d}, J=5.9 \mathrm{~Hz}, 6 \mathrm{H}), 1.43(\mathrm{~s}, 9 \mathrm{H}), 1.40$ $(\mathrm{s}, 3 \mathrm{H}), 1.32(\mathrm{~s}, 3 \mathrm{H}), 1.28(\mathrm{~s}, 3 \mathrm{H}), 1.26(\mathrm{~s}, 3 \mathrm{H}), 1.24(\mathrm{~s}, 3 \mathrm{H}), 1.07(\mathrm{~s}, 3 \mathrm{H}), 1.00(\mathrm{~s}, 3 \mathrm{H}) .{ }^{13} \mathrm{C} \mathrm{NMR}(100 \mathrm{MHz}$, 
$\left.\mathrm{CDCl}_{3}\right) \delta 212.9,211.7,201.1,172.6,169.7,155.9,152.8,140.6,120.5,119.4,79.2,77.8,73.7,71.7,54.3$, $50.34,50.1,48.7,48.5,48.1,43.3,42.2,36.1,34.4,33.9,30.9,29.8,29.5,28.6,26.5,23.9,23.8,21.9,21.4,20.2$, 19.8, 18.9. HRMS (ESI) calcd. for $\mathrm{C}_{42} \mathrm{H}_{63} \mathrm{NNaO}_{11}[\mathrm{M}+\mathrm{Na}]^{+}$780.4293, found 780.4295.

(2S,9R,13R,14S,16R)-17-((R,E)-6-Acetoxy-2-hydroxy-6-methyl-3-oxohept-4-en-2-yl)-2-hydroxy-4,4,9,13,14pentamethyl-3,11-dioxo-2,3,4,7,8,9,10,11,12,13,14,15,16,17-tetradecahydro-1H-cyclopenta[a]phenanthren-16-yl 3-(2-((tert-butoxycarbonyl)amino)phenyl)propanoate (3g) (47\% yield in two steps). (purity: $95 \%) .{ }^{1} \mathrm{H} \mathrm{NMR}$ $\left(400 \mathrm{MHz}, \mathrm{CDCl}_{3}\right) \delta 7.65(\mathrm{~d}, J=7.7 \mathrm{~Hz}, 1 \mathrm{H}), 7.20-7.04(\mathrm{~m}, 4 \mathrm{H}), 7.00(\mathrm{t}, J=7.3 \mathrm{~Hz}, 1 \mathrm{H}), 6.34(\mathrm{~d}, J=15.6$ $\mathrm{Hz}, 1 \mathrm{H}), 5.74(\mathrm{~d}, J=3.5 \mathrm{~Hz}, 1 \mathrm{H}), 5.15(\mathrm{t}, J=7.9 \mathrm{~Hz}, 1 \mathrm{H}), 4.38(\mathrm{~d}, J=9.1 \mathrm{~Hz}, 1 \mathrm{H}), 4.25(\mathrm{~s}, 1 \mathrm{H}), 3.61(\mathrm{~s}, 1 \mathrm{H})$, $3.19(\mathrm{~d}, J=14.5 \mathrm{~Hz}, 1 \mathrm{H}), 2.81(\mathrm{dt}, J=23.3,7.6 \mathrm{~Hz}, 2 \mathrm{H}), 2.69(\mathrm{~d}, J=14.2 \mathrm{~Hz}, 2 \mathrm{H}), 2.61(\mathrm{~d}, J=7.3 \mathrm{~Hz}, 1 \mathrm{H})$, $2.44(\mathrm{t}, J=7.7 \mathrm{~Hz}, 2 \mathrm{H}), 2.36(\mathrm{dd}, J=20.4,7.5 \mathrm{~Hz}, 1 \mathrm{H}), 2.27(\mathrm{~d}, J=11.7 \mathrm{~Hz}, 1 \mathrm{H}), 1.95(\mathrm{~s}, 3 \mathrm{H}), 1.94-1.78$ $(\mathrm{m}, 3 \mathrm{H}), 1.53(\mathrm{~d}, J=9.1 \mathrm{~Hz}, 3 \mathrm{H}), 1.49(\mathrm{~s}, 12 \mathrm{H}), 1.36(\mathrm{~s}, 3 \mathrm{H}), 1.31(\mathrm{~s}, 3 \mathrm{H}), 1.24(\mathrm{~s}, 5 \mathrm{H}), 1.11(\mathrm{~s}, 3 \mathrm{H})$, $1.04(\mathrm{~s}, 3 \mathrm{H}), 0.96(\mathrm{~s}, 3 \mathrm{H}) .{ }^{13} \mathrm{C}$ NMR $\left(100 \mathrm{MHz}, \mathrm{CDCl}_{3}\right) \delta 212.95,211.70,200.86,173.16,169.85,153.82$, 153.04, 140.37, 136.13, 129.31, 127.00, 124.28, 120.35, 119.09, 80.19, 79.15, 77.67, 74.02, 71.64, 65.61, 54.07, $50.28,49.93,48.55,48.36,47.92,42.97,42.07,35.99,34.12,33.71,29.36,28.45,27.06,26.18,25.59,23.75$, 23.57, 21.83, 21.34, 20.08, 19.69, 18.59. HRMS (ESI) calcd. for $\mathrm{C}_{46} \mathrm{H}_{63} \mathrm{NNaO}_{11}[\mathrm{M}+\mathrm{Na}]^{+} 828.4293$, found 828.4296 .

(2S,9R,13R,14S,16R)-17-((R,E)-6-Acetoxy-2-hydroxy-6-methyl-3-oxohept-4-en-2-yl)-2-hydroxy-4,4,9,13,14pentamethyl-3,11-dioxo-2,3,4,7,8,9,10,11,12,13,14,15,16,17-tetradecahydro-1H-cyclopenta[a]phenanthren-16-yl 4-methylbenzoate (3h) (79\% yield in two steps). (purity: $97 \%$ ). ${ }^{1} \mathrm{H} \mathrm{NMR}\left(400 \mathrm{MHz}, \mathrm{CDCl}_{3}\right) \delta 7.75$ $(\mathrm{d}, J=8.0 \mathrm{~Hz}, 2 \mathrm{H}), 7.16(\mathrm{~d}, J=7.9 \mathrm{~Hz}, 2 \mathrm{H}), 6.87(\mathrm{~d}, J=15.5 \mathrm{~Hz}, 1 \mathrm{H}), 6.51(\mathrm{~d}, J=15.5 \mathrm{~Hz}, 1 \mathrm{H}), 5.74(\mathrm{~d}$, $J=4.2 \mathrm{~Hz}, 1 \mathrm{H}), 5.54(\mathrm{t}, J=7.8 \mathrm{~Hz}, 1 \mathrm{H}), 4.42(\mathrm{~d}, J=10.8 \mathrm{~Hz}, 1 \mathrm{H}), 4.19(\mathrm{~s}, 1 \mathrm{H}), 3.61(\mathrm{~d}, J=2.2 \mathrm{~Hz}, 1 \mathrm{H})$, $3.29(\mathrm{~d}, J=14.5 \mathrm{~Hz}, 1 \mathrm{H}), 2.89(\mathrm{~d}, J=7.2 \mathrm{~Hz}, 1 \mathrm{H}), 2.74(\mathrm{~d}, J=18.2 \mathrm{~Hz}, 2 \mathrm{H}), 2.47-2.31(\mathrm{~m}, 4 \mathrm{H}), 2.10(\mathrm{dd}$, $J=13.6,9.1 \mathrm{~Hz}, 1 \mathrm{H}), 2.03(\mathrm{~d}, J=12.0 \mathrm{~Hz}, 5 \mathrm{H}), 1.46(\mathrm{~s}, 6 \mathrm{H}), 1.40(\mathrm{~s}, 3 \mathrm{H}), 1.37(\mathrm{~s}, 3 \mathrm{H}), 1.31(\mathrm{~s}, 3 \mathrm{H}), 1.25$ $(\mathrm{d}, J=8.9 \mathrm{~Hz}, 6 \mathrm{H}), 1.09(\mathrm{~s}, 3 \mathrm{H}), 1.06(\mathrm{~s}, 3 \mathrm{H}) .{ }^{13} \mathrm{C} \mathrm{NMR}\left(100 \mathrm{MHz}, \mathrm{CDCl}_{3}\right) \delta 213.0,211.9,201.3,169.8$, 165.9, 152.5, 143.8, 140.5, 129.7, 129.1, 127.4, 120.5, 119.5, 79.5, 78.2, 74.1, 71.7, 54.8, 50.4, 48.7, 48.5, 48.0, 43.6, 42.3, 36.1, 33.8, 32.0, 29.8, 29.5, 26.6, 25.8, 24.2, 23.9, 22.8, 22.1, 21.8, 21.4, 20.2, 19.8, 18.8. HRMS (ESI) calcd. for $\mathrm{C}_{40} \mathrm{H}_{52} \mathrm{NaO}_{9}[\mathrm{M}+\mathrm{Na}]^{+}$699.3504, found 699.3508 .

(2S,9R,13R,14S,16R)-17-((R,E)-6-Acetoxy-2-hydroxy-6-methyl-3-oxohept-4-en-2-yl)-2-hydroxy-4,4,9,13,14pentamethyl-3,11-dioxo-2,3,4,7,8,9,10,11,12,13,14,15,16,17-tetradecahydro-1H-cyclopenta[a]phenanthren-16-yl 4-fluorobenzoate (3i) (81\% yield in two steps). (purity: 98\%). ${ }^{1} \mathrm{H} \mathrm{NMR}\left(400 \mathrm{MHz}, \mathrm{CDCl}_{3}\right) \delta 7.96-7.82$ $(\mathrm{m}, 2 \mathrm{H}), 7.05(\mathrm{t}, J=8.4 \mathrm{~Hz}, 2 \mathrm{H}), 6.90(\mathrm{~d}, J=15.6 \mathrm{~Hz}, 1 \mathrm{H}), 6.48(\mathrm{~d}, J=15.6 \mathrm{~Hz}, 1 \mathrm{H}), 5.74(\mathrm{~d}, J=3.6 \mathrm{~Hz}$, $1 \mathrm{H}), 5.55(\mathrm{t}, J=7.8 \mathrm{~Hz}, 1 \mathrm{H}), 4.42(\mathrm{dd}, J=12.7,5.7 \mathrm{~Hz}, 1 \mathrm{H}), 4.14(\mathrm{~s}, 1 \mathrm{H}), 3.61(\mathrm{~s}, 1 \mathrm{H}), 3.29(\mathrm{~d}, J=14.6 \mathrm{~Hz}$, $1 \mathrm{H}), 2.87(\mathrm{~d}, J=7.3 \mathrm{~Hz}, 1 \mathrm{H}), 2.78(\mathrm{~d}, J=14.7 \mathrm{~Hz}, 1 \mathrm{H}), 2.73(\mathrm{~d}, J=12.4 \mathrm{~Hz}, 1 \mathrm{H}), 2.41(\mathrm{dd}, J=18.9,6.5 \mathrm{~Hz}$, $1 \mathrm{H}), 2.35-2.27(\mathrm{~m}, 1 \mathrm{H}), 2.19-2.07(\mathrm{~m}, 1 \mathrm{H}), 2.03(\mathrm{~d}, J=10.1 \mathrm{~Hz}, 4 \mathrm{H}), 1.97-1.86(\mathrm{~m}, 1 \mathrm{H}), 1.46(\mathrm{~s}, 6 \mathrm{H})$, $1.43(\mathrm{~s}, 3 \mathrm{H}), 1.36(\mathrm{~s}, 3 \mathrm{H}), 1.31(\mathrm{~s}, 3 \mathrm{H}), 1.26(\mathrm{~s}, 3 \mathrm{H}), 1.24(\mathrm{~s}, 2 \mathrm{H}), 1.09(\mathrm{~s}, 3 \mathrm{H}), 1.06(\mathrm{~s}, 3 \mathrm{H}) .{ }^{19} \mathrm{~F} \mathrm{NMR}(376$ $\left.\mathrm{MHz}, \mathrm{CDCl}_{3}\right) \delta-105.30-105.40(\mathrm{~m}) .{ }^{13} \mathrm{C}$ NMR $\left(100 \mathrm{MHz}, \mathrm{CDCl}_{3}\right) \delta 213.0,211.7,201.3,169.7,165.9$ $(\mathrm{d}, J=254.2 \mathrm{~Hz}), 164.9,152.8,140.5,132.2(\mathrm{~d}, J=9.2 \mathrm{~Hz}), 131.1,128.9,126.3(\mathrm{~d}, J=2.7 \mathrm{~Hz}), 120.4,119.3$, $115.6(\mathrm{~d}, J=22.0 \mathrm{~Hz}), 79.4,78.1,74.5,71.7,54.6,50.4,50.3,48.7,48.5,48.0,43.6,42.2,36.1,33.8,29.4,26.7$, 26.1, 24.1, 23.9, 22.1, 21.4, 20.2, 19.8, 18.9. HRMS (ESI) calcd. for $\mathrm{C}_{39} \mathrm{H}_{49} \mathrm{FNaO}_{9}[\mathrm{M}+\mathrm{Na}]^{+} 703.3253$, found 703.3258 .

(2S,9R,13R,14S,16R)-17-((R,E)-6-Acetoxy-2-hydroxy-6-methyl-3-oxohept-4-en-2-yl)-2-hydroxy-4,4,9,13,14pentamethyl-3,11-dioxo-2,3,4,7,8,9,10,11,12,13,14,15,16,17-tetradecahydro-1H-cyclopenta[a]phenanthren-16-yl 4-chlorobenzoate (3j) (69\% yield in two steps). (purity: 95\%). ${ }^{1} \mathrm{H}$ NMR $\left(400 \mathrm{MHz}, \mathrm{CDCl}_{3}\right) \delta 7.79$ $(\mathrm{d}, J=8.3 \mathrm{~Hz}, 2 \mathrm{H}), 7.34(\mathrm{~d}, J=8.3 \mathrm{~Hz}, 2 \mathrm{H}), 6.88(\mathrm{~d}, J=15.6 \mathrm{~Hz}, 1 \mathrm{H}), 6.48(\mathrm{~d}, J=15.6 \mathrm{~Hz}, 1 \mathrm{H}), 5.73$ $(\mathrm{s}, 1 \mathrm{H}), 5.55(\mathrm{t}, J=7.8 \mathrm{~Hz}, 1 \mathrm{H}), 4.41(\mathrm{dd}, J=12.7,5.7 \mathrm{~Hz}, 1 \mathrm{H}), 3.28(\mathrm{~d}, J=14.5 \mathrm{~Hz}, 1 \mathrm{H}), 2.87(\mathrm{~d}, J=7.2 \mathrm{~Hz}$, 1H), 2.81-2.67 (m, 2H), 2.50-2.26 (m, 2H), 2.16-2.06 (m, 1H), $2.02(\mathrm{~d}, J=10.9 \mathrm{~Hz}, 4 \mathrm{H}), 1.97-1.86(\mathrm{~m}, 2 \mathrm{H})$, $1.45(\mathrm{~s}, 6 \mathrm{H}), 1.42(\mathrm{~s}, 3 \mathrm{H}), 1.35(\mathrm{~s}, 3 \mathrm{H}), 1.30(\mathrm{~s}, 3 \mathrm{H}), 1.25(\mathrm{~s}, 3 \mathrm{H}), 1.24(\mathrm{~s}, 3 \mathrm{H}), 1.08(\mathrm{~s}, 3 \mathrm{H}), 1.05(\mathrm{~s}, 3 \mathrm{H}) .{ }^{13} \mathrm{C}$ 
NMR $\left(100 \mathrm{MHz}, \mathrm{CDCl}_{3}\right) \delta 212.9,211.7,201.3,169.7,165.0,152.8,140.5,139.6,131.1,128.8,120.4,119.4$, 79.4, 78.1, 74.6, 71.7, 54.6, 50.3, 50.3, 48.6, 48.4, 48.0, 43.5, 42.2, 36.1, 33.8, 29.4, 26.6, 26.1, 24.1, 23.9, 22.0, 21.3, 20.2, 19.8, 18.9. HRMS (ESI) calcd. for $\mathrm{C}_{39} \mathrm{H}_{49} \mathrm{ClNaO}_{9}[\mathrm{M}+\mathrm{Na}]^{+} 719.2957$, found 719.2962.

(2S,9R,13R,14S,16R)-17-((R,E)-6-Acetoxy-2-hydroxy-6-methyl-3-oxohept-4-en-2-yl)-2-hydroxy-4,4,9,13,14pentamethyl-3,11-dioxo-2,3,4,7,8,9,10,11,12,13,14,15,16,17-tetradecahydro-1H-cyclopenta[a]phenanthren-16-yl 4-bromobenzoate (3k) (64\% yield in two steps). (purity: 95\%). ${ }^{1} \mathrm{H} \mathrm{NMR}\left(400 \mathrm{MHz}, \mathrm{CDCl}_{3}\right) \delta 7.73$ (d, $J=8.5 \mathrm{~Hz}, 2 \mathrm{H}), 7.52(\mathrm{~d}, J=8.5 \mathrm{~Hz}, 2 \mathrm{H}), 6.90(\mathrm{~d}, J=15.6 \mathrm{~Hz}, 1 \mathrm{H}), 6.47(\mathrm{~d}, J=15.6 \mathrm{~Hz}, 1 \mathrm{H}), 5.74(\mathrm{~d}, J=5.4$ $\mathrm{Hz}, 1 \mathrm{H}), 5.55(\mathrm{t}, J=7.9 \mathrm{~Hz}, 1 \mathrm{H}), 4.42(\mathrm{dd}, J=12.9,5.9 \mathrm{~Hz}, 1 \mathrm{H}), 4.13(\mathrm{~d}, J=7.0 \mathrm{~Hz}, 1 \mathrm{H}), 3.29(\mathrm{~d}, J=14.7$ $\mathrm{Hz}, 1 \mathrm{H}), 2.87(\mathrm{~d}, J=7.4 \mathrm{~Hz}, 1 \mathrm{H}), 2.76(\mathrm{dd}, J=21.3,13.9 \mathrm{~Hz}, 2 \mathrm{H}), 2.47-2.28(\mathrm{~m}, 2 \mathrm{H}), 2.16-2.07(\mathrm{~m}, 1 \mathrm{H})$, 2.06-2.01 (m, 4H), $1.95(\mathrm{~d}, J=3.4 \mathrm{~Hz}, 1 \mathrm{H}), 1.46(\mathrm{~d}, J=4.2 \mathrm{~Hz}, 6 \mathrm{H}), 1.44(\mathrm{~s}, 3 \mathrm{H}), 1.36(\mathrm{~s}, 3 \mathrm{H}), 1.31(\mathrm{~s}, 3 \mathrm{H})$, 1.27 (s, 3H), 1.24 (s, 3H), 1.09 (s, 3H), 1.06 (s, 3H). ${ }^{13} \mathrm{C} \mathrm{NMR}\left(100 \mathrm{MHz}, \mathrm{CDCl}_{3}\right) \delta 213.0,211.7,201.2$, $169.8,165.2,152.9,140.5,131.8,131.2,128.9,128.3,120.4,119.3,79.4,78.1,74.7,71.7,54.6,50.4,50.3,48.7$, $48.5,48.0,43.5,42.2,36.1,33.8,29.4,26.7,26.1,24.1,23.9,22.1,21.4,20.2,19.8,18.9$. HRMS (ESI) calcd. for $\mathrm{C}_{39} \mathrm{H}_{49} \mathrm{BrNaO}_{9}[\mathrm{M}+\mathrm{Na}]^{+} 763.2452$, found 763.2458 .

(2S,9R,13R,14S,16R)-17-((R,E)-6-Acetoxy-2-hydroxy-6-methyl-3-oxohept-4-en-2-yl)-2-hydroxy-4,4,9,13,14pentamethyl-3,11-dioxo-2,3,4,7,8,9,10,11,12,13,14,15,16,17-tetradecahydro-1H-cyclopenta[a]phenanthren-16-yl 4-methoxybenzoate (31) (78\% yield in two steps). (purity: 99\%). $\left.{ }^{1} \mathrm{H} \mathrm{NMR} \mathrm{(400} \mathrm{MHz}_{2} \mathrm{CDCl}_{3}\right) \delta 7.82$ $(\mathrm{d}, J=8.8 \mathrm{~Hz}, 2 \mathrm{H}), 6.87(\mathrm{t}, J=12.0 \mathrm{~Hz}, 3 \mathrm{H}), 6.51(\mathrm{~d}, J=15.6 \mathrm{~Hz}, 1 \mathrm{H}), 5.74(\mathrm{~d}, J=5.4 \mathrm{~Hz}, 1 \mathrm{H}), 5.54$ $(\mathrm{t}, J=7.9 \mathrm{~Hz}, 1 \mathrm{H}), 4.42(\mathrm{dd}, J=7.2,3.2 \mathrm{~Hz}, 1 \mathrm{H}), 4.15(\mathrm{~s}, 1 \mathrm{H}), 3.83(\mathrm{~s}, 3 \mathrm{H}), 3.60(\mathrm{~d}, J=3.4 \mathrm{~Hz}, 1 \mathrm{H}), 3.29(\mathrm{~d}$, $J=14.6 \mathrm{~Hz}, 1 \mathrm{H}), 2.88(\mathrm{~d}, J=7.4 \mathrm{~Hz}, 1 \mathrm{H}), 2.78(\mathrm{~d}, J=14.7 \mathrm{~Hz}, 1 \mathrm{H}), 2.47-2.28(\mathrm{~m}, 2 \mathrm{H}), 2.14-2.03(\mathrm{~m}, 2 \mathrm{H})$, $2.02(\mathrm{~s}, 3 \mathrm{H}), 1.97-1.88(\mathrm{~m}, 1 \mathrm{H}), 1.46(\mathrm{~d}, J=5.3 \mathrm{~Hz}, 6 \mathrm{H}), 1.42(\mathrm{~s}, 3 \mathrm{H}), 1.37(\mathrm{~s}, 3 \mathrm{H}), 1.32(\mathrm{~d}, J=5.5 \mathrm{~Hz}, 3 \mathrm{H})$, $1.27(\mathrm{~d}, J=3.5 \mathrm{~Hz}, 3 \mathrm{H}), 1.25(\mathrm{~s}, 3 \mathrm{H}), 1.09(\mathrm{~s}, 3 \mathrm{H}), 1.06(\mathrm{~s}, 3 \mathrm{H}) .{ }^{13} \mathrm{C} \mathrm{NMR}\left(100 \mathrm{MHz}, \mathrm{CDCl}_{3}\right) \delta 213.1$, 211.9, 201.4, 169.8, 165.6, 163.6, 152.5, 140.6, 131.7, 122.6, 120.5, 119.6, 113.7, 79.5, 78.3, 74.0, 71.8, 55.6, 54.9, 50.4, 48.8, 48.5, 48.0, 43.6, 42.3, 36.1, 33.9, 29.8, 29.5, 26.7, 25.9, 24.3, 22.8, 22.1, 21.4, 20.2, 19.8, 18.9. HRMS (ESI) calcd. for $\mathrm{C}_{40} \mathrm{H}_{52} \mathrm{BrNaO}_{10}[\mathrm{M}+\mathrm{Na}]^{+} 715.3453$, found 715.3458 .

(2S,9R,13R,14S,16R)-17-((R,E)-6-Acetoxy-2-hydroxy-6-methyl-3-oxohept-4-en-2-yl)-2-hydroxy-4,4,9,13,14pentamethyl-3,11-dioxo-2,3,4,7,8,9,10,11,12,13,14,15,16,17-tetradecahydro-1H-cyclopenta[a]phenanthren-16-yl 4-nitrobenzoate (3m) (64\% yield in two steps). (purity: 95\%). $\left.{ }^{1} \mathrm{H} \mathrm{NMR} \mathrm{(400} \mathrm{MHz,} \mathrm{CDCl} 3\right) \delta 8.24$ $(\mathrm{d}, J=8.7 \mathrm{~Hz}, 2 \mathrm{H}), 8.05(\mathrm{~d}, J=8.7 \mathrm{~Hz}, 2 \mathrm{H}), 6.94(\mathrm{~d}, J=15.6 \mathrm{~Hz}, 1 \mathrm{H}), 6.47(\mathrm{~d}, J=15.6 \mathrm{~Hz}, 1 \mathrm{H}), 5.74$ $(\mathrm{s}, 1 \mathrm{H}), 5.61(\mathrm{t}, J=7.9 \mathrm{~Hz}, 1 \mathrm{H}), 4.42(\mathrm{~d}, J=10.8 \mathrm{~Hz}, 1 \mathrm{H}), 4.12(\mathrm{~s}, 1 \mathrm{H}), 3.60(\mathrm{~d}, J=2.8 \mathrm{~Hz}, 1 \mathrm{H}), 3.29(\mathrm{~d}, J=$ $14.6 \mathrm{~Hz}, 1 \mathrm{H}), 2.90(\mathrm{~d}, J=7.4 \mathrm{~Hz}, 1 \mathrm{H}), 2.80(\mathrm{~d}, J=14.6 \mathrm{~Hz}, 1 \mathrm{H}), 2.73(\mathrm{~d}, J=12.8 \mathrm{~Hz}, 1 \mathrm{H}), 2.52-2.27(\mathrm{~m}$, $2 \mathrm{H}), 2.16(\mathrm{dd}, J=14.1,9.0 \mathrm{~Hz}, 1 \mathrm{H}), 2.07-1.98(\mathrm{~m}, 4 \mathrm{H}), 1.48(\mathrm{~s}, 3 \mathrm{H}), 1.47(\mathrm{~s}, 3 \mathrm{H}), 1.37(\mathrm{~s}, 3 \mathrm{H}), 1.31(\mathrm{~s}, 3 \mathrm{H})$, 1.27 (s, 3H), 1.25 (s, 6H), $1.10(\mathrm{~s}, 3 \mathrm{H}), 1.08$ (s, 3H). ${ }^{13} \mathrm{C} \mathrm{NMR}\left(100 \mathrm{MHz}, \mathrm{CDCl}_{3}\right) \delta 212.9,211.5,201.1$, $169.8,164.2,153.4,150.7,140.7,135.4,130.9,128.9,123.7,120.4,119.2,79.3,77.9,75.5,71.7,54.3,50.4$, $50.3,48.6$, 48.5, 48.1, 43.6, 42.2, 36.1, 33.9, 29.8, 29.5, 26.6, 24.0, 23.9, 22.0, 21.4, 20.2, 19.7, 19.0. HRMS (ESI) calcd. for $\mathrm{C}_{39} \mathrm{H}_{49} \mathrm{NNaO}_{11}[\mathrm{M}+\mathrm{Na}]^{+} 730.3198$, found 730.3210 .

(2S,9R,13R,14S,16R)-17-((R,E)-6-Acetoxy-2-hydroxy-6-methyl-3-oxohept-4-en-2-yl)-2-hydroxy-4,4,9,13,14pentamethyl-3,11-dioxo-2,3,4,7,8,9,10,11,12,13,14,15,16,17-tetradecahydro-1H-cyclopenta[a]phenanthren-16-yl 3-fluorobenzoate (3n) (80\% yield in two steps). (purity: 95\%). $\left.{ }^{1} \mathrm{H} \mathrm{NMR} \mathrm{(400} \mathrm{MHz,} \mathrm{CDCl}_{3}\right) \delta 7.69$ $(\mathrm{d}, J=7.3 \mathrm{~Hz}, 1 \mathrm{H}), 7.51(\mathrm{~d}, J=8.3 \mathrm{~Hz}, 1 \mathrm{H}), 7.42-7.33(\mathrm{~m}, 1 \mathrm{H}), 7.22(\mathrm{~d}, J=7.4 \mathrm{~Hz}, 1 \mathrm{H}), 6.89(\mathrm{~d}, J=15.5 \mathrm{~Hz}$, $1 \mathrm{H}), 6.49(\mathrm{~d}, J=15.6 \mathrm{~Hz}, 1 \mathrm{H}), 5.74(\mathrm{~s}, 1 \mathrm{H}), 5.57(\mathrm{t}, J=7.5 \mathrm{~Hz}, 1 \mathrm{H}), 4.42(\mathrm{~d}, J=7.2 \mathrm{~Hz}, 1 \mathrm{H}), 4.19(\mathrm{~s}, 1 \mathrm{H})$, $3.60(\mathrm{~s}, 1 \mathrm{H}), 3.30(\mathrm{~d}, J=14.4 \mathrm{~Hz}, 1 \mathrm{H}), 2.89(\mathrm{~d}, J=7.0 \mathrm{~Hz}, 1 \mathrm{H}), 2.85-2.70(\mathrm{~m}, 2 \mathrm{H}), 2.41(\mathrm{~d}, J=19.3 \mathrm{~Hz}, 1 \mathrm{H})$, $2.31(\mathrm{~s}, 1 \mathrm{H}), 2.12(\mathrm{t}, J=11.3 \mathrm{~Hz}, 1 \mathrm{H}), 2.03(\mathrm{~d}, J=15.4 \mathrm{~Hz}, 3 \mathrm{H}), 1.93(\mathrm{~d}, J=15.3 \mathrm{~Hz}, 1 \mathrm{H}), 1.46(\mathrm{~s}, 6 \mathrm{H}), 1.42$ $(\mathrm{s}, 3 \mathrm{H}), 1.37(\mathrm{~s}, 3 \mathrm{H}), 1.31(\mathrm{~s}, 3 \mathrm{H}), 1.26(\mathrm{~d}, J=10.4 \mathrm{~Hz}, 6 \mathrm{H}), 1.08(\mathrm{~d}, J=10.4 \mathrm{~Hz}, 6 \mathrm{H}) .{ }^{13} \mathrm{C} \mathrm{NMR}(100 \mathrm{MHz}$, $\left.\mathrm{CDCl}_{3}\right) \delta 212.9,211.6,201.3,169.7,164.7,162.5(\mathrm{~d}, J=247.4 \mathrm{~Hz}), 152.9,140.6,132.2(\mathrm{~d}, J=7.1 \mathrm{~Hz}), 130.2$ $(\mathrm{d}, J=7.8 \mathrm{~Hz}), 125.6(\mathrm{~d}, J=2.7 \mathrm{~Hz}), 120.4,120.2(\mathrm{~d}, J=21.3 \mathrm{~Hz}), 119.4,116.4(\mathrm{~d}, J=22.7 \mathrm{~Hz}), 79.4,78.1$, 74.8, 71.7, 54.6, 50.4, 48.7, 48.5, 48.1, 43.6, 42.3, 36.1, 33.9, 29.5, 26.7, 25.7, 24.1, 23.1, 22.1, 21.4, 20.2, 19.8, 
18.9. ${ }^{19} \mathrm{~F}$ NMR $\left(376 \mathrm{MHz}, \mathrm{CDCl}_{3}\right) \delta-112.09(\mathrm{dd}, J=13.9,8.1 \mathrm{~Hz})$. HRMS (ESI) calcd. for $\mathrm{C}_{39} \mathrm{H}_{49} \mathrm{FNaO}_{9}$ $[\mathrm{M}+\mathrm{Na}]^{+}$703.3253, found 703.3258.

(2S,9R,13R,14S,16R)-17-((R,E)-6-Acetoxy-2-hydroxy-6-methyl-3-oxohept-4-en-2-yl)-2-hydroxy-4,4,9,13,14pentamethyl-3,11-dioxo-2,3,4,7,8,9,10,11,12,13,14,15,16,17-tetradecahydro-1H-cyclopenta[a]phenanthren-16-yl cinnamate (3o) (81\% yield in two steps). (purity: 97\%). ${ }^{1} \mathrm{H} \mathrm{NMR}\left(400 \mathrm{MHz}, \mathrm{CDCl}_{3}\right) \delta 7.60(\mathrm{~d}, J=15.9 \mathrm{~Hz}$, $1 \mathrm{H}), 7.52(\mathrm{~s}, 2 \mathrm{H}), 7.35(\mathrm{~s}, 3 \mathrm{H}), 7.07(\mathrm{~d}, J=15.5 \mathrm{~Hz}, 1 \mathrm{H}), 6.45(\mathrm{~d}, J=15.5 \mathrm{~Hz}, 1 \mathrm{H}), 6.32(\mathrm{~d}, J=16.0 \mathrm{~Hz}, 1 \mathrm{H})$, $5.76(\mathrm{~s}, 1 \mathrm{H}), 5.37(\mathrm{t}, J=7.5 \mathrm{~Hz}, 1 \mathrm{H}), 4.41(\mathrm{~d}, J=7.7 \mathrm{~Hz}, 1 \mathrm{H}), 4.29(\mathrm{~s}, 1 \mathrm{H}), 3.61(\mathrm{~s}, 1 \mathrm{H}), 3.28(\mathrm{~d}, J=14.5 \mathrm{~Hz}$, $1 \mathrm{H}), 2.85-2.66(\mathrm{~m}, 3 \mathrm{H}), 2.48-2.26(\mathrm{~m}, 2 \mathrm{H}), 2.03(\mathrm{~s}, 2 \mathrm{H}), 1.97(\mathrm{~s}, 3 \mathrm{H}), 1.52(\mathrm{~d}, J=11.6 \mathrm{~Hz}, 6 \mathrm{H}), 1.43(\mathrm{~s}, 3 \mathrm{H})$, $1.34(\mathrm{~s}, 3 \mathrm{H}), 1.32(\mathrm{~s}, 3 \mathrm{H}), 1.27(\mathrm{~s}, 3 \mathrm{H}), 1.25(\mathrm{~s}, 3 \mathrm{H}), 1.09(\mathrm{~s}, 3 \mathrm{H}), 1.04(\mathrm{~s}, 3 \mathrm{H}) .{ }^{13} \mathrm{C} \mathrm{NMR}\left(101 \mathrm{MHz}, \mathrm{CDCl}_{3}\right)$ $\delta$ 213.0, 211.8, 200.9, 169.7, 166.5, 152.8, 145.4, 140.5, 134.5, 130.4, 128.9, 128.3, 120.5, 119.3, 117.8, 79.2, 77.9, 73.7, 71.7, 54.5, 50.3, 50.2, 48.7, 48.5, 48.1, 43.4, 42.3, 36.1, 33.9, 29.8, 29.4, 26.8, 26.5, 23.9, 21.9, 21.4, 20.2, 19.8, 18.9. HRMS (ESI) calcd. for $\mathrm{C}_{41} \mathrm{H}_{52} \mathrm{NaO}_{9}[\mathrm{M}+\mathrm{Na}]^{+} 711.3504$, found 711.3507.

(2S,9R,13R,14S,16R)-17-((R,E)-6-Acetoxy-2-hydroxy-6-methyl-3-oxohept-4-en-2-yl)-2-hydroxy-4,4,9,13,14pentamethyl-3,11-dioxo-2,3,4,7,8,9,10,11,12,13,14,15,16,17-tetradecahydro-1H-cyclopenta[a]phenanthren-16-yl (E)-3-(4-cyanophenyl)acrylate (3p) (85\% yield in two steps). (purity: 97\%). $\left.{ }^{1} \mathrm{H} \mathrm{NMR} \mathrm{(400} \mathrm{MHz}, \mathrm{CDCl}_{3}\right) \delta$ $7.65(\mathrm{dd}, J=17.0,8.1 \mathrm{~Hz}, 4 \mathrm{H}), 7.58(\mathrm{~d}, J=15.9 \mathrm{~Hz}, 1 \mathrm{H}), 7.11(\mathrm{~d}, J=15.5 \mathrm{~Hz}, 1 \mathrm{H}), 6.50(\mathrm{~d}, J=15.8 \mathrm{~Hz}$, $1 \mathrm{H}), 6.41(\mathrm{~d}, J=15.6 \mathrm{~Hz}, 1 \mathrm{H}), 5.75(\mathrm{~d}, J=3.9 \mathrm{~Hz}, 1 \mathrm{H}), 5.36(\mathrm{t}, J=8.1 \mathrm{~Hz}, 1 \mathrm{H}), 4.41(\mathrm{dd}, J=12.4,5.3 \mathrm{~Hz}$, $1 \mathrm{H}), 4.29(\mathrm{~s}, 1 \mathrm{H}), 3.61(\mathrm{~s}, 1 \mathrm{H}), 3.27(\mathrm{~d}, J=14.6 \mathrm{~Hz}, 1 \mathrm{H}), 2.75(\mathrm{dd}, J=19.3,10.9 \mathrm{~Hz}, 3 \mathrm{H}), 2.48-2.27(\mathrm{~m}$, $2 \mathrm{H}), 2.02(\mathrm{~d}, J=8.0 \mathrm{~Hz}, 2 \mathrm{H}), 1.98(\mathrm{~s}, 3 \mathrm{H}), 1.56(\mathrm{~s}, 3 \mathrm{H}), 1.48(\mathrm{~s}, 3 \mathrm{H}), 1.43(\mathrm{~s}, 3 \mathrm{H}), 1.32(\mathrm{~d}, J=5.5 \mathrm{~Hz}, 6 \mathrm{H})$, $1.26(\mathrm{~s}, 3 \mathrm{H}), 1.24(\mathrm{~s}, 3 \mathrm{H}), 1.09(\mathrm{~s}, 3 \mathrm{H}), 1.05(\mathrm{~s}, 3 \mathrm{H}) .{ }^{13} \mathrm{C} \mathrm{NMR}\left(100 \mathrm{MHz}, \mathrm{CDCl}_{3}\right) \delta 212.9,211.7,200.8$, 169.7, 165.9, 153.1, 142.9, 140.6, 138.9, 132.6, 128.8, 121.6, 120.4, 119.1, 113.4, 79.2, 77.8, 74.2, 71.7, 54.2, 50.3, 50.1, 48.7, 48.5, 48.1, 43.4, 42.2, 36.1, 33.9, 29.8, 29.4, 27.3, 26.5, 23.9, 23.8, 21.9, 21.4, 20.2, 19.8, 18.9. HRMS (ESI) calcd. for $\mathrm{C}_{42} \mathrm{H}_{51} \mathrm{NNaO}_{9}[\mathrm{M}+\mathrm{Na}]^{+} 736.3456$, found 736.3458 .

(2S,9R,13R,14S,16R)-17-((R,E)-6-Acetoxy-2-hydroxy-6-methyl-3-oxohept-4-en-2-yl)-2-hydroxy-4,4,9,13,14pentamethyl-3,11-dioxo-2,3,4,7,8,9,10,11,12,13,14,15,16,17-tetradecahydro-1H-cyclopenta[a]phenanthren-16-yl (E)-3-(3,5-dimethoxyphenyl)acrylate (3q) (82\% yield in two steps). (purity: 95\%). ${ }^{1} \mathrm{H}$ NMR $(400 \mathrm{MHz}$, $\left.\mathrm{CDCl}_{3}\right) \delta 7.51(\mathrm{~d}, J=15.9 \mathrm{~Hz}, 1 \mathrm{H}), 7.07(\mathrm{~d}, J=15.6 \mathrm{~Hz}, 1 \mathrm{H}), 6.66(\mathrm{~d}, J=2.2 \mathrm{~Hz}, 2 \mathrm{H}), 6.45(\mathrm{t}, J=9.2 \mathrm{~Hz}$, $2 \mathrm{H}), 6.28(\mathrm{~d}, J=15.9 \mathrm{~Hz}, 1 \mathrm{H}), 5.75(\mathrm{~d}, J=5.5 \mathrm{~Hz}, 1 \mathrm{H}), 5.36(\mathrm{t}, J=7.8 \mathrm{~Hz}, 1 \mathrm{H}), 4.41(\mathrm{dd}, J=12.9,6.0 \mathrm{~Hz}$, $1 \mathrm{H}), 3.78(\mathrm{~s}, 7 \mathrm{H}), 3.27(\mathrm{~d}, J=14.7 \mathrm{~Hz}, 1 \mathrm{H}), 2.82-2.68(\mathrm{~m}, 3 \mathrm{H}), 2.48-2.26(\mathrm{~m}, 2 \mathrm{H}), 2.11-1.94(\mathrm{~m}, 6 \mathrm{H})$, $1.53(\mathrm{~d}, J=3.2 \mathrm{~Hz}, 6 \mathrm{H}), 1.43(\mathrm{~s}, 3 \mathrm{H}), 1.34(\mathrm{~s}, 3 \mathrm{H}), 1.31(\mathrm{~s}, 3 \mathrm{H}), 1.26(\mathrm{~s}, 3 \mathrm{H}), 1.24(\mathrm{~s}, 3 \mathrm{H}), 1.08(\mathrm{~s}, 3 \mathrm{H}), 1.04$ (s, 3H). ${ }^{13} \mathrm{C}$ NMR $\left(100 \mathrm{MHz}, \mathrm{CDCl}_{3}\right) \delta 213.0,211.9,200.9,169.8,166.4,161.1,152.9,145.5,140.5,136.3$, 120.5, 119.3, 118.2, 106.4, 102.5, 79.2, 77.9, 73.8, 71.7, 55.5, 54.4, 50.3, 50.2, 48.7, 48.5, 48.1, 43.4, 42.2, $36.1,33.8,29.8,29.4,26.8,26.7,23.9,21.9,21.4,20.2,19.8,18.8$. HRMS (ESI) calcd. for $\mathrm{C}_{43} \mathrm{H}_{56} \mathrm{NaO}_{11}$ $[\mathrm{M}+\mathrm{Na}]^{+} 771.3715$, found 771.3718 .

\subsubsection{Procedure for the Synthesis of Compounds 4}

(2S,9R,13R,14S,16R)-17-((R,E)-6-Acetoxy-2-hydroxy-6-methyl-3-oxohept-4-en-2-yl)-4,4,9,13,14pentamethyl-3,11-dioxo-2,3,4,7,8,9,10,11,12,13,14,15,16,17-tetradecahydro-1H-cyclopenta[a]phenanthrene2,16-diyl (2E,2'E)-bis(3-phenylacrylate) (4). To a solution of compound $\mathbf{1}(100.0 \mathrm{mg}, 0.18 \mathrm{mmol})$, EDCI (171.6 mg, $0.9 \mathrm{mmol})$, DMAP (1.2 mg, $0.01 \mathrm{mmol}$ ), and cinnamic acid (133.4 mg, $0.9 \mathrm{mmol})$ in $\mathrm{CH}_{2} \mathrm{Cl}_{2}$ $(2 \mathrm{~mL})$ was added $\mathrm{Et}_{3} \mathrm{~N}(125 \mu \mathrm{L}, 0.9 \mathrm{mmol})$ at $0{ }^{\circ} \mathrm{C}$. The mixture was stirred for $8 \mathrm{~h}$ at room temperature. The reaction was quenched with saturated aqueous $\mathrm{NaHCO}_{3}$ and extracted with $\mathrm{CH}_{2} \mathrm{Cl}_{2}(3 \times 15 \mathrm{~mL})$. The combined organic layers were washed with saturated brine, dried over $\mathrm{Na}_{2} \mathrm{SO}_{4}$, and concentrated to give an oily crude product, which was purified on a silica gel column to yield compound $4(112 \mathrm{mg}$, yield: $76 \%$ ) as a white solid. (purity: $95 \%) .{ }^{1} \mathrm{H}$ NMR $\left(400 \mathrm{MHz}, \mathrm{CDCl}_{3}\right) \delta 7.74(\mathrm{~d}, J=16.0 \mathrm{~Hz}, 1 \mathrm{H}), 7.61$ $(\mathrm{d}, J=15.9 \mathrm{~Hz}, 1 \mathrm{H}), 7.52(\mathrm{~s}, 4 \mathrm{H}), 7.37(\mathrm{~d}, J=8.6 \mathrm{~Hz}, 6 \mathrm{H}), 7.08(\mathrm{~d}, J=15.5 \mathrm{~Hz}, 1 \mathrm{H}), 6.49(\mathrm{t}, J=15.0 \mathrm{~Hz}$, $2 \mathrm{H}), 6.34(\mathrm{~d}, J=16.0 \mathrm{~Hz}, 1 \mathrm{H}), 5.79(\mathrm{~s}, 1 \mathrm{H}), 5.64(\mathrm{dd}, J=13.2,4.5 \mathrm{~Hz}, 1 \mathrm{H}), 5.38(\mathrm{t}, J=7.5 \mathrm{~Hz}, 1 \mathrm{H}), 3.31$ 
$(\mathrm{d}, J=14.5 \mathrm{~Hz}, 1 \mathrm{H}), 2.90(\mathrm{~d}, J=11.9 \mathrm{~Hz}, 1 \mathrm{H}), 2.79(\mathrm{t}, J=10.5 \mathrm{~Hz}, 2 \mathrm{H}), 2.43(\mathrm{~d}, J=19.1 \mathrm{~Hz}, 1 \mathrm{H}), 2.23(\mathrm{~d}$, $J=11.6 \mathrm{~Hz}, 1 \mathrm{H}), 2.07(\mathrm{t}, J=10.6 \mathrm{~Hz}, 2 \mathrm{H}), 1.99(\mathrm{~s}, 3 \mathrm{H}), 1.54(\mathrm{~s}, 3 \mathrm{H}), 1.52(\mathrm{~s}, 3 \mathrm{H}), 1.45(\mathrm{~s}, 3 \mathrm{H}), 1.37(\mathrm{~d}, J=$ $4.4 \mathrm{~Hz}, 5 \mathrm{H}), 1.30$ (s, 3H), 1.25 (s, 5H), 1.13 (s, 3H), 1.06 (s, 3H). ${ }^{13} \mathrm{C} \mathrm{NMR}\left(100 \mathrm{MHz}, \mathrm{CDCl}_{3}\right) \delta 212.1$, 205.8, 200.9, 169.7, 166.5, 166.0, 152.9, 145.9, 145.4, 139.9, 134.5, 134.4, 130.6, 130.4, 129.0, 128.9, 128.3, 120.6, 119.2, 117.8, 117.4, 79.3, 77.9, 73.7, 73.5, 54.4, 51.4, 50.2, 48.8, 48.6, 48.1, 43.4, 42.3, 34.5, 32.2, 32.0, $29.5,28.9,26.7,26.6,23.9,22.8,21.9,21.5,20.1,19.9,18.8$. HRMS (ESI) calcd. for $\mathrm{C}_{50} \mathrm{H}_{58} \mathrm{NaO}_{10}[\mathrm{M}+$ $\mathrm{Na}]^{+} 841.3922$, found 841.3928 .

\subsubsection{Procedure for the Synthesis of Compounds $6 \mathbf{a}-60$ and $7 \mathbf{a}-7 \mathrm{c}$}

Compounds $\mathbf{6 a}-\mathbf{6 o}$ and $7 \mathbf{a}-\mathbf{7 c}$ were synthesized according to the procedure previously reported $[42-44,46]$.

\subsubsection{Procedure for the Synthesis of Compound 8}

4-(((2S,9R,13R,14S,16R)-17-((R,E)-6-Acetoxy-2-hydroxy-6-methyl-3-oxohept-4-en-2-yl)-2-((tertbutyldimethylsilyl)oxy)-4,4,9,13,14-pentamethyl-3,11-dioxo-2,3,4,7,8,9,10,11,12,13,14,15,16,17-

tetradecahydro-1H-cyclopenta[a]phenanthren-16-yl)oxy)-4-oxobutanoic acid (8). To a solution of compound $2(50.0 \mathrm{mg}, 0.074 \mathrm{mmol})$ in dry DCM $(2 \mathrm{~mL})$ was added succinic anhydride $(37.4 \mathrm{mg}, 0.37 \mathrm{mmol})$ and DMAP $(10.0 \mathrm{mg}, 0.08 \mathrm{mmol})$. The mixture was stirred for $4 \mathrm{~h}$ at room temperature. The reaction was quenched with $1 \mathrm{~N} \mathrm{HCl}$, the $\mathrm{pH}$ was adjusted to $2-3$, and extraction was performed with $\mathrm{CH}_{2} \mathrm{Cl}_{2}$ $(3 \times 15 \mathrm{~mL})$. The combined organic layers were washed with saturated brine, dried over $\mathrm{Na}_{2} \mathrm{SO}_{4}$, and concentrated to give an oily crude product, which was purified on a silica gel column to yield compound 8 (49.0 mg, yield: $86 \%)$ as a white solid. ${ }^{1} \mathrm{H}$ NMR $(400 \mathrm{MHz}$, DMSO-d6) $\delta 12.21(\mathrm{~s}, 1 \mathrm{H}), 6.88$ $(\mathrm{d}, J=15.7 \mathrm{~Hz}, 1 \mathrm{H}), 6.73(\mathrm{~d}, J=15.8 \mathrm{~Hz}, 1 \mathrm{H}), 5.65(\mathrm{~s}, 1 \mathrm{H}), 5.32(\mathrm{~s}, 2 \mathrm{H}), 4.72(\mathrm{~d}, J=11.9 \mathrm{~Hz}, 1 \mathrm{H}), 3.47(\mathrm{~d}, J$ $=14.2 \mathrm{~Hz}, 1 \mathrm{H}), 3.02(\mathrm{~d}, J=11.6 \mathrm{~Hz}, 1 \mathrm{H}), 2.60(\mathrm{~d}, J=6.2 \mathrm{~Hz}, 1 \mathrm{H}), 2.44(\mathrm{~s}, 1 \mathrm{H}), 2.39-2.17(\mathrm{~m}, 5 \mathrm{H}), 1.95$ $(\mathrm{s}, 3 \mathrm{H}), 1.84(\mathrm{dd}, J=26.6,10.6 \mathrm{~Hz}, 4 \mathrm{H}), 1.46(\mathrm{~s}, 6 \mathrm{H}), 1.26(\mathrm{~s}, 3 \mathrm{H}), 1.20(\mathrm{~s}, 7 \mathrm{H}), 1.12(\mathrm{~d}, J=15.3 \mathrm{~Hz}, 4 \mathrm{H})$, 0.88 (s, 3H), 0.83 (s, 12H), 0.02 (s, 3H), -0.05 (s, 3H). ${ }^{13} \mathrm{C}$ NMR (100 MHz, DMSO-d6) $\delta 212.3,210.7$, 203.5, 173.4, 171.3, 169.4, 150.3, 140.5, 120.4, 118.8, 79.3, 78.3, 73.5, 73.0, 55.1, 50.6, 49.8, 48.7, 47.7, 47.3, 42.7, 41.6, 35.9, 32.5, 29.0, 28.9, 28.7, 26.3, 26.2, 25.8, 24.7, 23.4, 21.7, 21.5, 19.8, 19.3, 18.1, 18.0, -4.5, -5.2. HRMS (ESI) calcd. for $\mathrm{C}_{42} \mathrm{H}_{64} \mathrm{NaO}_{11} \mathrm{Si}[\mathrm{M}+\mathrm{Na}]^{+}$795.4110, found 795.4115.

\subsubsection{General Procedure for the Synthesis of Compounds 9a-9c}

Compounds 7a-7c $(1.5 \mathrm{mmol})$ were dissolved in dry DCM. TFA (20\% in DCM) was dropwise added into the reaction mixture at $0{ }^{\circ} \mathrm{C}$, then the mixture was allowed to warm at $20{ }^{\circ} \mathrm{C}$ for $2 \mathrm{~h}$. The solvent was removed by reduced pressure. The residue was purified by flash chromatography to obtain the crude amine as a colored oily matter.

Compound 8 (154 mg, $0.2 \mathrm{mmol})$ and HATU $(95.1 \mathrm{mg}, 0.25 \mathrm{mmol})$ were dissolved in dry DMF $(4 \mathrm{~mL})$, then DIPEA $(44 \mu \mathrm{L}, 0.25 \mathrm{mmol})$ was added. The mixture was stirred at $30^{\circ} \mathrm{C}$ for $1 \mathrm{~h}$, then the corresponding amine $(0.6 \mathrm{mmol}, 3$ eq.) was added. The reaction was stirred for $2 \mathrm{~h}$ at this temperature. Then, the reaction was quenched with saturated aqueous $\mathrm{NH}_{4} \mathrm{Cl}$ and extracted with $\mathrm{EA}(3 \times 15 \mathrm{~mL})$. The combined organic layers were washed with saturated brine, dried over $\mathrm{Na}_{2} \mathrm{SO}_{4}$, and concentrated to give an oily crude product, which was purified on a silica gel column (PE/EA = 3:1-1:1) to give compound 7 as a yellow solid, which was simple purified to yield a white solid. The solid was used for the next step directly. The solid was dissolved in THF $(2 \mathrm{~mL})$. To the mixture was added HOAc $(38 \mu \mathrm{L}$, $0.65 \mathrm{mmol}$ ) and TBAF (169 mg, $0.65 \mathrm{mmol})$. The mixture was stirred at room temperature for $24 \mathrm{~h}$, and then diluted with ethyl acetate $(20 \mathrm{~mL})$. The organic phase was washed with $\mathrm{H}_{2} \mathrm{O}(3 \times 20 \mathrm{~mL})$, dried over $\mathrm{Na}_{2} \mathrm{SO}_{4}$, and concentrated. The residue was purified by column chromatography on silica gel to obtain a white solid $\mathbf{9 a}-\mathbf{9 c}$. 
3-((l1-oxidanyl)(oxo)(phenyl)-15-sulfanyl)-4-(2-(4-(((9R,13R,14S,16R)-17-((R,E)-6-acetoxy-2-hydroxy-6methyl-3-oxohept-4-en-2-yl)-2-Hydroxy-4,4,9,13,14-pentamethyl-3,11-dioxo-2,3,4,7,8,9,10,11,12,13,14,15,16, 17-tetradecahydro-1H-cyclopenta[a]phenanthren-16-yl)oxy)-4-oxobutanamido)ethoxy)-1,2,5-oxadiazole 2-oxide (9a) (67\% yield in three steps). (purity: 99\%). ${ }^{1} \mathrm{H}$ NMR $\left(400 \mathrm{MHz}, \mathrm{CDCl}_{3}\right) \delta 8.13-8.02(\mathrm{~m}, 2 \mathrm{H}), 7.78$ $(\mathrm{t}, J=7.5 \mathrm{~Hz}, 1 \mathrm{H}), 7.65(\mathrm{t}, J=7.8 \mathrm{~Hz}, 2 \mathrm{H}), 7.16(\mathrm{~d}, J=15.6 \mathrm{~Hz}, 1 \mathrm{H}), 6.57(\mathrm{t}, J=5.7 \mathrm{~Hz}, 1 \mathrm{H}), 6.40(\mathrm{~d}, J=$ $15.6 \mathrm{~Hz}, 1 \mathrm{H}), 5.76(\mathrm{~d}, J=5.4 \mathrm{~Hz}, 1 \mathrm{H}), 5.18(\mathrm{t}, J=7.9 \mathrm{~Hz}, 1 \mathrm{H}), 4.52(\mathrm{t}, J=5.8 \mathrm{~Hz}, 2 \mathrm{H}), 4.46-4.34(\mathrm{~m}, 1 \mathrm{H})$, $4.25(\mathrm{~s}, 1 \mathrm{H}), 3.64-3.42(\mathrm{~m}, 3 \mathrm{H}), 3.24(\mathrm{~d}, J=14.6 \mathrm{~Hz}, 1 \mathrm{H}), 2.71(\mathrm{dd}, J=17.2,7.2 \mathrm{~Hz}, 3 \mathrm{H}), 2.56-2.27(\mathrm{~m}$, $6 \mathrm{H}), 2.16-2.05(\mathrm{~m}, 2 \mathrm{H}), 2.02(\mathrm{~s}, 3 \mathrm{H}), 2.00-1.87(\mathrm{~m}, 3 \mathrm{H}), 1.56(\mathrm{~d}, J=7.8 \mathrm{~Hz}, 6 \mathrm{H}), 1.40(\mathrm{~s}, 3 \mathrm{H}), 1.33(\mathrm{~s}, 3 \mathrm{H})$, $1.26(\mathrm{~s}, 3 \mathrm{H}), 1.24(\mathrm{~s}, 3 \mathrm{H}), 1.07(\mathrm{~s}, 3 \mathrm{H}), 1.00(\mathrm{~s}, 3 \mathrm{H}) .{ }^{13} \mathrm{C} \mathrm{NMR}\left(100 \mathrm{MHz}, \mathrm{CDCl}_{3}\right) \delta 213.1,211.8,201.2$, 172.5, 172.0, 170.1, 158.9, 153.1, 140.4, 137.8, 136.0, 129.9, 128.7, 120.5, 119.3, 110.6, 79.4, 77.8, 73.9, 71.7, 70.7, 54.2, 50.4, 50.1, 48.7, 48.5, 48.1, 43.1, 42.2, 37.1, 36.1, 33.8, 30.8, 29.4, 28.6, 26.9, 26.5, 23.8, 23.7, 22.1, 21.4, 20.2, 19.8, 18.9. HRMS (ESI) calcd. for $\mathrm{C}_{46} \mathrm{H}_{59} \mathrm{~N}_{3} \mathrm{NaO}_{15} \mathrm{~S}[\mathrm{M}+\mathrm{Na}]^{+} 948.3559$, found 948.3562 .

4-(3-(4-(((9R,13R,14S,16R)-17-((R,E)-6-Acetoxy-2-hydroxy-6-methyl-3-oxohept-4-en-2-yl)-2-hydroxy-4,4,9,13, 14-pentamethyl-3,11-dioxo-2,3,4,7,8,9,10,11,12,13,14,15,16,17-tetradecahydro-1H-cyclopenta[a]phenanthren16-yl)oxy)-4-oxobutanamido)propoxy)-3-(phenylsulfonyl)-1,2,5-oxadiazole 2-oxide (9b) (73\% yield in three steps) (purity: 99\%). ${ }^{1} \mathrm{H}$ NMR $\left(400 \mathrm{MHz}, \mathrm{CDCl}_{3}\right) \delta 8.11-8.01(\mathrm{~m}, 2 \mathrm{H}), 7.77(\mathrm{t}, J=7.5 \mathrm{~Hz}, 1 \mathrm{H}), 7.64(\mathrm{t}, J=$ $7.9 \mathrm{~Hz}, 2 \mathrm{H}), 7.18(\mathrm{~d}, J=15.6 \mathrm{~Hz}, 1 \mathrm{H}), 6.65(\mathrm{t}, J=5.9 \mathrm{~Hz}, 1 \mathrm{H}), 6.40(\mathrm{~d}, J=15.6 \mathrm{~Hz}, 1 \mathrm{H}), 5.75(\mathrm{~d}, J=5.5 \mathrm{~Hz}$, $1 \mathrm{H}), 5.17(\mathrm{t}, J=7.9 \mathrm{~Hz}, 1 \mathrm{H}), 4.50(\mathrm{t}, J=5.1 \mathrm{~Hz}, 2 \mathrm{H}), 4.45-4.35(\mathrm{~m}, 1 \mathrm{H}), 4.25(\mathrm{~s}, 1 \mathrm{H}), 3.79-3.66(\mathrm{~m}, 2 \mathrm{H})$, $3.61(\mathrm{~d}, J=3.8 \mathrm{~Hz}, 1 \mathrm{H}), 3.24(\mathrm{~d}, J=14.6 \mathrm{~Hz}, 1 \mathrm{H}), 2.70(\mathrm{t}, J=11.3 \mathrm{~Hz}, 3 \mathrm{H}), 2.57-2.24(\mathrm{~m}, 6 \mathrm{H}), 2.03(\mathrm{~s}, 3 \mathrm{H})$, $1.99-1.80(\mathrm{~m}, 4 \mathrm{H}), 1.58(\mathrm{~s}, 3 \mathrm{H}), 1.54(\mathrm{~s}, 3 \mathrm{H}), 1.40(\mathrm{~s}, 3 \mathrm{H}), 1.32(\mathrm{~s}, 3 \mathrm{H}), 1.28(\mathrm{~s}, 3 \mathrm{H}), 1.24(\mathrm{~d}, J=4.4 \mathrm{~Hz}, 6 \mathrm{H})$, $1.07(\mathrm{~s}, 3 \mathrm{H}), 1.00(\mathrm{~s}, 3 \mathrm{H}) .{ }^{13} \mathrm{C}$ NMR $\left(100 \mathrm{MHz}, \mathrm{CDCl}_{3}\right) \delta 213.1,211.8,201.3,172.3,172.2,170.3,159.1$, 153.3, 140.4, 137.9, 135.9, 129.9, 128.7, 120.5, 119.3, 110.7, 79.4, 77.8, 74.0, 71.7, 70.5, 54.0, 50.4, 50.1, 48.6, 48.5, 48.1, 43.1, 42.2, 38.4, 36.1, 33.8, 31.0, 29.8, 29.4, 29.4, 27.2, 26.4, 23.8, 23.6, 22.1, 21.4, 20.1, 19.8, 18.9. HRMS (ESI) calcd. for $\mathrm{C}_{47} \mathrm{H}_{61} \mathrm{~N}_{3} \mathrm{NaO}_{15} \mathrm{~S}[\mathrm{M}+\mathrm{Na}]^{+}$962.3716, found 962.3720 .

4-(2-(4-(4-(((9R,13R,14S,16R)-17-((R,E)-6-Acetoxy-2-hydroxy-6-methyl-3-oxohept-4-en-2-yl)-2-hydroxy-4,4,9, 13,14-pentamethyl-3,11-dioxo-2,3,4,7,8,9,10,11,12,13,14,15,16,17-tetradecahydro-1H-cyclopenta[a]phenanthren16-yl)oxy)-4-oxobutanoyl)piperazin-1-yl)ethoxy)-3-(phenylsulfonyl)-1,2,5-oxadiazole 2-oxide (9c) (44\% yield in three steps). (purity: 95\%). ${ }^{1} \mathrm{H}$ NMR $\left(400 \mathrm{MHz}, \mathrm{CDCl}_{3}\right) \delta 8.04(\mathrm{~d}, J=7.6 \mathrm{~Hz}, 2 \mathrm{H}), 7.76(\mathrm{t}, J=7.5 \mathrm{~Hz}, 1 \mathrm{H})$, $7.62(\mathrm{t}, J=7.9 \mathrm{~Hz}, 2 \mathrm{H}), 7.16(\mathrm{~d}, J=15.6 \mathrm{~Hz}, 1 \mathrm{H}), 6.41(\mathrm{~d}, J=15.6 \mathrm{~Hz}, 1 \mathrm{H}), 5.75(\mathrm{~d}, J=5.4 \mathrm{~Hz}, 1 \mathrm{H}), 5.26-5.12$ $(\mathrm{m}, 1 \mathrm{H}), 4.55(\mathrm{t}, J=5.3 \mathrm{~Hz}, 2 \mathrm{H}), 4.40(\mathrm{dd}, J=12.8,5.9 \mathrm{~Hz}, 1 \mathrm{H}), 4.29(\mathrm{~s}, 1 \mathrm{H}), 3.68-3.52(\mathrm{~m}, 3 \mathrm{H}), 3.47(\mathrm{t}, J=8.3$ $\mathrm{Hz}, 2 \mathrm{H}), 3.25(\mathrm{~d}, J=14.6 \mathrm{~Hz}, 1 \mathrm{H}), 2.88(\mathrm{t}, J=5.3 \mathrm{~Hz}, 2 \mathrm{H}), 2.79(\mathrm{~s}, 1 \mathrm{H}), 2.71(\mathrm{dd}, J=11.0,7.4 \mathrm{~Hz}, 3 \mathrm{H}), 2.63$ $(\mathrm{dt}, J=9.5,6.1 \mathrm{~Hz}, 2 \mathrm{H}), 2.54(\mathrm{dd}, J=9.3,4.9 \mathrm{~Hz}, 2 \mathrm{H}), 2.50-2.25(\mathrm{~m}, 5 \mathrm{H}), 2.01(\mathrm{~s}, 3 \mathrm{H}), 1.98(\mathrm{~d}, J=9.7 \mathrm{~Hz}, 2 \mathrm{H})$, $1.57(\mathrm{~d}, J=1.3 \mathrm{~Hz}, 6 \mathrm{H}), 1.41(\mathrm{~s}, 3 \mathrm{H}), 1.31(\mathrm{~d}, J=7.5 \mathrm{~Hz}, 6 \mathrm{H}), 1.26(\mathrm{~s}, 3 \mathrm{H}), 1.24(\mathrm{~s}, 3 \mathrm{H}), 1.07(\mathrm{~s}, 3 \mathrm{H}), 1.00(\mathrm{~s}$, 3H). ${ }^{13} \mathrm{C}$ NMR $\left(100 \mathrm{MHz}, \mathrm{CDCl}_{3}\right) \delta$ 213.1, 211.9, 201.2, 172.7, 169.8, 169.7, 159.0, 153.0, 140.4, 138.1, 135.8, 129.8, 128.6, 120.5, 119.4, 110.6, 79.2, 77.8, 73.9, 71.7, 69.4, 56.2, 54.3, 53.5, 53.2, 50.4, 50.1, 48.7, 48.5, 48.1, $45.3,43.1,42.2,41.8,38.7,36.1,33.8,29.4,28.9,27.8,26.7,26.6,23.7,22.0,21.4,20.2,19.8,18.9$. HRMS (ESI) calcd. for $\mathrm{C}_{50} \mathrm{H}_{67} \mathrm{~N}_{4} \mathrm{O}_{15} \mathrm{~S}[\mathrm{M}+\mathrm{H}]^{+}$995.4318, found 995.4322 .

\subsubsection{General Procedure for the Synthesis of Compounds 10a-10o}

To a solution of $\mathbf{6 a}-\mathbf{6 o}(0.5 \mathrm{mmol})$ in dry DCM $(20 \mathrm{~mL})$ was added succinic anhydride $(75 \mathrm{mg}$, $0.75 \mathrm{mmol})$ and DMAP $(61 \mathrm{mg}, 0.5 \mathrm{mmol})$. The mixture was stirred for $4 \mathrm{~h}$ at room temperature. The reaction was quenched with $1 \mathrm{~N} \mathrm{HCl}$, the $\mathrm{pH}$ was adjusted to 2-3 and extraction was performed with $\mathrm{CH}_{2} \mathrm{Cl}_{2}(3 \times 15 \mathrm{~mL})$. The combined organic layers were washed with saturated brine, dried over $\mathrm{Na}_{2} \mathrm{SO}_{4}$, and concentrated to give an oily crude product, which was purified on a silica gel column to obtain the corresponding acid in a yield of $86-96 \%$.

To a solution of compound 2 (135 mg, $0.2 \mathrm{mmol})$, EDCI $(96 \mathrm{mg}, 0.5 \mathrm{mmol})$, DMAP $(1.2 \mathrm{mg}$, $0.01 \mathrm{mmol})$, and the corresponding acid $\left(0.4 \mathrm{mmol}, 2 \mathrm{eq}\right.$.) in $\mathrm{CH}_{2} \mathrm{Cl}_{2}(2 \mathrm{~mL})$ was added $\mathrm{Et}_{3} \mathrm{~N}(69.5 \mu \mathrm{L}$, $0.5 \mathrm{mmol}$ ) at $0{ }^{\circ} \mathrm{C}$. The mixture was stirred for $8 \mathrm{~h}$ at room temperature. The reaction was quenched 
with saturated aqueous $\mathrm{NaHCO}_{3}$ and extracted with $\mathrm{CH}_{2} \mathrm{Cl}_{2}(3 \times 15 \mathrm{~mL})$. The combined organic layers were washed with saturated brine, dried over $\mathrm{Na}_{2} \mathrm{SO}_{4}$, and concentrated to give an oily crude product, which was simple purified to yield a white solid. The solid was used for the next step directly. The solid was dissolved in THF $(2 \mathrm{~mL})$. HOAc $(38 \mu \mathrm{L}, 0.65 \mathrm{mmol})$ and TBAF $(169 \mathrm{mg}, 0.65 \mathrm{mmol})$ were added to the mixture. The mixture was stirred at room temperature for $24 \mathrm{~h}$, and then diluted with ethyl acetate $(20 \mathrm{~mL})$. The organic phase was washed with $\mathrm{H}_{2} \mathrm{O}(3 \times 20 \mathrm{~mL})$, dried over $\mathrm{Na}_{2} \mathrm{SO}_{4}$, and concentrated. The residue was purified by column chromatography on silica gel to obtain a white solid 10a-10o.

4-(2-((4-(((9R,13R,14S,16R)-17-((R,E)-6-Acetoxy-2-hydroxy-6-methyl-3-oxohept-4-en-2-yl)-2-hydroxy-4,4,9, 13,14-pentamethyl-3,11-dioxo-2,3,4,7,8,9,10,11,12,13,14,15,16,17-tetradecahydro-1H-cyclopenta[a]phenanthren16-yl)oxy)-4-oxobutanoyl)oxy)ethoxy)-3-(phenylsulfonyl)-1,2,5-oxadiazole 2-oxide (10a) (81\% yield in two steps). (purity: 95\%). ${ }^{1} \mathrm{H}$ NMR $\left(400 \mathrm{MHz}, \mathrm{CDCl}_{3}\right) \delta 8.05(\mathrm{~d}, J=7.7 \mathrm{~Hz}, 2 \mathrm{H}), 7.77(\mathrm{t}, J=7.5 \mathrm{~Hz}, 1 \mathrm{H}), 7.63(\mathrm{t}, J=7.8$ $\mathrm{Hz}, 2 \mathrm{H}), 7.18(\mathrm{~d}, J=15.6 \mathrm{~Hz}, 1 \mathrm{H}), 6.40(\mathrm{~d}, J=15.6 \mathrm{~Hz}, 1 \mathrm{H}), 5.75(\mathrm{~d}, J=5.2 \mathrm{~Hz}, 1 \mathrm{H}), 5.19(\mathrm{~s}, 1 \mathrm{H}), 4.67-4.56$ $(\mathrm{m}, 2 \mathrm{H}), 4.55-4.46(\mathrm{~m}, 2 \mathrm{H}), 4.45-4.35(\mathrm{~m}, 1 \mathrm{H}), 4.28(\mathrm{~s}, 1 \mathrm{H}), 3.60(\mathrm{~d}, J=3.7 \mathrm{~Hz}, 1 \mathrm{H}), 3.25(\mathrm{~d}, J=14.6 \mathrm{~Hz}, 1 \mathrm{H})$, 2.78-2.66 (m, 3H), 2.65-2.25 (m, 6H), 2.05-1.85 (m, 6H), $1.58(\mathrm{~s}, 3 \mathrm{H}), 1.55(\mathrm{~s}, 3 \mathrm{H}), 1.40(\mathrm{~s}, 3 \mathrm{H}), 1.32(\mathrm{~s}, 3 \mathrm{H})$, $1.29(\mathrm{~s}, 3 \mathrm{H}), 1.25(\mathrm{~s}, 3 \mathrm{H}), 1.24(\mathrm{~s}, 2 \mathrm{H}), 1.07(\mathrm{~s}, 3 \mathrm{H}), 1.00(\mathrm{~s}, 3 \mathrm{H}) .{ }^{13} \mathrm{C} \mathrm{NMR}\left(100 \mathrm{MHz}, \mathrm{CDCl}_{3}\right) \delta$ 213.1, 211.8, 201.1, 172.2, 171.7, 169.8, 158.8, 153.2, 140.5, 138.0, 135.9, 129.9, 128.7, 120.5, 119.2, 110.5, 79.2, 77.8, 74.1, 71.7, 68.9, 61.5, 54.2, 50.3, 50.1, 48.6, 48.5, 48.1, 43.1, 42.2, 36.1, 33.8, 29.4, 28.8, 28.6, 26.9, 26.3, 23.8, 23.7, 22.0, 21.4, 20.1, 19.8, 18.9. HRMS (ESI) calcd. for $\mathrm{C}_{46} \mathrm{H}_{58} \mathrm{~N}_{2} \mathrm{NaO}_{16} \mathrm{~S}[\mathrm{M}+\mathrm{Na}]^{+}$949.3399, found, 949.3402 .

4-(3-((4-(((9R,13R,14S,16R)-17-((R,E)-6-Acetoxy-2-hydroxy-6-methyl-3-oxohept-4-en-2-yl)-2-hydroxy-4,4,9, 13,14-pentamethyl-3,11-dioxo-2,3,4,7,8,9,10,11,12,13,14,15,16,17-tetradecahydro-1H-cyclopenta[a]phenanthren16-yl)oxy)-4-oxobutanoyl)oxy)propoxy)-3-(phenylsulfonyl)-1,2,5-oxadiazole 2-oxide (10b) (74\% yield in two steps). (purity: 99\%). ${ }^{1} \mathrm{H}$ NMR $\left(400 \mathrm{MHz}, \mathrm{CDCl}_{3}\right) \delta 8.05(\mathrm{~d}, J=8.0 \mathrm{~Hz}, 2 \mathrm{H}), 7.76(\mathrm{t}, J=7.4 \mathrm{~Hz}, 1 \mathrm{H}), 7.63(\mathrm{t}$, $J=7.7 \mathrm{~Hz}, 2 \mathrm{H}), 7.17(\mathrm{~d}, J=15.6 \mathrm{~Hz}, 1 \mathrm{H}), 6.39(\mathrm{~d}, J=15.6 \mathrm{~Hz}, 1 \mathrm{H}), 5.76(\mathrm{~d}, J=5.0 \mathrm{~Hz}, 1 \mathrm{H}), 5.18(\mathrm{t}, J=8.0 \mathrm{~Hz}$, $1 \mathrm{H}), 4.51(\mathrm{t}, J=6.0 \mathrm{~Hz}, 2 \mathrm{H}), 4.45-4.36(\mathrm{~m}, 1 \mathrm{H}), 4.36-4.21(\mathrm{~m}, 3 \mathrm{H}), 3.60(\mathrm{~d}, J=3.7 \mathrm{~Hz}, 1 \mathrm{H}), 3.24(\mathrm{~d}, J=14.6$ $\mathrm{Hz}, 1 \mathrm{H}), 2.71(\mathrm{dd}, J=15.6,11.0 \mathrm{~Hz}, 3 \mathrm{H}), 2.65-2.34(\mathrm{~m}, 5 \mathrm{H}), 2.30(\mathrm{dd}, J=9.0,5.7 \mathrm{~Hz}, 1 \mathrm{H}), 2.21(\mathrm{p}, J=5.9 \mathrm{~Hz}$, $2 \mathrm{H}), 2.01(\mathrm{~s}, 3 \mathrm{H}), 2.00-1.86(\mathrm{~m}, 3 \mathrm{H}), 1.58(\mathrm{~s}, 3 \mathrm{H}), 1.55(\mathrm{~s}, 3 \mathrm{H}), 1.45-1.33(\mathrm{~m}, 4 \mathrm{H}), 1.32(\mathrm{~s}, 3 \mathrm{H}), 1.28(\mathrm{~s}, 3 \mathrm{H})$, $1.26(\mathrm{~s}, 3 \mathrm{H}), 1.24(\mathrm{~s}, 1 \mathrm{H}), 1.07(\mathrm{~s}, 3 \mathrm{H}), 1.00(\mathrm{~s}, 3 \mathrm{H}) .{ }^{13} \mathrm{C} \mathrm{NMR}\left(100 \mathrm{MHz}, \mathrm{CDCl}_{3}\right) \delta 213.1,211.7,201.0,172.3$, 171.8, 169.8, 159.0, 153.1, 140.5, 138.1, 135.8, 129.8, 128.7, 120.5, 119.3, 110.6, 79.2, 77.8, 74.1, 71.7, 68.1, 60.6, $54.2,50.3,50.0,48.6,48.5,48.1,43.1,42.2,36.1,33.8,29.4,28.9,28.7,28.1,26.9,26.4,23.8,23.7,22.0,21.4,20.2$, 19.8, 18.9. HRMS (ESI) calcd. for $\mathrm{C}_{47} \mathrm{H}_{60} \mathrm{~N}_{2} \mathrm{NaO}_{16} \mathrm{~S}[\mathrm{M}+\mathrm{Na}]^{+} 963.3556$, found 963.3560 .

4-(4-((4-(((9R,13R,14S,16R)-17-((R,E)-6-Acetoxy-2-hydroxy-6-methyl-3-oxohept-4-en-2-yl)-2-hydroxy-4,4,9, 13,14-pentamethyl-3,11-dioxo-2,3,4,7,8,9,10,11,12,13,14,15,16,17-tetradecahydro-1H-cyclopenta[a]phenanthren16-yl)oxy)-4-oxobutanoyl)oxy)butoxy)-3-(phenylsulfonyl)-1,2,5-oxadiazole 2-oxide (10c) (78\% yield in two steps). (purity: 99\%). ${ }^{1} \mathrm{H} \mathrm{NMR}\left(400 \mathrm{MHz}, \mathrm{CDCl}_{3}\right) \delta 8.09-8.00(\mathrm{~m}, 2 \mathrm{H}), 7.76(\mathrm{t}, J=7.5 \mathrm{~Hz}, 1 \mathrm{H}), 7.63(\mathrm{t}, J=7.9 \mathrm{~Hz}$, $2 \mathrm{H}), 7.17(\mathrm{~d}, J=15.6 \mathrm{~Hz}, 1 \mathrm{H}), 6.40(\mathrm{~d}, J=15.6 \mathrm{~Hz}, 1 \mathrm{H}), 5.76(\mathrm{~d}, J=5.5 \mathrm{~Hz}, 1 \mathrm{H}), 5.19(\mathrm{t}, J=7.9 \mathrm{~Hz}, 1 \mathrm{H}), 4.45$ $(\mathrm{t}, J=6.3 \mathrm{~Hz}, 2 \mathrm{H}), 4.42-4.36(\mathrm{~m}, 1 \mathrm{H}), 4.27(\mathrm{~s}, 1 \mathrm{H}), 4.23-4.11(\mathrm{~m}, 2 \mathrm{H}), 3.60(\mathrm{~d}, J=3.9 \mathrm{~Hz}, 1 \mathrm{H}), 3.25(\mathrm{~d}, J=14.6$ $\mathrm{Hz}, 1 \mathrm{H}), 2.78-2.65(\mathrm{~m}, 3 \mathrm{H}), 2.65-2.24(\mathrm{~m}, 6 \mathrm{H}), 2.01(\mathrm{~s}, 3 \mathrm{H}), 2.00-1.93(\mathrm{~m}, 4 \mathrm{H}), 1.82(\mathrm{dt}, J=13.0,6.4 \mathrm{~Hz}, 2 \mathrm{H})$, $1.67(\mathrm{~s}, 1 \mathrm{H}), 1.58(\mathrm{~s}, 3 \mathrm{H}), 1.55(\mathrm{~s}, 3 \mathrm{H}), 1.41(\mathrm{~s}, 3 \mathrm{H}), 1.37(\mathrm{~d}, J=14.5 \mathrm{~Hz}, 1 \mathrm{H}), 1.32(\mathrm{~s}, 3 \mathrm{H}), 1.29(\mathrm{~s}, 3 \mathrm{H}), 1.26(\mathrm{~s}$, $3 \mathrm{H}), 1.22(\mathrm{~d}, J=13.6 \mathrm{~Hz}, 1 \mathrm{H}), 1.07(\mathrm{~s}, 3 \mathrm{H}), 1.00(\mathrm{~s}, 3 \mathrm{H}) .{ }^{13} \mathrm{C} \mathrm{NMR}\left(100 \mathrm{MHz}, \mathrm{CDCl}_{3}\right) \delta$ 213.0, 211.7, 201.0, 172.4, 171.8, 169.8, 159.0, 153.1, 140.5, 138.1, 135.8, 129.8, 128.7, 120.5, 119.3, 110.6, 79.2, 77.8, 74.1, 71.7, 71.0, 64.0, 54.2, 50.3, 50.1, 48.6, 48.5, 48.1, 43.1, 42.2, 36.1, 33.8, 29.4, 28.9, 28.7, 26.9, 26.4, 25.3, 25.1, 23.9, 23.7, 22.0, 21.4, 20.2, 19.8, 18.9. HRMS (ESI) calcd. for $\mathrm{C}_{48} \mathrm{H}_{62} \mathrm{~N}_{2} \mathrm{NaO}_{16} \mathrm{~S}[\mathrm{M}+\mathrm{Na}]^{+}$977.3712, found 977.3718.

4-((5-((4-)((9R,13R,14S,16R)-17-((R,E)-6-Acetoxy-2-hydroxy-6-methyl-3-oxohept-4-en-2-yl)-2-hydroxy-4,4,9, 13,14-pentamethyl-3,11-dioxo-2,3,4,7,8,9,10,11,12,13,14,15,16,17-tetradecahydro-1H-cyclopenta[a]phenanthren16-yl)oxy)-4-oxobutanoyl)oxy)pentyl)oxy)-3-(phenylsulfonyl)-1,2,5-oxadiazole 2-oxide (10d) (82\% yield in two steps). (purity: 98\%). ${ }^{1} \mathrm{H}$ NMR (400 MHz, $\left.\mathrm{CDCl}_{3}\right) \delta 8.04(\mathrm{~d}, J=7.9 \mathrm{~Hz}, 2 \mathrm{H}), 7.76(\mathrm{t}, J=7.4 \mathrm{~Hz}, 1 \mathrm{H}), 7.62(\mathrm{t}$, 
$J=7.7 \mathrm{~Hz}, 2 \mathrm{H}), 7.17(\mathrm{~d}, J=15.6 \mathrm{~Hz}, 1 \mathrm{H}), 6.40(\mathrm{~d}, J=15.6 \mathrm{~Hz}, 1 \mathrm{H}), 5.76(\mathrm{~d}, J=4.7 \mathrm{~Hz}, 1 \mathrm{H}), 5.19(\mathrm{~s}, 1 \mathrm{H}), 4.42$ $(\mathrm{t}, J=6.3 \mathrm{~Hz}, 3 \mathrm{H}), 4.26(\mathrm{~s}, 1 \mathrm{H}), 4.12(\mathrm{dd}, J=9.8,6.2 \mathrm{~Hz}, 2 \mathrm{H}), 3.59(\mathrm{~d}, J=3.6 \mathrm{~Hz}, 1 \mathrm{H}), 3.24(\mathrm{~d}, J=14.6 \mathrm{~Hz}$, $1 \mathrm{H}), 2.80-2.66(\mathrm{~m}, 3 \mathrm{H}), 2.64-2.25(\mathrm{~m}, 6 \mathrm{H}), 2.09-1.85(\mathrm{~m}, 8 \mathrm{H}), 1.76-1.61(\mathrm{~m}, 3 \mathrm{H}), 1.58(\mathrm{~s}, 3 \mathrm{H}), 1.55(\mathrm{~d}, J=7.0$ $\mathrm{Hz}, 4 \mathrm{H}), 1.40(\mathrm{~d}, J=6.5 \mathrm{~Hz}, 3 \mathrm{H}), 1.32(\mathrm{~s}, 3 \mathrm{H}), 1.29(\mathrm{~s}, 3 \mathrm{H}), 1.25(\mathrm{~d}, J=7.4 \mathrm{~Hz}, 5 \mathrm{H}), 1.07(\mathrm{~s}, \mathrm{H}), 1.00(\mathrm{~s}, 3 \mathrm{H})$. ${ }^{13} \mathrm{C}$ NMR $\left(100 \mathrm{MHz}, \mathrm{CDCl}_{3}\right) \delta 213.0,211.7,201.0,172.5,171.8,169.7,159.1,153.0,140.5,138.2,135.8,129.8$, 128.7, 120.5, 119.3, 110.6, 79.2, 77.8, 74.1, 71.7, 71.4, 64.4, 54.3, 50.3, 50.1, 48.7, 48.5, 48.1, 43.2, 42.2, 36.1, 33.8, 29.5, 29.0, 28.8, 28.2, 28.2, 26.8, 26.4, 23.9, 23.7, 22.3, 22.0, 21.4, 20.2, 19.8, 18.9. HRMS (MALDI) calcd. for $\mathrm{C}_{49} \mathrm{H}_{64} \mathrm{~N}_{2} \mathrm{NaO}_{16} \mathrm{~S}[\mathrm{M}+\mathrm{Na}]^{+}$991.3869, found 991.3875 .

4-((6-((4-(((9R,13R,14S,16R)-17-((R,E)-6-Acetoxy-2-hydroxy-6-methyl-3-oxohept-4-en-2-yl)-2-hydroxy-4,4,9, 13,14-pentamethyl-3,11-dioxo-2,3,4,7,8,9,10,11,12,13,14,15,16,17-tetradecahydro-1H-cyclopenta[a]phenanthren16-yl)oxy)-4-oxobutanoyl)oxy)hexyl)oxy)-3-(phenylsulfonyl)-1,2,5-oxadiazole 2-oxide (10e) (72\% yield in two steps). (purity: 96\%). ${ }^{1} \mathrm{H}$ NMR $\left(400 \mathrm{MHz}, \mathrm{CDCl}_{3}\right) \delta 8.05(\mathrm{~d}, J=7.7 \mathrm{~Hz}, 2 \mathrm{H}), 7.76(\mathrm{t}, J=7.4 \mathrm{~Hz}, 1 \mathrm{H}), 7.62$ $(\mathrm{t}, J=7.8 \mathrm{~Hz}, 2 \mathrm{H}), 7.17(\mathrm{~d}, J=15.6 \mathrm{~Hz}, 1 \mathrm{H}), 6.40(\mathrm{~d}, J=15.6 \mathrm{~Hz}, 1 \mathrm{H}), 5.75(\mathrm{~s}, 1 \mathrm{H}), 5.19(\mathrm{t}, J=7.9 \mathrm{~Hz}, 1 \mathrm{H})$, $4.42(\mathrm{t}, J=6.4 \mathrm{~Hz}, 3 \mathrm{H}), 4.28(\mathrm{~s}, 1 \mathrm{H}), 4.08(\mathrm{dt}, J=10.7,6.3 \mathrm{~Hz}, 2 \mathrm{H}), 3.60(\mathrm{~d}, J=3.7 \mathrm{~Hz}, 1 \mathrm{H}), 3.25(\mathrm{~d}, J=14.5$ $\mathrm{Hz}, 1 \mathrm{H}), 2.71(\mathrm{dd}, J=15.1,11.0 \mathrm{~Hz}, 3 \mathrm{H}), 2.64-2.26(\mathrm{~m}, 6 \mathrm{H}), 2.06-1.93(\mathrm{~m}, 6 \mathrm{H}), 1.91-1.85(\mathrm{~m}, 2 \mathrm{H}), 1.71-1.62$ $(\mathrm{m}, 2 \mathrm{H}), 1.58(\mathrm{~s}, 3 \mathrm{H}), 1.56(\mathrm{~s}, 3 \mathrm{H}), 1.50-1.39(\mathrm{~m}, 7 \mathrm{H}), 1.33(\mathrm{~s}, 3 \mathrm{H}), 1.29(\mathrm{~s}, 3 \mathrm{H}), 1.26(\mathrm{~s}, 3 \mathrm{H}), 1.24(\mathrm{~s}, 2 \mathrm{H}), 1.07$ (s, 3H), 1.00 (s, 3H). ${ }^{13} \mathrm{C}$ NMR $\left(100 \mathrm{MHz}, \mathrm{CDCl}_{3}\right) \delta$ 213.0, 211.7, 201.0, 172.5, 171.8, 169.7, 159.2, 153.1, 140.5, 138.2, 135.8, 129.8, 128.7, 120.5, 119.3, 110.6, 79.2, 77.8, 74.0, 71.7, 71.5, 64.6, 54.3, 50.4, 50.1, 48.7, 48.5, 48.1, 43.2, 42.2, 36.1, 33.8, 29.5, 29.0, 28.8, 28.6, 28.4, 26.8, 26.4, 25.6, 25.4, 23.9, 23.7, 22.0, 21.4, 20.2, 19.8, 18.9. HRMS (ESI) calcd. for $\mathrm{C}_{50} \mathrm{H}_{66} \mathrm{~N}_{2} \mathrm{NaO}_{16} \mathrm{~S}[\mathrm{M}+\mathrm{Na}]^{+} 1005.4025$, found 1005.4028.

4-((7-((4-(((9R,13R,14S,16R)-17-((R,E)-6-Acetoxy-2-hydroxy-6-methyl-3-oxohept-4-en-2-yl)-2-hydroxy-4,4,9, 13,14-pentamethyl-3,11-dioxo-2,3,4,7,8,9,10,11,12,13,14,15,16,17-tetradecahydro-1H-cyclopenta[a]phenanthren16-yl)oxy)-4-oxobutanoyl)oxy)heptyl)oxy)-3-(phenylsulfonyl)-1,2,5-oxadiazole 2-oxide (10f) (76\% yield in two steps). (purity: 95\%). ${ }^{1} \mathrm{H}$ NMR $\left(400 \mathrm{MHz}, \mathrm{CDCl}_{3}\right) \delta 8.04(\mathrm{~d}, J=7.9 \mathrm{~Hz}, 2 \mathrm{H}), 7.76(\mathrm{t}, J=7.5 \mathrm{~Hz}, 1 \mathrm{H}), 7.62$ $(\mathrm{t}, J=7.8 \mathrm{~Hz}, 2 \mathrm{H}), 7.16(\mathrm{~d}, J=15.6 \mathrm{~Hz}, 1 \mathrm{H}), 6.40(\mathrm{~d}, J=15.6 \mathrm{~Hz}, 1 \mathrm{H}), 5.75(\mathrm{~d}, J=5.3 \mathrm{~Hz}, 1 \mathrm{H}), 5.19(\mathrm{t}, J=7.9$ $\mathrm{Hz}, 1 \mathrm{H}), 4.40(\mathrm{t}, J=6.5 \mathrm{~Hz}, 3 \mathrm{H}), 4.27(\mathrm{~s}, 1 \mathrm{H}), 4.07(\mathrm{td}, J=6.6,2.0 \mathrm{~Hz}, 2 \mathrm{H}), 3.59(\mathrm{~d}, J=3.8 \mathrm{~Hz}, 1 \mathrm{H}), 3.24(\mathrm{~d}, J$ $=14.6 \mathrm{~Hz}, 1 \mathrm{H}), 2.71(\mathrm{dd}, J=16.0,7.8 \mathrm{~Hz}, 3 \mathrm{H}), 2.63-2.24(\mathrm{~m}, 6 \mathrm{H}), 2.04-1.82(\mathrm{~m}, 8 \mathrm{H}), 1.67-1.60(\mathrm{~m}, 2 \mathrm{H})$, $1.58(\mathrm{~s}, 3 \mathrm{H}), 1.55(\mathrm{~s}, 3 \mathrm{H}), 1.44(\mathrm{dd}, J=8.3,5.8 \mathrm{~Hz}, 2 \mathrm{H}), 1.40(\mathrm{~s}, 3 \mathrm{H}), 1.35(\mathrm{~s}, 4 \mathrm{H}), 1.32(\mathrm{~s}, 3 \mathrm{H}), 1.28(\mathrm{~s}, 3 \mathrm{H})$, $1.26(\mathrm{~s}, 3 \mathrm{H}), 1.24(\mathrm{~s}, 2 \mathrm{H}), 1.07(\mathrm{~s}, 3 \mathrm{H}), 1.00(\mathrm{~s}, 3 \mathrm{H}) .{ }^{13} \mathrm{C} \mathrm{NMR}\left(100 \mathrm{MHz}, \mathrm{CDCl}_{3}\right)$ \& 213.0, 211.7, 201.0, 172.5, 171.8, 169.7, 159.2, 153.1, 140.5, 138.2, 135.8, 129.8, 128.6, 120.5, 119.3, 110.6, 79.2, 77.8, 74.0, 71.7, 71.6, 64.8, 54.2, 50.3, 50.1, 48.6, 48.5, 48.1, 43.1, 42.2, 36.1, 33.8, 29.4, 29.0, 28.8, 28.8, 28.6, 28.4, 26.8, 26.4, 25.9, 25.6, 23.8, 23.7, 22.0, 21.4, 20.2, 19.8, 18.9. HRMS (MALDI) calcd. for $\mathrm{C}_{51} \mathrm{H}_{68} \mathrm{~N}_{2} \mathrm{NaO}_{16} \mathrm{~S}[\mathrm{M}+\mathrm{Na}]^{+} 1019.4182$, found 1019.4185 .

4-((8-((4-(((9R,13R,14S,16R)-17-((R,E)-6-Acetoxy-2-hydroxy-6-methyl-3-oxohept-4-en-2-yl)-2-hydroxy-4,4,9, 13,14-pentamethyl-3,11-dioxo-2,3,4,7,8,9,10,11,12,13,14,15,16,17-tetradecahydro-1H-cyclopenta[a]phenanthren16-yl)oxy)-4-oxobutanoyl)oxy)octyl)oxy)-3-(phenylsulfonyl)-1,2,5-oxadiazole 2-oxide (10g) (66\% yield in two steps). (purity: 99\%). ${ }^{1} \mathrm{H}$ NMR (400 MHz, $\left.\mathrm{CDCl}_{3}\right) \delta 8.04(\mathrm{dd}, J=8.5,1.2 \mathrm{~Hz}, 2 \mathrm{H}), 7.79-7.72(\mathrm{~m}, 1 \mathrm{H}), 7.61$ $(\mathrm{dd}, J=10.8,5.0 \mathrm{~Hz}, 2 \mathrm{H}), 7.16(\mathrm{~d}, J=15.6 \mathrm{~Hz}, 1 \mathrm{H}), 6.40(\mathrm{~d}, J=15.6 \mathrm{~Hz}, 1 \mathrm{H}), 5.75(\mathrm{~d}, J=5.6 \mathrm{~Hz}, 1 \mathrm{H}), 5.19(\mathrm{t}$, $J=7.8 \mathrm{~Hz}, 1 \mathrm{H}), 4.40(\mathrm{t}, J=6.5 \mathrm{~Hz}, 3 \mathrm{H}), 4.26(\mathrm{~s}, 1 \mathrm{H}), 4.06(\mathrm{td}, J=6.7,1.7 \mathrm{~Hz}, 2 \mathrm{H}), 3.58(\mathrm{~d}, J=3.7 \mathrm{~Hz}, 1 \mathrm{H})$, $3.24(\mathrm{~d}, J=14.7 \mathrm{~Hz}, 1 \mathrm{H}), 2.71(\mathrm{dd}, J=15.6,7.5 \mathrm{~Hz}, 3 \mathrm{H}), 2.60-2.34(\mathrm{~m}, 5 \mathrm{H}), 2.30(\mathrm{ddd}, J=9.1,6.7,3.4 \mathrm{~Hz}$, $1 \mathrm{H}), 2.04-1.92(\mathrm{~m}, 6 \mathrm{H}), 1.90-1.81(\mathrm{~m}, 2 \mathrm{H}), 1.66-1.60(\mathrm{~m}, 2 \mathrm{H}), 1.57(\mathrm{~d}, J=8.1 \mathrm{~Hz}, 6 \mathrm{H}), 1.45(\mathrm{dd}, J=9.4,5.9$ $\mathrm{Hz}, 2 \mathrm{H}), 1.40(\mathrm{~s}, 3 \mathrm{H}), 1.39(\mathrm{~s}, 1 \mathrm{H}), 1.35(\mathrm{~d}, J=1.4 \mathrm{~Hz}, 6 \mathrm{H}), 1.32(\mathrm{~s}, 3 \mathrm{H}), 1.28(\mathrm{~s}, 3 \mathrm{H}), 1.26(\mathrm{~s}, 3 \mathrm{H}), 1.24(\mathrm{~s}, 1 \mathrm{H})$, 1.07 (s, 3H), $1.00(\mathrm{~s}, 3 \mathrm{H}) .{ }^{13} \mathrm{C} \mathrm{NMR}\left(100 \mathrm{MHz}, \mathrm{CDCl}_{3}\right) \delta 212.9,211.6,200.9,172.3,171.7,169.6,159.1,152.9$, 140.4, 138.1, 135.6, 129.6, 128.5, 120.3, 119.2, 110.5, 79.1, 77.7, 73.9, 71.6, 71.6, 64.8, 54.2, 50.2, 50.0, 48.5, 48.4, 48.0, 43.1, 42.1, 36.0, 33.7, 29.3, 29.1, 29.0, 28.9, 28.7, 28.6, 28.4, 26.7, 26.3, 25.8, 25.5, 23.8, 23.6, 21.8, 21.3, 20.0, 19.7, 18.8. HRMS (MALDI) calcd. for $\mathrm{C}_{52} \mathrm{H}_{70} \mathrm{~N}_{2} \mathrm{NaO}_{16} \mathrm{~S}[\mathrm{M}+\mathrm{Na}]^{+} 1033.4338$, found 1033.4342 . 
4-((9-((4-(((9R,13R,14S,16R)-17-((R,E)-6-Acetoxy-2-hydroxy-6-methyl-3-oxohept-4-en-2-yl)-2-hydroxy-4,4,9, 13,14-pentamethyl-3,11-dioxo-2,3,4,7,8,9,10,11,12,13,14,15,16,17-tetradecahydro-1H-cyclopenta[a]phenanthren16-yl)oxy)-4-oxobutanoyl)oxy)nonyl)oxy)-3-(phenylsulfonyl)-1,2,5-oxadiazole 2-oxide (10h) (69\% yield in two steps). (purity: 97\%). ${ }^{1} \mathrm{H}$ NMR $\left(400 \mathrm{MHz}, \mathrm{CDCl}_{3}\right) \delta 8.05(\mathrm{dd}, J=8.4,1.1 \mathrm{~Hz}, 2 \mathrm{H}), 7.76(\mathrm{dd}, J=10.7,4.3 \mathrm{~Hz}$, $1 \mathrm{H}), 7.62(\mathrm{t}, J=7.9 \mathrm{~Hz}, 2 \mathrm{H}), 7.16(\mathrm{~d}, J=15.6 \mathrm{~Hz}, 1 \mathrm{H}), 6.41(\mathrm{~d}, J=15.6 \mathrm{~Hz}, 1 \mathrm{H}), 5.76(\mathrm{~d}, J=5.6 \mathrm{~Hz}, 1 \mathrm{H}), 5.20$ $(\mathrm{t}, J=7.8 \mathrm{~Hz}, 1 \mathrm{H}), 4.41(\mathrm{t}, J=6.6 \mathrm{~Hz}, 3 \mathrm{H}), 4.27(\mathrm{~s}, 1 \mathrm{H}), 4.08(\mathrm{dt}, J=6.9,6.5 \mathrm{~Hz}, 2 \mathrm{H}), 3.70(\mathrm{~s}, 1 \mathrm{H}), 3.59(\mathrm{~d}, J=$ $3.9 \mathrm{~Hz}, 1 \mathrm{H}), 3.25(\mathrm{~d}, J=14.7 \mathrm{~Hz}, 1 \mathrm{H}), 2.72(\mathrm{dd}, J=15.2,11.0 \mathrm{~Hz}, 3 \mathrm{H}), 2.61-2.35(\mathrm{~m}, 5 \mathrm{H}), 2.35-2.27(\mathrm{~m}, 1 \mathrm{H})$, 2.04-1.93 (m, 6H), 1.92-1.81 (m, 2H), $1.61(\mathrm{~d}, J=7.5 \mathrm{~Hz}, 3 \mathrm{H}), 1.59(\mathrm{~s}, 3 \mathrm{H}), 1.56(\mathrm{~s}, 3 \mathrm{H}), 1.44(\mathrm{~d}, J=7.4 \mathrm{~Hz}$, 2H), $1.41(\mathrm{~s}, 3 \mathrm{H}), 1.33(\mathrm{~s}, 8 \mathrm{H}), 1.29(\mathrm{~s}, 3 \mathrm{H}), 1.27(\mathrm{~s}, 3 \mathrm{H}), 1.25(\mathrm{~s}, 3 \mathrm{H}), 1.08(\mathrm{~s}, 3 \mathrm{H}), 1.01(\mathrm{~s}, 3 \mathrm{H}) .{ }^{13} \mathrm{C}$ NMR $(100$ $\left.\mathrm{MHz}, \mathrm{CDCl}_{3}\right) \delta 213.1,211.7,201.0,172.5,171.8,169.8,159.1,153.1,140.5,138.2,135.7,129.8,128.7,120.5$, $119.3,110.6,100.1,79.2,77.8,74.0,71.7,65.0,54.3,50.4,50.1,48.7,48.5,48.1,43.2,42.2,36.1,33.8,29.8,29.5$, 29.3, 29.2, 29.0, 28.8, 28.7, 28.5, 26.8, 26.4, 26.0, 25.7, 23.9, 23.7, 22.0, 21.4, 20.2, 19.8, 18.9. HRMS (MALDI) calcd. for $\mathrm{C}_{53} \mathrm{H}_{72} \mathrm{~N}_{2} \mathrm{NaO}_{16} \mathrm{~S}[\mathrm{M}+\mathrm{Na}]^{+}$1047.4495, found 1047.4498.

4-((10-((4-)((9R,13R,14S,16R)-17-((R,E)-6-Acetoxy-2-hydroxy-6-methyl-3-oxohept-4-en-2-yl)-2-hydroxy-4,4,9, 13,14-pentamethyl-3,11-dioxo-2,3,4,7,8,9,10,11,12,13,14,15,16,17-tetradecahydro-1H-cyclopenta[a]phenanthren16-yl)oxy)-4-oxobutanoyl)oxy)decyl)oxy)-3-(phenylsulfonyl)-1,2,5-oxadiazole 2-oxide (10i) (71\% yield in two steps). (purity: 95\%). ${ }^{1} \mathrm{H}$ NMR $\left(400 \mathrm{MHz}, \mathrm{CDCl}_{3}\right) \delta 8.08-7.98(\mathrm{~m}, 2 \mathrm{H}), 7.74(\mathrm{t}, J=7.5 \mathrm{~Hz}, 1 \mathrm{H}), 7.60(\mathrm{t}, J=$ $7.9 \mathrm{~Hz}, 2 \mathrm{H}), 7.14(\mathrm{~d}, J=15.6 \mathrm{~Hz}, 1 \mathrm{H}), 6.40(\mathrm{~d}, J=15.6 \mathrm{~Hz}, 1 \mathrm{H}), 5.74(\mathrm{~d}, J=5.5 \mathrm{~Hz}, 1 \mathrm{H}), 5.18(\mathrm{t}, J=7.9 \mathrm{~Hz}$, $1 \mathrm{H}), 4.44-4.35(\mathrm{~m}, 3 \mathrm{H}), 4.27(\mathrm{~d}, J=7.8 \mathrm{~Hz}, 1 \mathrm{H}), 4.10-3.99(\mathrm{~m}, 2 \mathrm{H}), 3.58(\mathrm{~d}, J=3.9 \mathrm{~Hz}, 1 \mathrm{H}), 3.24(\mathrm{~d}, J=14.6$ $\mathrm{Hz}, 1 \mathrm{H}), 2.76-2.66(\mathrm{~m}, 3 \mathrm{H}), 2.60-2.23(\mathrm{~m}, 6 \mathrm{H}), 2.04-1.90(\mathrm{~m}, 6 \mathrm{H}), 1.90-1.79(\mathrm{~m}, 2 \mathrm{H}), 1.65-1.58(\mathrm{~m}, 2 \mathrm{H}), 1.56$ $(\mathrm{s}, 3 \mathrm{H}), 1.55(\mathrm{~s}, 3 \mathrm{H}), 1.38-1.44(\mathrm{~m}, 6 \mathrm{H}), 1.31(\mathrm{~s}, 13 \mathrm{H}), 1.27(\mathrm{~s}, 3 \mathrm{H}), 1.25(\mathrm{~s}, 3 \mathrm{H}), 1.23(\mathrm{~s}, 1 \mathrm{H}), 1.05(\mathrm{~s}, 3 \mathrm{H}), 0.99$ (s, 3H). ${ }^{13} \mathrm{C}$ NMR $\left(100 \mathrm{MHz}, \mathrm{CDCl}_{3}\right) \delta 213.0,211.7,201.0,172.4,171.7,169.7,159.1,153.0,140.5,138.2$, 135.7, 129.7, 128.6, 120.4, 119.3, 110.6, 79.2, 77.8, 74.0, 71.7, 71.7, 64.9, 54.2, 50.3, 50.0, 48.6, 48.5, 48.1, 43.1, 42.2, 36.0, 33.8, 29.5, 29.4, 29.3, 29.1, 29.0, 28.8, 28.7, 28.5, 26.7, 26.4, 25.9, 25.6, 23.8, 23.7, 21.9, 21.3, 20.1, 19.8, 18.8. HRMS (MALDI) calcd. for $\mathrm{C}_{54} \mathrm{H}_{74} \mathrm{~N}_{2} \mathrm{NaO}_{16} \mathrm{~S}[\mathrm{M}+\mathrm{Na}]^{+} 1061.4651$, found 1061.4655.

4-((11-((4-(((9R,13R,14S,16R)-17-((R,E)-6-Acetoxy-2-hydroxy-6-methyl-3-oxohept-4-en-2-yl)-2-hydroxy-4,4,9, 13,14-pentamethyl-3,11-dioxo-2,3,4,7,8,9,10,11,12,13,14,15,16,17-tetradecahydro-1H-cyclopenta[a]phenanthren16-yl)oxy)-4-oxobutanoyl)oxy)undecyl)oxy)-3-(phenylsulfonyl)-1,2,5-oxadiazole 2-oxide (10j) (75\% yield in two steps). (purity: 95\%). ${ }^{1} \mathrm{H}$ NMR $\left(400 \mathrm{MHz}, \mathrm{CDCl}_{3}\right) \delta 8.05(\mathrm{~d}, J=8.1 \mathrm{~Hz}, 2 \mathrm{H}), 7.75(\mathrm{t}, J=7.3 \mathrm{~Hz}, 1 \mathrm{H}), 7.61(\mathrm{t}$, $J=7.5 \mathrm{~Hz}, 2 \mathrm{H}), 7.16(\mathrm{~d}, J=15.5 \mathrm{~Hz}, 1 \mathrm{H}), 6.40(\mathrm{~d}, J=15.6 \mathrm{~Hz}, 1 \mathrm{H}), 5.76(\mathrm{~d}, J=4.0 \mathrm{~Hz}, 1 \mathrm{H}), 5.20(\mathrm{t}, J=8.0 \mathrm{~Hz}$, $1 \mathrm{H}), 4.41(\mathrm{t}, J=6.5 \mathrm{~Hz}, 3 \mathrm{H}), 4.27(\mathrm{~s}, 1 \mathrm{H}), 4.05(\mathrm{t}, J=6.7 \mathrm{~Hz}, 2 \mathrm{H}), 3.59(\mathrm{~s}, 1 \mathrm{H}), 3.24(\mathrm{~d}, J=14.6 \mathrm{~Hz}, 1 \mathrm{H}), 2.71$ $(\mathrm{dd}, J=14.1,11.1 \mathrm{~Hz}, 3 \mathrm{H}), 2.65-2.26(\mathrm{~m}, 6 \mathrm{H}), 2.05-1.92(\mathrm{~m}, 6 \mathrm{H}), 1.92-1.79(\mathrm{~m}, 3 \mathrm{H}), 1.61(\mathrm{~d}, J=6.1 \mathrm{~Hz}, 1 \mathrm{H})$, $1.58(\mathrm{~s}, 3 \mathrm{H}), 1.56(\mathrm{~s}, 3 \mathrm{H}), 1.48-1.38(\mathrm{~m}, 6 \mathrm{H}), 1.28(\mathrm{dd}, J=21.2,12.1 \mathrm{~Hz}, 22 \mathrm{H}), 1.07(\mathrm{~s}, 3 \mathrm{H}), 1.00(\mathrm{~s}, 3 \mathrm{H}) .{ }^{13} \mathrm{C}$ NMR $\left(100 \mathrm{MHz}_{2} \mathrm{CDCl}_{3}\right) \delta$ 213.0, 211.7, 201.0, 172.5, 171.8, 169.7, 159.2, 153.0, 140.6, 138.3, 135.7, 129.8, 128.7, 120.5, 119.3, 110.6, 79.2, 77.8, 74.0, 71.8, 71.7, 65.0, 54.3, 50.4, 50.1, 48.7, 48.5, 48.1, 43.2, 42.2, 36.1, 33.8, 29.8, 29.6, 29.6, 29.5, 29.4, 29.2, 29.0, 28.9, 28.7, 28.5, 26.8, 26.4, 26.0, 25.7, 23.9, 23.7, 22.0, 21.4, 20.2, 19.8, 18.9. HRMS (MALDI) calcd. for $\mathrm{C}_{55} \mathrm{H}_{76} \mathrm{~N}_{2} \mathrm{NaO}_{16} \mathrm{~S}[\mathrm{M}+\mathrm{Na}]^{+} 1075.4808$, found 1075.4812.

4-((12-((4-(((9R,13R,14S,16R)-17-((R,E)-6-Acetoxy-2-hydroxy-6-methyl-3-oxohept-4-en-2-yl)-2-hydroxy-4,4,9, 13,14-pentamethyl-3,11-dioxo-2,3,4,7,8,9,10,11,12,13,14,15,16,17-tetradecahydro-1H-cyclopenta[a]phenanthren16-yl)oxy)-4-oxobutanoyl)oxy)dodecyl)oxy)-3-(phenylsulfonyl)-1,2,5-oxadiazole 2-oxide (10k) (73\% yield in two steps). (purity: 96\%). ${ }^{1} \mathrm{H}$ NMR $\left(400 \mathrm{MHz}, \mathrm{CDCl}_{3}\right) \delta 8.04(\mathrm{~d}, J=7.5 \mathrm{~Hz}, 2 \mathrm{H}), 7.75(\mathrm{t}, J=7.5 \mathrm{~Hz}, 1 \mathrm{H}), 7.61(\mathrm{t}$, $J=7.8 \mathrm{~Hz}, 2 \mathrm{H}), 7.15(\mathrm{~d}, J=15.6 \mathrm{~Hz}, 1 \mathrm{H}), 6.41(\mathrm{~d}, J=15.6 \mathrm{~Hz}, 1 \mathrm{H}), 5.76(\mathrm{~d}, J=5.3 \mathrm{~Hz}, 1 \mathrm{H}), 5.20(\mathrm{t}, J=7.9 \mathrm{~Hz}$, $1 \mathrm{H}), 4.40(\mathrm{t}, J=6.6 \mathrm{~Hz}, 3 \mathrm{H}), 4.26(\mathrm{~s}, 1 \mathrm{H}), 4.05(\mathrm{t}, J=6.8 \mathrm{~Hz}, 2 \mathrm{H}), 3.58(\mathrm{~d}, J=3.6 \mathrm{~Hz}, 1 \mathrm{H}), 3.24(\mathrm{~d}, J=14.7 \mathrm{~Hz}$, $1 \mathrm{H}), 2.79-2.65(\mathrm{~m}, 3 \mathrm{H}), 2.60-2.34(\mathrm{~m}, 5 \mathrm{H}), 2.30(\mathrm{ddd}, J=12.3,6.1,3.2 \mathrm{~Hz}, 1 \mathrm{H}), 2.05-1.92(\mathrm{~m}, 6 \mathrm{H}), 1.91-1.81$ $(\mathrm{m}, 2 \mathrm{H}), 1.61(\mathrm{~d}, J=6.2 \mathrm{~Hz}, 2 \mathrm{H}), 1.57(\mathrm{~d}, J=7.9 \mathrm{~Hz}, 6 \mathrm{H}), 1.46-1.37(\mathrm{~m}, 6 \mathrm{H}), 1.32(\mathrm{~s}, 6 \mathrm{H}), 1.28(\mathrm{~s}, 12 \mathrm{H}), 1.26$ $(\mathrm{s}, 3 \mathrm{H}), 1.24(\mathrm{~s}, 3 \mathrm{H}), 1.07(\mathrm{~s}, 3 \mathrm{H}), 1.00(\mathrm{~s}, 3 \mathrm{H}) .{ }^{13} \mathrm{C} \mathrm{NMR}\left(100 \mathrm{MHz}, \mathrm{CDCl}_{3}\right) \delta$ 213.0, 211.7, 201.1, 172.4, 171.8, 169.7, 159.2, 153.0, 140.6, 138.3, 135.7, 129.7, 128.7, 120.5, 119.4, 110.6, 79.2, 77.8, 74.0, 71.8, 71.7, 65.0, 54.3, $50.3,50.1,48.7,48.5,48.1,43.2,42.2,36.1,33.9,29.8,29.7,29.6,29.6,29.5,29.4,29.2,29.0,28.9,28.7,28.5$, 
26.8, 26.4, 26.0, 25.7, 23.9, 23.8, 22.0, 21.4, 20.2, 19.8, 18.9. HRMS (MALDI) calcd. for $\mathrm{C}_{56} \mathrm{H}_{78} \mathrm{~N}_{2} \mathrm{NaO}_{16} \mathrm{~S}$ $[\mathrm{M}+\mathrm{Na}]^{+} 1089.4964$, found 1089.4968 .

4-(((E)-4-((4-(((9R,13R,14S,16R)-17-((R,E)-6-Acetoxy-2-hydroxy-6-methyl-3-oxohept-4-en-2-yl)-2-hydroxy-4,4, 9,13,14-pentamethyl-3,11-dioxo-2,3,4,7,8,9,10,11,12,13,14,15,16,17-tetradecahydro-1H-cyclopenta[a]phenanthren16-yl)oxy)-4-oxobutanoyl)oxy)but-2-en-1-yl)oxy)-3-(phenylsulfonyl)-1,2,5-oxadiazole 2-oxide (101) (61\% yield in two steps). (purity: 99\%). ${ }^{1} \mathrm{H} \mathrm{NMR}\left(400 \mathrm{MHz}, \mathrm{CDCl}_{3}\right) \delta 8.06(\mathrm{~d}, J=7.5 \mathrm{~Hz}, 2 \mathrm{H}), 7.77(\mathrm{t}, J=7.5 \mathrm{~Hz}, 1 \mathrm{H})$, $7.63(\mathrm{t}, J=7.8 \mathrm{~Hz}, 2 \mathrm{H}), 7.18(\mathrm{~d}, J=15.6 \mathrm{~Hz}, 1 \mathrm{H}), 6.39(\mathrm{~d}, J=15.6 \mathrm{~Hz}, 1 \mathrm{H}), 5.91(\mathrm{t}, J=5.5 \mathrm{~Hz}, 2 \mathrm{H}), 5.76(\mathrm{~d}, J=$ $5.4 \mathrm{~Hz}, 1 \mathrm{H}), 5.20(\mathrm{t}, J=8.0 \mathrm{~Hz}, 1 \mathrm{H}), 5.05(\mathrm{~d}, J=5.0 \mathrm{~Hz}, 2 \mathrm{H}), 4.74(\mathrm{~d}, J=4.9 \mathrm{~Hz}, 2 \mathrm{H}), 4.46-4.36(\mathrm{~m}, 1 \mathrm{H}), 4.28$ $(\mathrm{s}, 1 \mathrm{H}), 3.60(\mathrm{~d}, J=3.8 \mathrm{~Hz}, 1 \mathrm{H}), 3.25(\mathrm{~d}, J=14.7 \mathrm{~Hz}, 1 \mathrm{H}), 2.72(\mathrm{dd}, J=19.1,10.9 \mathrm{~Hz}, 3 \mathrm{H}), 2.66-2.27(\mathrm{~m}, 7 \mathrm{H})$, 2.04-1.97 (m, 4H), $1.58(\mathrm{~s}, 3 \mathrm{H}), 1.55(\mathrm{~s}, 3 \mathrm{H}), 1.41(\mathrm{~s}, 3 \mathrm{H}), 1.33(\mathrm{~s}, 3 \mathrm{H}), 1.29(\mathrm{~s}, 3 \mathrm{H}), 1.26(\mathrm{~s}, 3 \mathrm{H}), 1.25(\mathrm{~s}, 3 \mathrm{H})$, $1.08(\mathrm{~s}, 3 \mathrm{H}), 1.01(\mathrm{~s}, 3 \mathrm{H}) .{ }^{13} \mathrm{C}$ NMR $\left(100 \mathrm{MHz}, \mathrm{CDCl}_{3}\right) \delta 213.1,211.7,201.0,172.1,171.8,169.8,153.2,140.5$, 135.9, 130.4, 129.9, 128.7, 125.9, 120.5, 119.2, 79.2, 77.8, 74.1, 71.7, 66.7, 60.3, 54.2, 50.4, 50.1, 48.6, 48.5, 48.2, 43.2, 42.2, 36.1, 33.8, 29.8, 29.5, 28.9, 28.7, 26.9, 26.4, 23.9, 23.7, 22.0, 21.4, 20.2, 19.8, 18.9. HRMS (ESI) calcd. for $\mathrm{C}_{48} \mathrm{H}_{60} \mathrm{~N}_{2} \mathrm{NaO}_{16} \mathrm{~S}$ [M+Na] ${ }^{+}$975.3556, found 975.3560 .

4-((4-((4-(((9R,13R,14S,16R)-17-((R,E)-6-Acetoxy-2-hydroxy-6-methyl-3-oxohept-4-en-2-yl)-2-hydroxy-4,4,9, 13,14-pentamethyl-3,11-dioxo-2,3,4,7,8,9,10,11,12,13,14,15,16,17-tetradecahydro-1H-cyclopenta[a]phenanthren16-yl)oxy)-4-oxobutanoyl)oxy)but-2-yn-1-yl)oxy)-3-(phenylsulfonyl)-1,2,5-oxadiazole 2-oxide (10m) (77\% yield in two steps). (purity: 99\%). ${ }^{1} \mathrm{H} \mathrm{NMR}\left(400 \mathrm{MHz}, \mathrm{CDCl}_{3}\right) \delta 8.07(\mathrm{~d}, J=7.5 \mathrm{~Hz}, 2 \mathrm{H}), 7.77(\mathrm{t}, J=7.3 \mathrm{~Hz}, 1 \mathrm{H})$, $7.64(\mathrm{t}, J=7.6 \mathrm{~Hz}, 2 \mathrm{H}), 7.18(\mathrm{~d}, J=14.9 \mathrm{~Hz}, 1 \mathrm{H}), 6.40(\mathrm{~d}, J=15.4 \mathrm{~Hz}, 1 \mathrm{H}), 5.77(\mathrm{~s}, 1 \mathrm{H}), 5.21(\mathrm{t}, J=7.5 \mathrm{~Hz}$, $1 \mathrm{H}), 5.10(\mathrm{~s}, 2 \mathrm{H}), 4.79-4.67(\mathrm{~m}, 2 \mathrm{H}), 4.41(\mathrm{~d}, J=12.7 \mathrm{~Hz}, 1 \mathrm{H}), 4.27(\mathrm{~s}, 1 \mathrm{H}), 3.59(\mathrm{~s}, 1 \mathrm{H}), 3.25(\mathrm{~d}, J=14.8 \mathrm{~Hz}$, $1 \mathrm{H}), 2.74-2.67(\mathrm{~m}, 3 \mathrm{H}), 2.65-2.54(\mathrm{~m}, 2 \mathrm{H}), 2.43(\mathrm{~d}, J=4.5 \mathrm{~Hz}, 2 \mathrm{H}), 2.40-2.27(\mathrm{~m}, 2 \mathrm{H}), 2.01(\mathrm{~d}, J=9.7 \mathrm{~Hz}$, $4 \mathrm{H}), 1.59(\mathrm{~s}, 3 \mathrm{H}), 1.56(\mathrm{~s}, 3 \mathrm{H}), 1.41(\mathrm{~s}, 3 \mathrm{H}), 1.33(\mathrm{~s}, 3 \mathrm{H}), 1.29(\mathrm{~s}, 3 \mathrm{H}), 1.27(\mathrm{~s}, 3 \mathrm{H}), 1.25(\mathrm{~s}, 4 \mathrm{H}), 1.08(\mathrm{~s}, 3 \mathrm{H})$, 1.01 (s, 3H). ${ }^{13} \mathrm{C}$ NMR $\left(100 \mathrm{MHz}, \mathrm{CDCl}_{3}\right) \delta$ 213.0, 211.7, 201.1, 171.6, 169.8, 158.0, 153.2, 140.6, 137.8, 135.9, 129.9, 128.8, 120.5, 119.3, 100.0, 84.0, 79.2, 78.8, 77.8, 74.2, 71.8, 58.7, 54.3, 52.2, 50.4, 50.1, 48.7, 48.5, 48.2, 43.2, 42.2, 36.1, 33.9, 29.8, 29.5, 28.8, 28.7, 27.0, 26.4, 23.9, 23.8, 22.0, 21.4, 20.2, 19.8, 18.9. HRMS (ESI) calcd. for $\mathrm{C}_{48} \mathrm{H}_{58} \mathrm{~N}_{2} \mathrm{NaO}_{16} \mathrm{~S}[\mathrm{M}+\mathrm{Na}]^{+}$973.3399, found 973.3402 .

4-(3-((4-(((9R,13R,14S,16R)-17-((R,E)-6-Acetoxy-2-hydroxy-6-methyl-3-oxohept-4-en-2-yl)-2-hydroxy-4,4,9, 13,14-pentamethyl-3,11-dioxo-2,3,4,7,8,9,10,11,12,13,14,15,16,17-tetradecahydro-1H-cyclopenta[a]phenanthren16-yl)oxy)-4-oxobutanoyl)oxy)-2,2-dimethylpropoxy)-3-(phenylsulfonyl)-1,2,5-oxadiazole 2-oxide (10n) (71\% yield in two steps). (purity: 95\%). ${ }^{1} \mathrm{H}$ NMR $\left(400 \mathrm{MHz}, \mathrm{CDCl}_{3}\right) \delta 8.04(\mathrm{~d}, J=7.9 \mathrm{~Hz}, 2 \mathrm{H}), 7.75(\mathrm{t}, J=7.4 \mathrm{~Hz}, 1 \mathrm{H})$, $7.62(\mathrm{t}, J=7.7 \mathrm{~Hz}, 2 \mathrm{H}), 7.17(\mathrm{~d}, J=15.6 \mathrm{~Hz}, 1 \mathrm{H}), 6.39(\mathrm{~d}, J=15.6 \mathrm{~Hz}, 1 \mathrm{H}), 5.76(\mathrm{~d}, J=4.3 \mathrm{~Hz}, 1 \mathrm{H}), 5.15(\mathrm{t}, J=$ $8.0 \mathrm{~Hz}, 1 \mathrm{H}), 4.45-4.35(\mathrm{~m}, 1 \mathrm{H}), 4.26(\mathrm{~s}, 1 \mathrm{H}), 4.22-4.14(\mathrm{~m}, 2 \mathrm{H}), 4.09(\mathrm{~d}, J=10.9 \mathrm{~Hz}, 1 \mathrm{H}), 3.98(\mathrm{~d}, J=11.0 \mathrm{~Hz}$, $1 \mathrm{H}), 3.60(\mathrm{~d}, J=3.5 \mathrm{~Hz}, 1 \mathrm{H}), 3.24(\mathrm{~d}, J=14.6 \mathrm{~Hz}, 1 \mathrm{H}), 2.76-2.26(\mathrm{~m}, 9 \mathrm{H}), 2.04-1.85(\mathrm{~m}, 6 \mathrm{H}), 1.56(\mathrm{~d}, J=$ $11.9 \mathrm{~Hz}, 6 \mathrm{H}), 1.40(\mathrm{~s}, 3 \mathrm{H}), 1.32(\mathrm{~s}, 3 \mathrm{H}), 1.28(\mathrm{~s}, 3 \mathrm{H}), 1.26(\mathrm{~s}, 3 \mathrm{H}), 1.24(\mathrm{~s}, 2 \mathrm{H}), 1.09(\mathrm{~s}, 6 \mathrm{H}), 1.07(\mathrm{~s}, 3 \mathrm{H}), 1.00$ (s, 3H). ${ }^{13} \mathrm{C}$ NMR $\left(100 \mathrm{MHz}, \mathrm{CDCl}_{3}\right) \delta 213.1,211.7,201.1,172.2,171.8,169.8,159.3,153.1,140.5,138.3$, 135.8, 129.9, 128.7, 120.6, 119.3, 110.6, 79.2, 77.8, 75.8, 74.1, 71.8, 68.8, 54.3, 50.4, 50.1, 48.7, 48.5, 48.2, 43.1, 42.2, 35.6, 33.9, 30.5, 29.5, 28.9, 28.8, 27.0, 26.4, 23.7, 22.0, 21.7, 21.4, 20.2, 19.8, 18.9. HRMS (ESI) calcd. for $\mathrm{C}_{49} \mathrm{H}_{64} \mathrm{~N}_{2} \mathrm{NaO}_{16} \mathrm{~S}[\mathrm{M}+\mathrm{Na}]^{+}$991.3869, found 991.3873.

4-((4-(((4-(((9R,13R,14S,16R)-17-((R,E)-6-Acetoxy-2-hydroxy-6-methyl-3-oxohept-4-en-2-yl)-2-hydroxy-4,4,9, 13,14-pentamethyl-3,11-dioxo-2,3,4,7,8,9,10,11,12,13,14,15,16,17-tetradecahydro-1H-cyclopenta[a]phenanthren16-yl)oxy)-4-oxobutanoyl)oxy)methyl)benzyl)oxy)-3-(phenylsulfonyl)-1,2,5-oxadiazole 2-oxide (10o) (63\% yield in two steps). (purity: 95\%). ${ }^{1} \mathrm{H}$ NMR $\left(400 \mathrm{MHz}, \mathrm{CDCl}_{3}\right) \delta 8.07-7.98(\mathrm{~m}, 2 \mathrm{H}), 7.74(\mathrm{~d}, J=7.5 \mathrm{~Hz}, 1 \mathrm{H}), 7.59$ $(\mathrm{t}, J=7.9 \mathrm{~Hz}, 2 \mathrm{H}), 7.45(\mathrm{~d}, J=8.1 \mathrm{~Hz}, 2 \mathrm{H}), 7.39(\mathrm{~d}, J=8.2 \mathrm{~Hz}, 2 \mathrm{H}), 7.17(\mathrm{~d}, J=15.6 \mathrm{~Hz}, 1 \mathrm{H}), 7.17(\mathrm{~d}, J=$ $15.6 \mathrm{~Hz}, 1 \mathrm{H}), 6.40(\mathrm{~d}, J=15.6 \mathrm{~Hz}, 1 \mathrm{H}), 5.76(\mathrm{~d}, J=5.5 \mathrm{~Hz}, 1 \mathrm{H}), 5.44(\mathrm{~s}, 2 \mathrm{H}), 5.21(\mathrm{t}, J=7.9 \mathrm{~Hz}, 1 \mathrm{H}), 5.15(\mathrm{~s}$, $2 \mathrm{H}), 4.45-4.36(\mathrm{~m}, 1 \mathrm{H}), 4.28(\mathrm{~s}, 1 \mathrm{H}), 3.60(\mathrm{~d}, J=3.9 \mathrm{~Hz}, 1 \mathrm{H}), 3.25(\mathrm{~d}, J=14.6 \mathrm{~Hz}, 1 \mathrm{H}), 2.78-2.25(\mathrm{~m}, 10 \mathrm{H})$, 2.05-1.86 (m, 6H), $1.57(\mathrm{~s}, 3 \mathrm{H}), 1.54(\mathrm{~s}, 3 \mathrm{H}), 1.41(\mathrm{~s}, 3 \mathrm{H}), 1.33(\mathrm{~s}, 3 \mathrm{H}), 1.29(\mathrm{~s}, 3 \mathrm{H}), 1.25(\mathrm{~d}, J=6.5 \mathrm{~Hz}, 4 \mathrm{H})$, 1.07 (s, 3H), 1.01 (s, 3H). ${ }^{13} \mathrm{C}$ NMR $\left(101 \mathrm{MHz}, \mathrm{CDCl}_{3}\right) \delta 213.0,211.7,201.0,172.2,171.8,169.8,158.7,153.2$, 
$140.5,138.1,137.0,135.8,133.9,129.8,128.7,128.6,128.5,120.5,119.3,110.6,79.2,77.8,74.1,72.3,71.7,66.0$, 54.3, 50.3, 50.1, 48.6, 48.5, 48.1, 43.2, 42.2, 36.1, 33.8, 29.5, 29.0, 28.8, 26.9, 26.4, 23.9, 23.7, 22.0, 21.4, 20.2, 19.8, 18.9. HRMS (ESI) calcd. for $\mathrm{C}_{52} \mathrm{H}_{62} \mathrm{~N}_{2} \mathrm{NaO}_{16} \mathrm{~S}[\mathrm{M}+\mathrm{Na}]^{+} 1025.3712$, found 1025.3718 .

3.1.10. Procedure for the Synthesis of Compound 11

4-(((2S,9R,13R,14S,16R)-17-((R,E)-6-Acetoxy-2-hydroxy-6-methyl-3-oxohept-4-en-2-yl)-2-hydroxy-4,4,9,13,14pentamethyl-3,11-dioxo-2,3,4,7,8,9,10,11,12,13,14,15,16,17-tetradecahydro-1H-cyclopenta[a]phenanthren-16yl)oxy)-4-oxobutanoic acid (11). Compound 8 (77 mg, $0.1 \mathrm{mmol}$ ) was dissolved in THF (5 mL). HOAc $(28 \mu \mathrm{L}, 0.5 \mathrm{mmol})$ and TBAF $(131 \mathrm{mg}, 0.5 \mathrm{mmol})$ were added to the mixture. The mixture was stirred at room temperature for $24 \mathrm{~h}$, and then diluted with ethyl acetate $(20 \mathrm{~mL})$. The organic phase was washed with $\mathrm{H}_{2} \mathrm{O}(3 \times 20 \mathrm{~mL})$, dried over $\mathrm{Na}_{2} \mathrm{SO}_{4}$, and concentrated. The residue was purified by column chromatography on silica gel to obtain a white solid 11 (52 mg, 79\% yield). (purity: 95\%). ${ }^{1} \mathrm{H}$ NMR (400 $\left.\mathrm{MHz} \mathrm{CDCl}_{3}\right) \delta 7.16(\mathrm{~d}, J=15.6 \mathrm{~Hz}, 1 \mathrm{H}), 6.41(\mathrm{~d}, J=15.6 \mathrm{~Hz}, 1 \mathrm{H}), 5.77(\mathrm{~d}, J=5.5 \mathrm{~Hz}, 1 \mathrm{H}), 5.22(\mathrm{t}, J=7.8$ $\mathrm{Hz}, 1 \mathrm{H}), 4.41(\mathrm{dd}, J=12.9,6.0 \mathrm{~Hz}, 1 \mathrm{H}), 3.25(\mathrm{~d}, J=14.6 \mathrm{~Hz}, 1 \mathrm{H}), 2.77-2.67(\mathrm{~m}, 3 \mathrm{H}), 2.58(\mathrm{dd}, J=12.2,6.5$ $\mathrm{Hz}, 2 \mathrm{H}), 2.43(\mathrm{t}, J=6.7 \mathrm{~Hz}, 2 \mathrm{H}), 2.38(\mathrm{~d}, J=7.8 \mathrm{~Hz}, 1 \mathrm{H}), 2.31(\mathrm{ddd}, J=12.5,5.8,3.4 \mathrm{~Hz}, 1 \mathrm{H}), 2.04-1.93$ $(\mathrm{m}, 6 \mathrm{H}), 1.59$ (s, 3H), 1.55 (s, 3H), $1.41(\mathrm{~s}, 3 \mathrm{H}), 1.39$ (s, 1H), 1.33 (s, 3H), 1.28 (d, J = 4.5 Hz, 6H), 1.25 (s, $3 \mathrm{H}), 1.08$ (s, 3H), 1.01 (s, 3H). ${ }^{13} \mathrm{C}$ NMR $\left(100 \mathrm{MHz}, \mathrm{CDCl}_{3}\right) \delta 213.1,211.8,201.1,176.9,171.7,170.0,153.1$, 140.5, 120.5, 119.3, 79.4, 77.9, 74.3, 71.8, 54.3, 50.4, 50.1, 48.7, 48.5, 48.1, 43.2, 42.2, 36.09, 33.9, 29.5, 28.9, 28.8, 27.0, 26.3, 23.9, 23.8, 21.9, 21.4, 20.2, 19.9, 18.8. HRMS (ESI) calcd. for $\mathrm{C}_{36} \mathrm{H}_{50} \mathrm{NaO}_{11}[\mathrm{M}+\mathrm{Na}]^{+} 681.3245$, found 681.3250 .

\subsection{Biological Assay}

\subsubsection{Cell Culture}

HepG-2 human hepatocellular carcinoma cells and L-O2 human normal liver cells were maintained in DMEM culture medium supplemented with $10 \%$ FBS at $37{ }^{\circ} \mathrm{C}$ under a humidified atmosphere with $5 \% \mathrm{CO}_{2}$.

\subsubsection{MTT Assay}

HepG-2 and L-O2 cells in logarithmic growth phase were seeded into a 96-well plate at $5 \times 10^{3} /$ well $/ 200 \mu \mathrm{L}$. After $12 \mathrm{~h}$, compounds at different concentrations were added and incubated for $72 \mathrm{~h}$ at $37^{\circ} \mathrm{C}, 5 \% \mathrm{CO}_{2}$. Then, $20 \mu \mathrm{L}$ MTT $(5 \mathrm{mg} / \mathrm{mL})$ was added into each well and incubated for 4 h. The supernatant was discarded, and the precipitate was dissolved with DMSO. The absorbance of the optical density (OD) at $570 \mathrm{~nm}$ was detected using a microplate reader and the $\mathrm{IC}_{50}$ was calculated with GraphPad Prism 5.

\subsubsection{Cell Apoptosis Assay}

HepG-2 cells were seeded into a 24-well plate with $5 \times 10^{4} /$ well $/ 1 \mathrm{~mL}$. After $12 \mathrm{~h}$, cells were treated with compound $\mathbf{1 0 b}$ at different concentrations for $48 \mathrm{~h}$. The cells were collected, washed with cold PBS, and stained with Annexin-V/PI according to the manufacturer's instructions. Then, the cells were analyzed with flow cytometry.

\subsubsection{Western Blot Assay}

HepG-2 cells were treated with compound $10 \mathrm{~b}$ for $24 \mathrm{~h}$, and the cell lysates were collected. Then, the total protein was separated by SDS-PAGE and transferred to PVDF membranes. The membranes were incubated with primary antibodies (1:1000) at $4{ }^{\circ} \mathrm{C}$ overnight. After being washed with PBST (PBS $+0.5 \%$ Tween 20) 5 times, the membranes were incubated with HRP-conjugated secondary antibodies (1:5000 dilution) for $2 \mathrm{~h}$ at room temperature. The membranes were then washed with PBST 5 times and the protein blots were detected by ECL chemiluminescence. 


\subsubsection{Animal Assay}

Five-week-old Balb/C mice were purchased from the Chinese Academy of Sciences and maintained under specific pathogen free (SPF) conditions. The mice were divided into a control group, a cucurbitacin B group, and a compound $10 \mathrm{~b}$ group. The control group mice were treated with vehicle buffer intravenously. The cucurbitacin B group mice were treated with cucurbitacin B at doses of $2 \mathrm{mg} / \mathrm{kg}, 5 \mathrm{mg} / \mathrm{kg}, 10 \mathrm{mg} / \mathrm{kg}, 20 \mathrm{mg} / \mathrm{kg}$, and $50 \mathrm{mg} / \mathrm{kg}$, respectively (three mice each dose). The compound $10 \mathrm{~b}$ group mice were treated with compound $10 \mathrm{~b}$ at doses of $2 \mathrm{mg} / \mathrm{kg}, 5 \mathrm{mg} / \mathrm{kg}, 10 \mathrm{mg} / \mathrm{kg}$, $20 \mathrm{mg} / \mathrm{kg}$, and $50 \mathrm{mg} / \mathrm{kg}$ respectively (three mice each dose). The clinical symptoms, deaths, and body weight were observed and recorded.

\section{Conclusion}

In summary, 37 cucurbitacin B derivatives were synthesized and evaluated for their anti-hepatocellular carcinoma activities against the HepG-2 cell line. These compounds were also tested for their toxicity against the L-O2 normal cell line. These studies indicated that the introduction of a phenylsulfonyl-substituted furoxan NO-releasing moiety could reduce the toxicity against normal cells and maintain potent anti-HCC activity to some extent. The compound with the most potential, 10b, exhibited potent activity against the HepG-2 cell line, with an $\mathrm{IC}_{50}$ value of $0.63 \mu \mathrm{M}$. Moreover, compound $10 \mathrm{~b}$ showed the highest TI value (4.71), which is a 14.7-fold improvement compared to its parent compound cucurbitacin B (Table 2). The preliminary study of the molecular mechanism of $\mathbf{1 0 b}$ indicated that $10 \mathrm{~b}$ could inhibit P-STAT3 to induce the activation of mitochondrial apoptotic pathways (Figure 2). An in vivo acute toxicity study indicated that compound $\mathbf{1 0 b}$ has preferable safety and tolerability compared with cucurbitacin B (Figure 3). These findings indicate that compound $\mathbf{1 0 b}$ might be considered as a lead compound for exploring effective anti-HCC drugs.

Supplementary Materials: Copies of the ${ }^{1} \mathrm{H} /{ }^{13} \mathrm{C}$ NMR spectra, HPLC, and dose-response curves of all new compounds.

Author Contributions: Conceptualization and design of the study: Y.C., Y.D., and Q.Z.; Synthesis of the compounds: W.G. and X.C.; Performance of the pharmacological tests: W.M. and Y.D.; Statistical analysis of the data: W.G., X.C., Z.L., T.W., Y.C., Y.D., and Q.Z.; Writing and revising of the manuscript: W.G., Y.C., Y.D., and Q.Z.

Funding: This work was supported by the National Natural Science Foundation of China (NO. 81573282 to Y.C.; NOs. 81573308 and 81872764 to Q.Z.), The National Science Fund for Distinguished Young Scholars (NO. 81625021 to Y.C.), the Natural Science Foundation of Tianjin (NO. 17JCQNJC13400 to Q.Z.), the Hundred Young Academic Leaders Program of Nankai University to Y.C., and the Fundamental Research Funds for the Central Universities to Y.D.

Conflicts of Interest: The authors declare no conflict of interest.

\section{References}

1. Dorsey, E.R.; Elbaz, A.; Nichols, E.; Abd-Allah, F.; Abdelalim, A.; Adsuar, J.C.; Ansha, M.G.; Brayne, C.; Choi, J.-Y.J.; Collado-Mateo, D.; et al. Global, regional, and national burden of Parkinson's disease, 1990-2016: A systematic analysis for the Global Burden of Disease Study 2016. Lancet Neurol. 2018, 17, 939-953. [CrossRef]

2. Meacham, C.E.; Morrison, S.J. Tumour heterogeneity and cancer cell plasticity. Nature 2013, 501, $328-337$. [CrossRef] [PubMed]

3. Goel, P.; Alam, O.; Naim, M.J.; Nawaz, F.; Iqbal, M.; Alam, M.I. Recent advancement of piperidine moiety in treatment of cancer-A review. Eur. J. Med. Chem. 2018, 157, 480-502. [CrossRef] [PubMed]

4. Ferlay, J.; Soerjomataram, I.; Dikshit, R.; Eser, S.; Mathers, C.; Rebelo, M.; Parkin, D.M.; Forman, D.; Bray, F. Cancer incidence and mortality worldwide: Sources, methods and major patterns in GLOBOCAN 2012. Int. J. Cancer 2015, 136, E359-E386. [CrossRef] [PubMed]

5. Fisher, R.; Pusztai, L.; Swanton, C. Cancer heterogeneity: Implications for targeted therapeutics. Br. J. Cancer 2013, 108, 479-485. [CrossRef] [PubMed] 
6. Qin, M.; Zhai, X.; Xie, H.; Ma, J.; Lu, K.; Wang, Y.; Wang, L.; Gu, Y.; Gong, P. Design and synthesis of novel 2-(4-(2-(dimethylamino)ethyl)-4H-1,2,4-triazol-3-yl)pyridines as potential antitumor agents. Eur. J. Med. Chem. 2014, 81, 47-58. [CrossRef] [PubMed]

7. Rashid, H.U.; Xu, Y.; Muhammad, Y.; Wang, L.; Jiang, J. Research advances on anticancer activities of matrine and its derivatives: An updated overview. Eur. J. Med. Chem. 2018, 161, 205-238. [CrossRef] [PubMed]

8. Gurney, H. Dose calculation of anticancer drugs: A review of the current practice and introduction of an alternative. J. Clin. Oncol. 1996, 14, 2590-2611. [CrossRef] [PubMed]

9. Kerru, N.; Singh, P.; Koorbanally, N.; Raj, R.; Kumar, V. Recent advances (2015-2016) in anticancer hybrids. Eur. J. Med. Chem. 2017, 142, 179-212. [CrossRef] [PubMed]

10. Wang, Y.; Gu, W.; Shari, Y.; Liu, F.; Ku, X.; Yang, Y.; Zhang, Q.; Zhang, Y.; Kuang, H.; Wang, Z.; et al. Design, synthesis and anticancer activity of novel nopinone-based thiosemicarbazone derivatives. Biorg. Med. Chem. Lett. 2017, 27, 2360-2363. [CrossRef] [PubMed]

11. Millimouno, F.M.; Dong, J.; Yang, L.; Li, J.; Li, X. Targeting apoptosis pathways in cancer and perspectives with natural compounds from mother nature. Cancer Prev. Res. 2014, 7, 1081-1107. [CrossRef] [PubMed]

12. Mangal, M.; Sagar, P.; Singh, H.; Raghava, G.P.S.; Agarwal, S.M. NPACT: Naturally Occurring plant-based anti-cancer compound-activity-target database. Nucleic Acids Res. 2013, 41, D1124-D1129. [CrossRef] [PubMed]

13. da Rocha, A.B.; Lopes, R.M.; Schwartsmann, G. Natural products in anticancer therapy. Curr. Opin. Pharm. 2001, 1, 364-369. [CrossRef]

14. Cai, Y.; Fang, X.; He, C.; Li, P.; Xiao, F.; Wang, Y.; Chen, M. Cucurbitacins: A systematic review of the phytochemistry and anticancer Activity. Am. J. Chin. Med. 2015, 43, 1331-1350. [CrossRef] [PubMed]

15. Jayaprakasam, B.; Seeram, N.P.; Nair, M.G. Anticancer and antiinflammatory activities of cucurbitacins from Cucurbita andreana. Cancer Lett. 2003, 189, 11-16. [CrossRef]

16. Huang, W.-W.; Yang, J.-S.; Lin, M.-W.; Chen, P.-Y.; Chiou, S.-M.; Chueh, F.-S.; Lan, Y.-H.; Pai, S.-J.; Tsuzuki, M.; Ho, W.-J.; et al. Cucurbitacin E induces G(2)/M phase arrest through STAT3/p53/p21 signaling and provokes apoptosis via Fas/CD95 and mitochondria-dependent pathways in human bladder cancer T24 cells. Evid. Based Complement. Alternat. Med. 2012, 2012, 952762. [CrossRef]

17. Zheng, C.H.; Fu, H.W.; Pei, Y.H. A new cucurbitacin from Bolbostemma paniculatum franguent. J. Asian Nat. Prod. Res. 2007, 9, 187-190. [CrossRef] [PubMed]

18. Kaushik, U.; Aeri, V.; Mir, S.R. Cucurbitacins-An insight into medicinal leads from nature. Pharmacogn. Rev. 2015, 9, 12-18. [PubMed]

19. Chen, J.C.; Chiu, M.H.; Nie, R.L.; Cordell, G.A.; Qiu, S.X. Cucurbitacins and cucurbitane glycosides: Structures and biological activities. Nat. Prod. Rep. 2005, 22, 386-399. [CrossRef] [PubMed]

20. Dzubak, P.; Hajduch, M.; Vydra, D.; Hustova, A.; Kvasnica, M.; Biedermann, D.; Markova, L.; Urban, M.; Sarek, J. Pharmacological activities of natural triterpenoids and their therapeutic implications. Nat. Prod. Rep. 2006, 23, 394-411. [CrossRef] [PubMed]

21. Takasaki, M.; Konoshima, T.; Murata, Y.; Sugiura, M.; Nishino, H.; Tokuda, H.; Matsumoto, K.; Kasai, R.; Yamasaki, K. Anticarcinogenic activity of natural sweeteners, cucurbitane glycosides, from Momordica grosvenori. Cancer Lett. 2003, 198, 37-42. [CrossRef]

22. Dong, Y.; Lu, B.; Zhang, X.; Zhang, J.; Lai, L.; Li, D.; Wu, Y.; Song, Y.; Luo, J.; Pang, X.; et al. Cucurbitacin $\mathrm{E}$, a tetracyclic triterpenes compound from Chinese medicine, inhibits tumor angiogenesis through VEGFR2-mediated Jak2-STAT3 signaling pathway. Carcinogenesis 2010, 31, 2097-2104. [CrossRef] [PubMed]

23. Attard, E.; Brincat, M.P.; Cuschieri, A. Immunomodulatory activity of cucurbitacin E isolated from Ecballium elaterium. Fitoterapia 2005, 76, 439-441. [CrossRef] [PubMed]

24. Ku, J.M.; Hong, S.H.; Kim, M.-S.; Kim, H.I.; Kang, S.-Y.; Lee, K.; Choi, Y.-J.; Cheon, C.; Huang, C.W.; Ko, Y.; et al. Cucurbitacin D induces cell cycle arrest and apoptosis by inhibiting STAT3 and NF-kappa B signaling in doxorubicin-resistant human breast carcinoma (MCF7/ADR) cells. Cancer Res. 2017, 77, 33-43. [CrossRef]

25. Shang, Y.; Ma, Y.; Zhou, Y.; Zhang, H.; Duan, L.; Chen, H.; Zeng, J.; Zhou, Q.; Wang, S.; Gu, W.; et al. Biosynthesis, regulation, and domestication of bitterness in cucumber. Science 2014, 346, 1084-1088. [CrossRef] [PubMed]

26. Gao, Y.; Islam, M.S.; Tian, J.; Lui, V.W.Y.; Xiao, D. Inactivation of ATP citrate lyase by cucurbitacin B: A bioactive compound from cucumber, inhibits prostate cancer growth. Cancer Lett. 2014, 349, 15-25. [CrossRef] [PubMed] 
27. Dakeng, S.; Duangmano, S.; Jiratchariyakul, W.; U-Pratya, Y.; Boegler, O.; Patmasiriwat, P. Inhibition of Wnt signaling by cucurbitacin B in breast cancer cells: Reduction of Wnt-associated proteins and reduced translocation of galectin-3-mediated beta-catenin to the nucleus. J. Cell. Biochem. 2012, 113, 49-60. [CrossRef] [PubMed]

28. Thoennissen, N.H.; Iwanski, G.B.; Doan, N.B.; Okamoto, R.; Lin, P.; Abbassi, S.; Song, J.H.; Yin, D.; Toh, M.; Xie, W.D.; et al. Cucurbitacin B induces apoptosis by inhibition of the JAK/STAT pathway and potentiates antiproliferative effects of gemcitabine on pancreatic cancer cells. Cancer Res. 2009, 69, 5876-5884. [CrossRef] [PubMed]

29. Kausar, H.; Munagala, R.; Bansal, S.S.; Aqil, F.; Vadhanam, M.V.; Gupta, R.C. Cucurbitacin B potently suppresses non-small-cell lung cancer growth: Identification of intracellular thiols as critical targets. Cancer Lett. 2013, 332, 35-45. [CrossRef] [PubMed]

30. Liu, T.; Zhang, M.; Zhang, H.; Sun, C.; Yang, X.; Deng, Y.; Ji, W. Combined antitumor activity of cucurbitacin B and docetaxel in laryngeal cancer. Eur. J. Pharmacol. 2008, 587, 78-84. [CrossRef] [PubMed]

31. Guo, J.; Zhao, W.; Hao, W.; Ren, G.; Lu, J.; Chen, X. Cucurbitacin B induces DNA damage, G2/M phase arrest, and apoptosis mediated by reactive oxygen species (ROS) in leukemia K562 cells. Anticancer Agents Med. Chem. 2014, 14, 1146-1153. [CrossRef] [PubMed]

32. Chen, X.; Bao, J.; Guo, J.; Ding, Q.; Lu, J.; Huang, M.; Wang, Y. Biological activities and potential molecular targets of cucurbitacins: A focus on cancer. Anti-Cancer Drugs. 2012, 23, 777-787. [CrossRef] [PubMed]

33. Liu, T.; Zhang, M.; Zhang, H.; Sun, C.; Deng, Y. Inhibitory effects of cucurbitacin B on laryngeal squamous cell carcinoma. Eur. Arch. Otorhinolaryngol. 2008, 265, 1225-1232. [CrossRef] [PubMed]

34. Wakimoto, N.; Yin, D.; O'Kelly, J.; Haritunians, T.; Karlan, B.; Said, J.; Xing, H.; Koeffler, H.P. Cucurbitacin B has a potent antiproliferative effect on breast cancer cells in vitro and in vivo. Cancer Sci. 2008, 99, $1793-1797$. [CrossRef] [PubMed]

35. Zhang, M.; Zhang, H.; Sun, C.; Shan, X.; Yang, X.; Li-Ling, J.; Deng, Y. Targeted constitutive activation of signal transducer and activator of transcription 3 in human hepatocellular carcinoma cells by cucurbitacin $B$. Cancer Chemother. Pharmacol. 2009, 63, 635-642. [CrossRef] [PubMed]

36. Chan, K.T.; Meng, F.Y.; Li, Q.; Ho, C.Y.; Lam, T.S.; To, Y.; Lee, W.H.; Li, M.; Chu, K.H.; Toh, M. Cucurbitacin B induces apoptosis and $\mathrm{S}$ phase cell cycle arrest in BEL-7402 human hepatocellular carcinoma cells and is effective via oral administration. Cancer Lett. 2010, 294, 118-124. [CrossRef] [PubMed]

37. Yasuda, S.; Yogosawa, S.; Izutani, Y.; Nakamura, Y.; Watanabe, H.; Sakai, T. Cucurbitacin B induces G(2) arrest and apoptosis via a reactive oxygen species-dependent mechanism in human colon adenocarcinoma SW480 cells. Mol Nutr Food Res. 2010, 54, 559-565. [CrossRef] [PubMed]

38. Zhang, Y.; Ouyang, D.; Xu, L.; Ji, Y.; Zha, Q.; Cai, J.; He, X. Cucurbitacin B induces rapid depletion of the G-actin pool through reactive oxygen species-dependent actin aggregation in melanoma cells. Acta Biochim. Biophys. Sin. 2011, 43, 556-567. [CrossRef] [PubMed]

39. Chen, W.; Leiter, A.; Yin, D.; Meiring, M.; Louw, V.J.; Koeffler, H.P. Cucurbitacin B inhibits growth, arrests the cell cycle, and potentiates antiproliferative efficacy of cisplatin in cutaneous squamous cell carcinoma cell lines. Int. J. Oncol. 2010, 37, 737-743. [PubMed]

40. Aribi, A.; Gery, S.; Lee, D.H.; Thoennissen, N.H.; Thoennissen, G.B.; Alvarez, R.; Quoc, H.; Lee, K.; Doan, N.B.; Chan, K.T.; et al. The triterpenoid cucurbitacin B augments the antiproliferative activity of chemotherapy in human breast cancer. Int. J. Cancer 2013, 132, 2730-2737. [CrossRef] [PubMed]

41. Lang, K.L.; Silva, I.T.; Zimmermann, L.A.; Machado, V.R.; Teixeira, M.R.; Ivana Lapuh, M.; Alejandra Galetti, M.; Alejandro Palermo, J.; Myriam Cabrera, G.; Campos Bernardes, L.S.; et al. Synthesis and cytotoxic activity evaluation of dihydrocucurbitacin B and cucurbitacin B derivatives. Biorg. Med. Chem. 2012, 20, 3016-3030. [CrossRef] [PubMed]

42. Ai, Y.; Kang, F.; Huang, Z.; Xue, X.; Lai, Y.; Peng, S.; Tian, J.; Zhang, Y. Synthesis of CDDO-amino acid-nitric oxide donor trihybrids as potential antitumor agents against both drug-sensitive and drug-resistant colon cancer. J. Med. Chem. 2015, 58, 2452-2464. [CrossRef] [PubMed]

43. Liu, M.-M.; Chen, X.-Y.; Huang, Y.-Q.; Feng, P.; Guo, Y.-L.; Yang, G.; Chen, Y. Hybrids of phenylsulfonylfuroxan and coumarin as potent antitumor agents. J. Med. Chem. 2014, 57, 9343-9356. [CrossRef] [PubMed] 
44. Tang, W.; Xie, J.; Xu, S.; Lv, H.; Lin, M.; Yuan, S.; Bai, J.; Hou, Q.; Yu, S. Novel nitric oxide-releasing derivatives of brusatol as anti-inflammatory agents: Design, synthesis, biological evaluation, and nitric oxide release studies. J. Med. Chem. 2014, 57, 7600-7612. [CrossRef] [PubMed]

45. Huang, Z.; Fu, J.; Zhang, Y. Nitric oxide donor-based cancer therapy: Advances and prospects. J. Med. Chem. 2017, 60, 7617-7635. [CrossRef] [PubMed]

46. Duan, W.; Li, J.; Inks, E.S.; Chou, C.J.; Jia, Y.; Chu, X.; Li, X.; Xu, W.; Zhang, Y. Design, synthesis, and antitumor evaluation of novel histone deacetylase inhibitors equipped with a phenylsulfonylfuroxan module as a nitric oxide donor. J. Med. Chem. 2015, 58, 6319. [CrossRef] [PubMed]

Sample Availability: Samples of the compounds 3, 4, 9-11 are available from the authors.

(C) 2018 by the authors. Licensee MDPI, Basel, Switzerland. This article is an open access article distributed under the terms and conditions of the Creative Commons Attribution (CC BY) license (http:// creativecommons.org/licenses/by/4.0/). 